\title{
EFFECTS OF CHELATING AGENTS ON TEXTURE OF LOWFAT CHEDDAR CHEESE
}

\author{
A Thesis \\ presented to the \\ Faculty of California Polytechnic State University, \\ San Luis Obispo \\ In Partial Fulfillment \\ of the Requirements for the Degree \\ Master of Science in Agriculture, \\ with Specialization in Dairy Products Technology \\ By \\ Mariela Fernanda Poveda, \\ June 2013
}


(C)2013

Mariela Fernanda Poveda

ALL RIGHTS RESERVED 


\section{COMMITTEE MEMBERSHIP}

TITLE:

EFFECTS OF CHELATING AGENTS ON TEXTURE OF LOW FAT CHEDDAR CHEESE

AUTHOR: $\quad$ Mariela Fernanda Poveda

DATE SUBMITTED: June 14, 2013

COMMITEE CHAIR: $\quad$ Dr. Nana Farkye, PhD., Professor

Department of Dairy Science

California Polytechnic State University

San Luis Obispo

COMMITTEE MEMBER: Dr. Andrew Schaffner, PhD., Professor

Department of Statistics

California Polytechnic State University

San Luis Obispo

COMMITTEE MEMBER: $\quad$ Dr. Amy Lammert, PhD., Professor

Department of Food Science and Nutrition

California Polytechnic State University

San Luis Obispo 
"There are only two mistakes one can make along the road to truth; not going all the way, and not starting”.

\section{- Buddha}




\section{ABSTRACT \\ EFFECTS OF CHELATING AGENTS ON TEXTURE OF LOW FAT CHEDDAR CHEESE}

\section{Mariela Fernanda Poveda}

Effects of two types of chelating agents on proteolysis and texture properties of low fat Cheddar cheese (LFC) were analyzed and compared to full fat Cheddar (FFC) control during ripening for 120 days at $8^{\circ} \mathrm{C}$. We hypothesized that chelating agents would bind calcium ions from cheese matrix to give a softer curd due to a decrease of protein-protein interactions and simultaneously increasing moisture content. Cheese milk containing ( $0.59 \%$ fat) was divided into three lots (A, B \& C). Sodium citrate (3Na) and disodium EDTA (EDTA) were added to A \& B at the rate of $(0.02 \%$ and $0.2 \%$ respectively. C served as control (LFC). Cheesemilk $\left(88^{\circ} \mathrm{F}\right)$ was preacidified to $\mathrm{pH} 6.2$ prior to setting using $34 \mathrm{ml}$ chymosin/454 kg and starter culture addition. After cutting, curd was cooked to $96^{\circ} \mathrm{F}$ for $30 \mathrm{~min}$ and held for $10 \mathrm{~min}$. After cooking, the curd was washed, salted, hooped and pressed. FFC was made on subsequence days from same batch of milk by the stirred curd method for Cheddar cheese, cheesemaking was replicated 5 times. Significant difference in moisture content $(\mathrm{P}<0.05)$ was observed between FFC and LFC. Calcium content on the EDTA and $3 \mathrm{Na}$ was significantly reduced $(\mathrm{P}<0.05)$ compared to FFC. No significant difference $(\mathrm{P}>0.05)$ in hardness was observed between FFC and LFC at day 7 and 30. After day 30, significant differences $(\mathrm{P}<0.05)$ among FFC and all LFC were observed. Increase of gumminess in LFC and 3Na compared to FFC was statistically significant $(\mathrm{P}<0.05)$ during the first 60 days during ripening. Springiness, 
cohesiveness and chewiness did not report any differences between LF variants and FFC counterpart. No significant differences in the breakdown of $\beta$-casein and $\alpha$ s1_1-casein irrespective of cheese over time. However breakdown of as1-casein was faster than any other cheese protein, especially in the LF cheddar variants. Significant differences $(\mathrm{P}<0.05)$ at all ripening sampling times between cheese samples.

Keywords: low fat cheddar cheese, chelating agents, texture, proteolysis 


\section{ACKNOWLEDGMENTS}

It is with immense gratitude that I acknowledge the support and help of my advisor Dr. Nana Farkye whose patience and kindness, as well as his academic experience, has been invaluable to me. I cannot find words to express my gratitude for his moral support and wisdom throughout my journey.

It gives me great pleasure in acknowledging the support and help of my committee members: Dr. Andrew Schaffner and Dr. Amy Lammert, who gave me their advice, guidance, and time, and who shared their knowledge for the completion of this thesis.

I praise the enormous amount of help and teaching the technical details of work to Matt Arnold and Andrea Laubscher. Thank you Matt for been always a wonderful person and for helping me out in the use of correct grammar and consistent notation in my writings.

I am indebted to Dr. Bruce Golden and Dr. Philip Tong for their support and I would like to express my gratitude to Dr. Brian Hampson for his encouragement and practical advice.

I will always be grateful to all my DPTC friends for they all helped me stay sane through difficult moments, for all the happy hour and farmers market shared, I will treasure those memories forever. Special thanks to my friend Xiomara Elias-Argote who has been a true friend ever since we met, for all her support and care helped me overcome setbacks and stay focused on my graduate study. I am also grateful to José M. López, Julie Lucca, Juan José Galindo, Luis Gonzalez, Juan Carlos de la Parra, Salomé Ramirez and Anthony Cano for being my second family in the U.S. 
Thank you to Keyla Maria, Leonardo Rafael, Aron Pompero, Lira Capitu, Honey Maria and Moro Aroma for all their unconditional love.

This thesis is dedicated to my father Nelson Ernesto Poveda, my mother Mariana Arteaga and my brother Nelson Alejandro Poveda for been my source of love, concern, support and strength all my life. 


\section{TABLE OF CONTENTS}

LIST OF TABLES

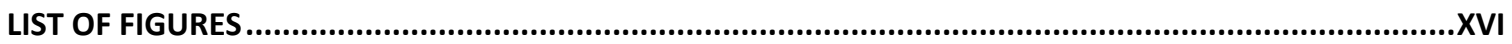

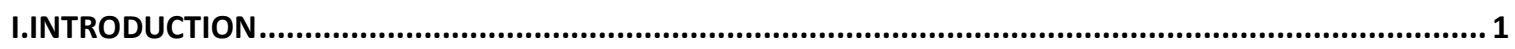

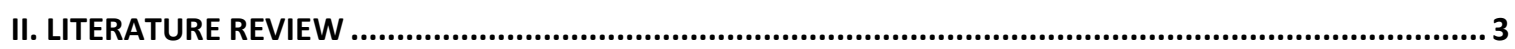

CHEESE

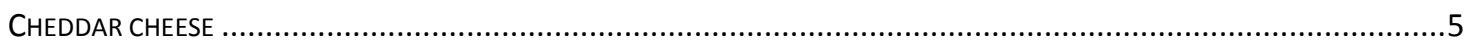

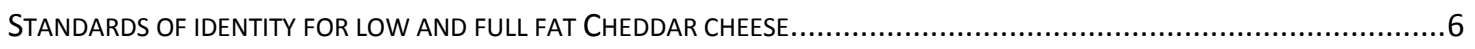

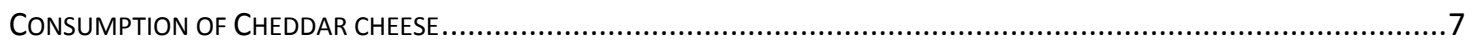

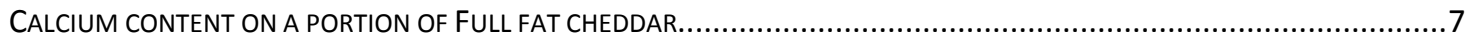

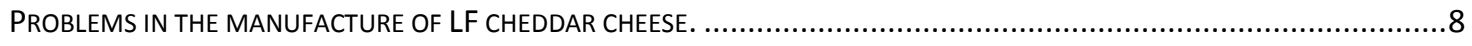

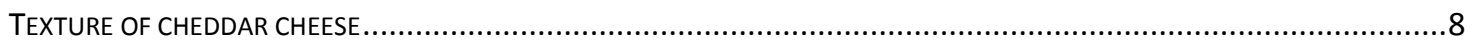

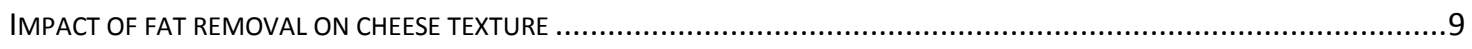

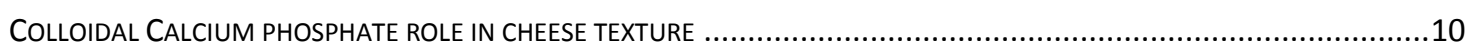

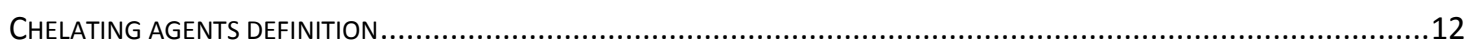

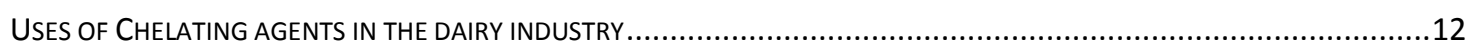

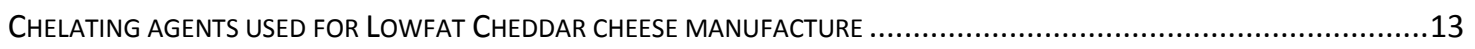

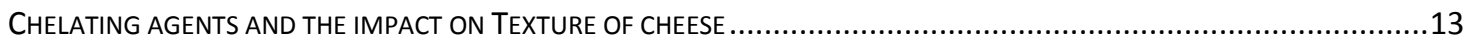

III. PRELIMINARY STUDIES ON COAGULATION USING CHELATING AGENTS ........................................... 15

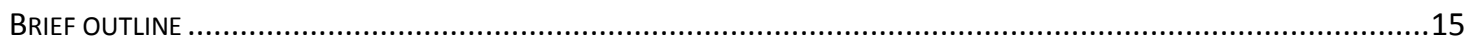

DETERMINATION OF DISODIUM CITRATE CONCENTRATION AND COAGULATION TIME..............................................15

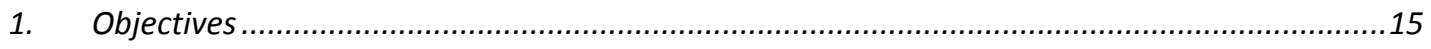

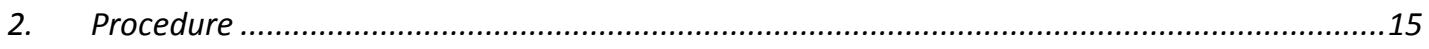

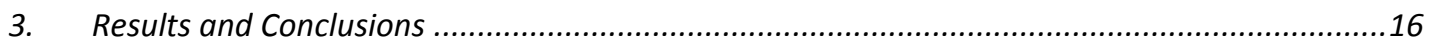


SELECTING THE APPROPRIATE EDTA FOR CHEESE MAKING PURPOSES .......................................................... 18

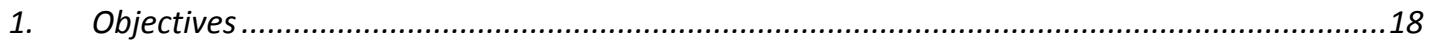

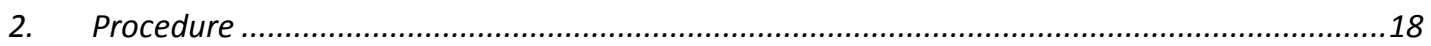

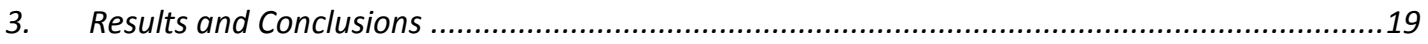

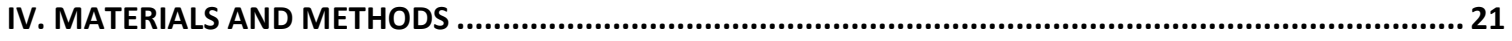

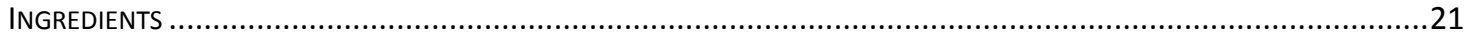

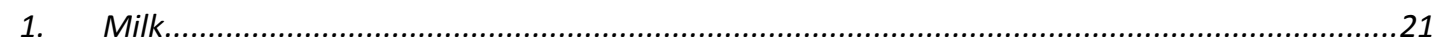

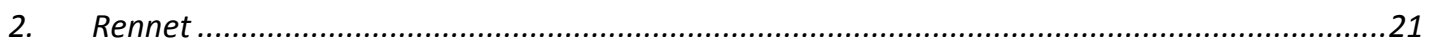

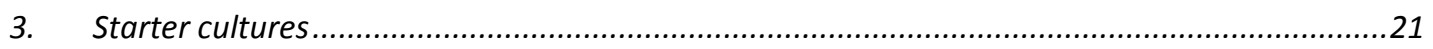

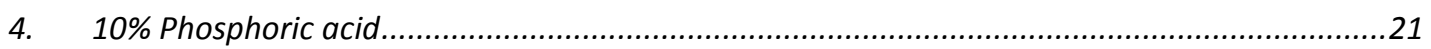

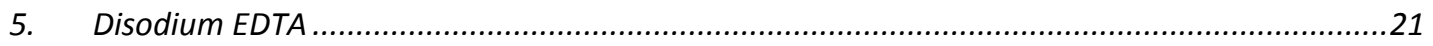

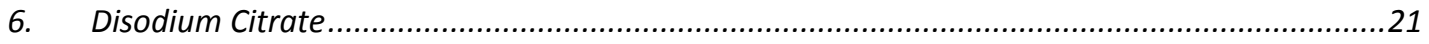

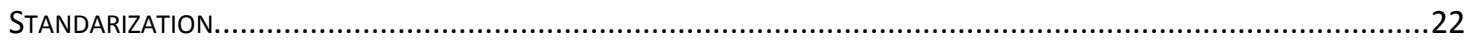

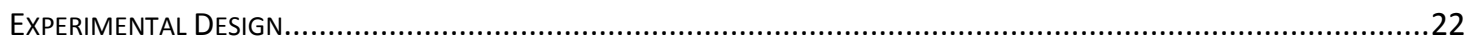

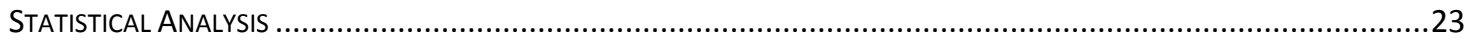

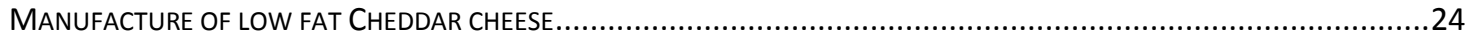

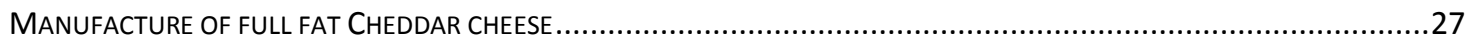

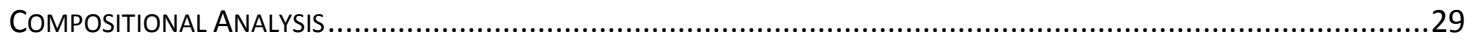

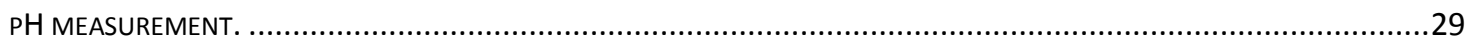

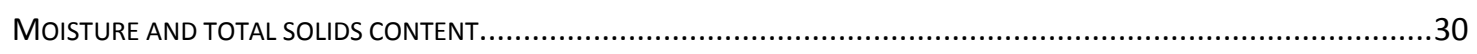

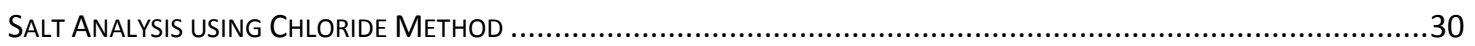

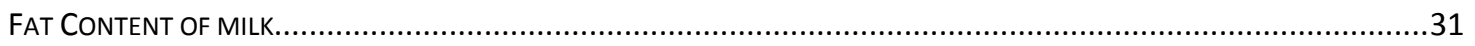

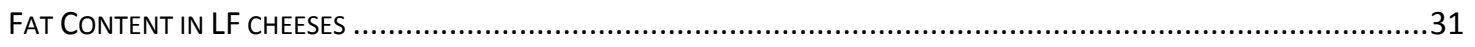

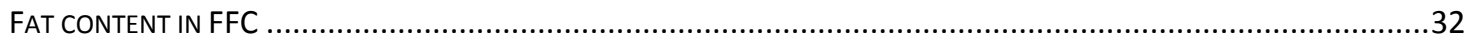




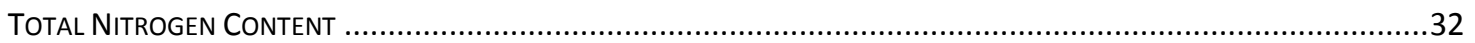

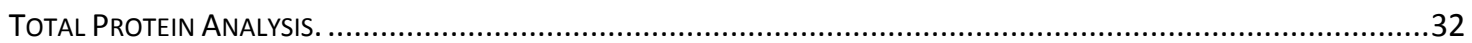

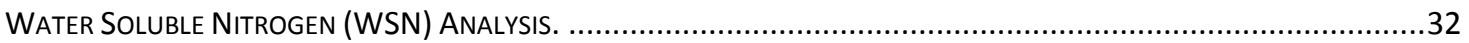

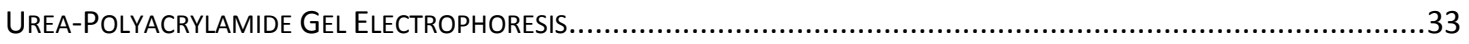

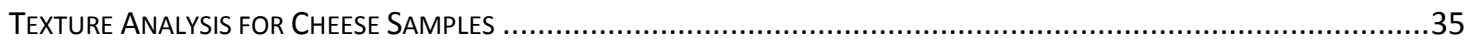

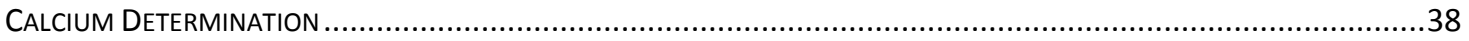

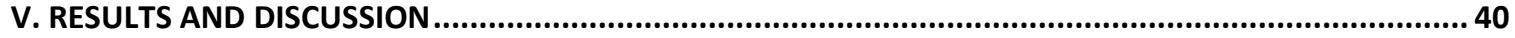

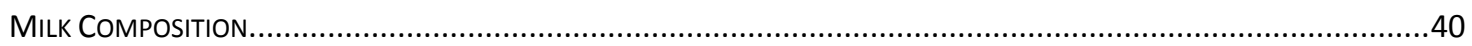

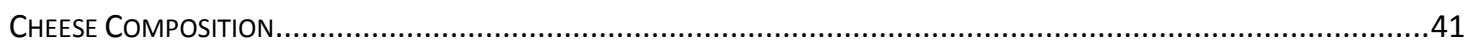

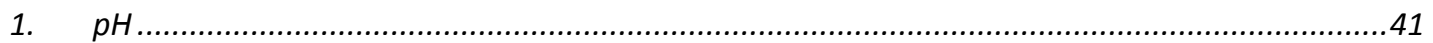

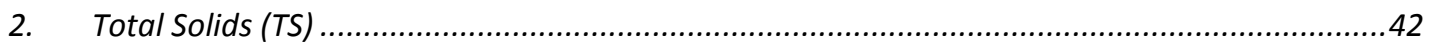

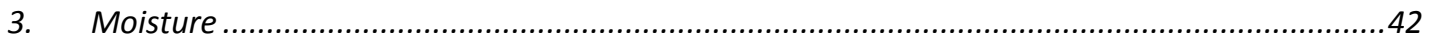

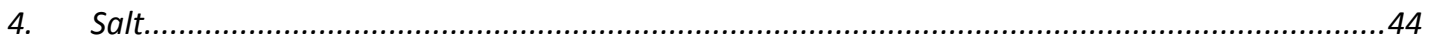

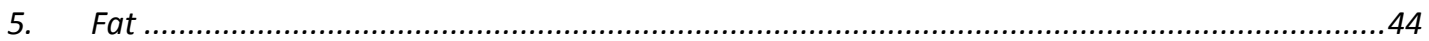

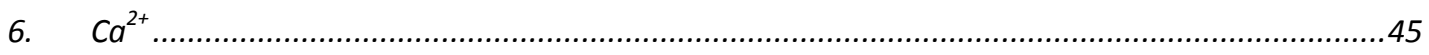

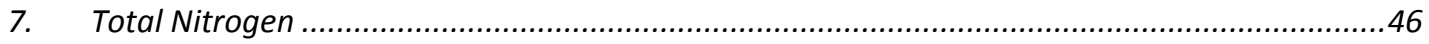

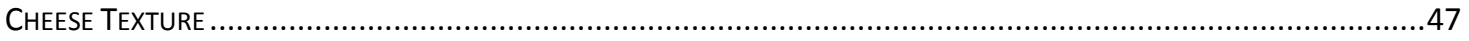

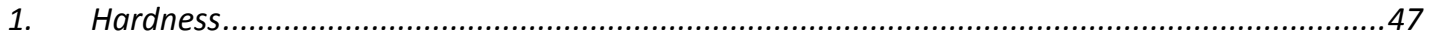

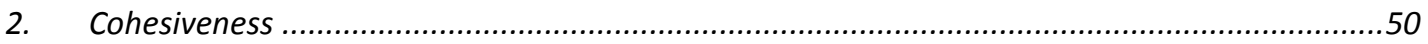

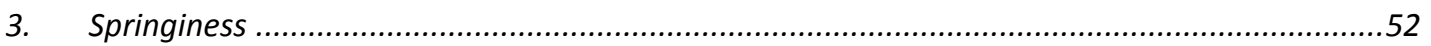

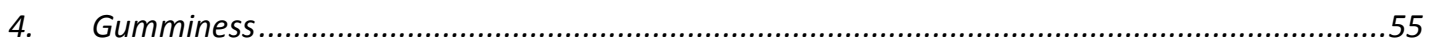

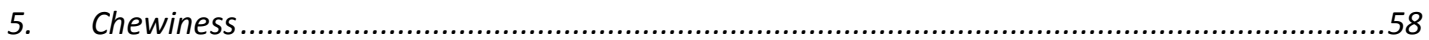

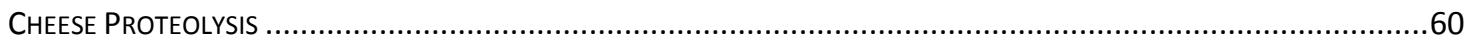

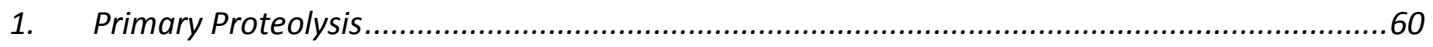

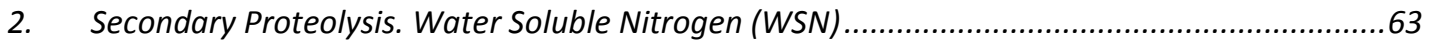




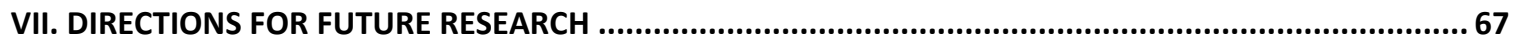

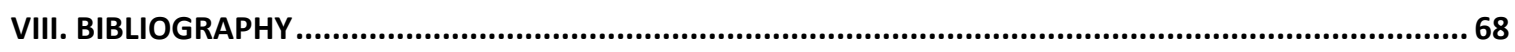

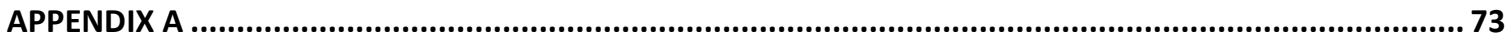

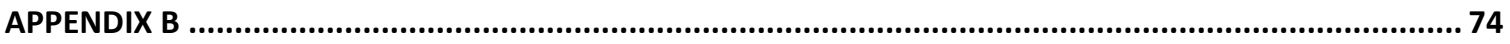

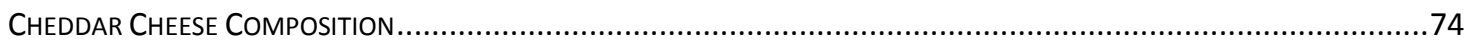

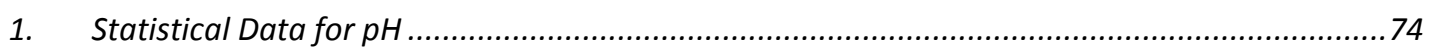

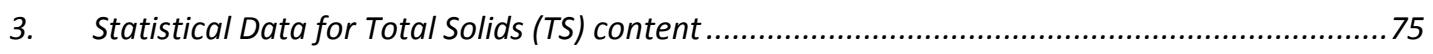

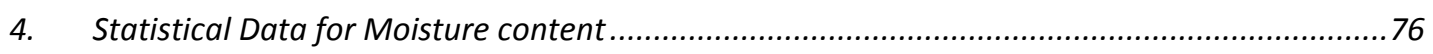

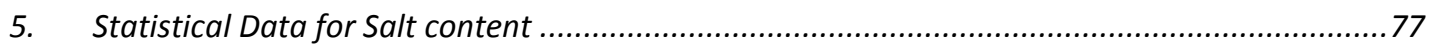

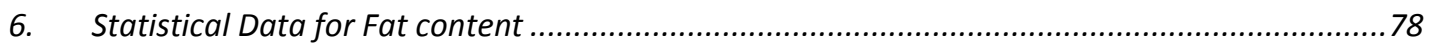

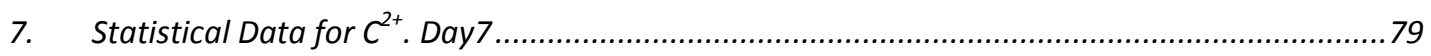

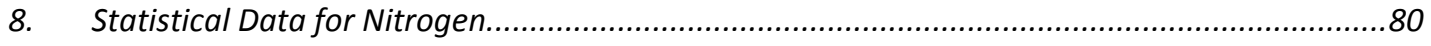

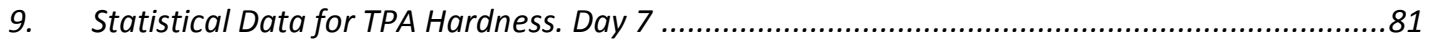

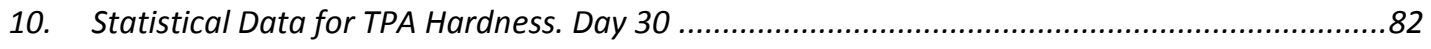

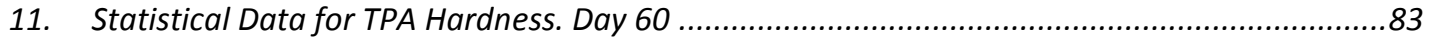

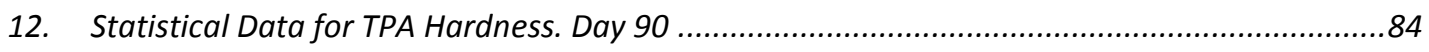

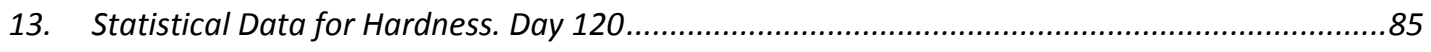

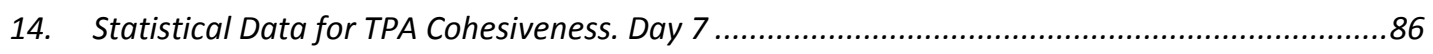

15. Statistical Data for TPA Cohesiveness. Day 30 ..................................................................

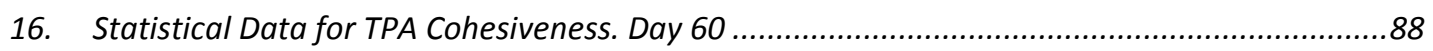

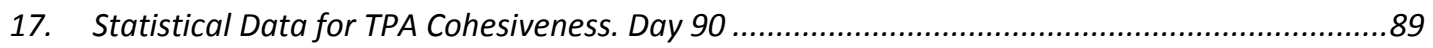

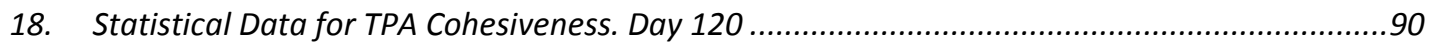

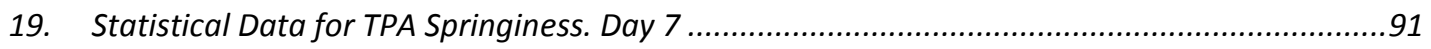




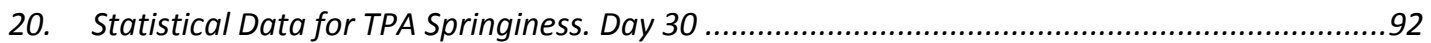

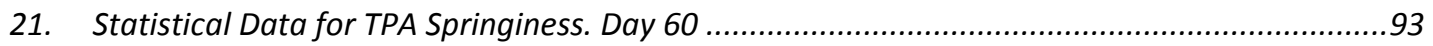

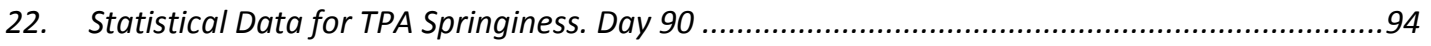

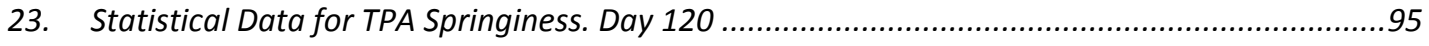

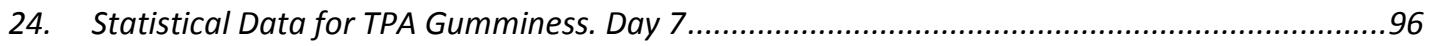

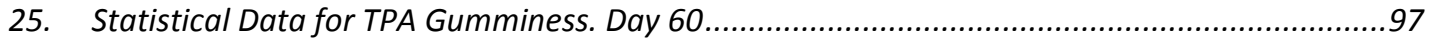

26. Statistical Data for TPA Gumminess. Day 90.....................................................................98

27. Statistical Data for TPA Gumminess. Day 120 .....................................................................

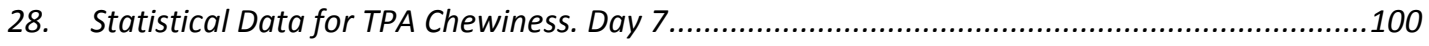

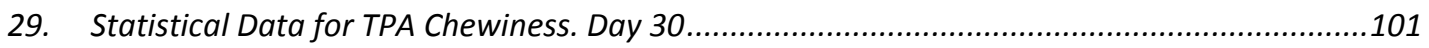

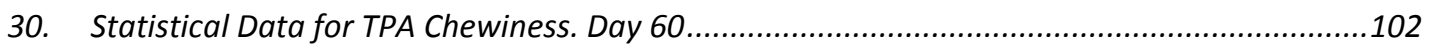

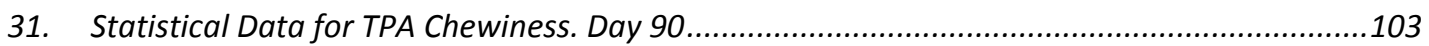

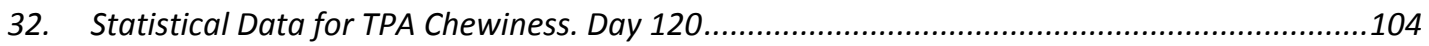

33. Statistical Data for Water Soluble Nitrogen (WSN) content in Cheese. Day 7 .........................105

34. Statistical Data for Water Soluble Nitrogen (WSN) content in Cheese. Day 30 ......................106

35. Statistical Data for Water Soluble Nitrogen (WSN) content in Cheese. Day 60 ......................107

36. Statistical Data for Water Soluble Nitrogen (WSN) content in Cheese. Day 90 .......................108

37. Statistical Data for Water Soluble Nitrogen (WSN) content in Cheese. Day 120 .....................109 


\section{LIST OF TABLES}

TABLE 1. Classification OF CHEESE BASEd ON MoISTURE CONTENT (FARKYE, 2004) ...............................................

TAble 2. Principal factors affecting the Rennet-coAgulation time of MiLK (FoX ANd McSWeeney, 1998).............5

TAble 3. Texture Analysis Settings. SpeCific settings SeleCted for yogurt using TA-XT2 TeXture AnAlyzer.........16

TAble 4. Texture Analysis Settings. SpeCific Settings SeleCted for yogurt using TA-XT2 TeXture ANalyzer.........19

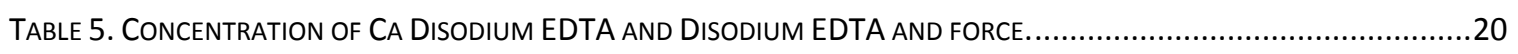

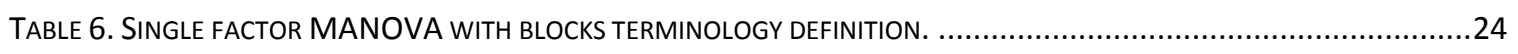

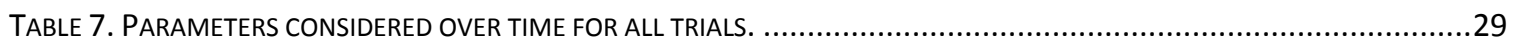

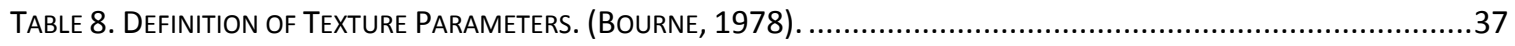

Table 9. Texture Analysis Settings. SpeCific Settings Selected for TPA With the TA-XT2 TeXture AnalyZer.........38

TABLE 10. MEANS ${ }^{1}$ DIfFERENCE TUKEY LSD FOR CHEESEMAKING MILK. .............................................................40

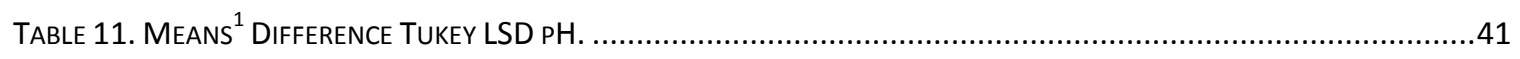

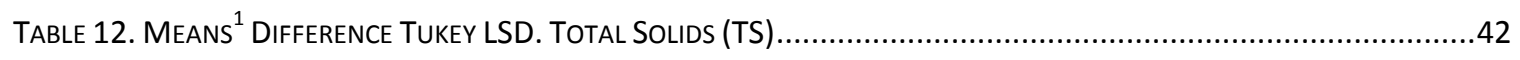

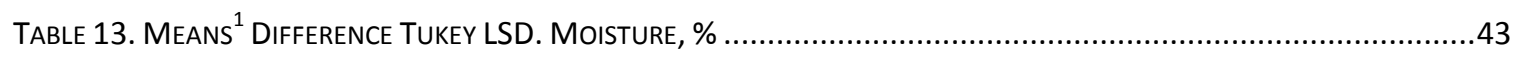

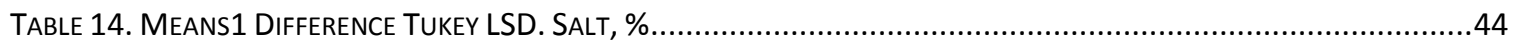

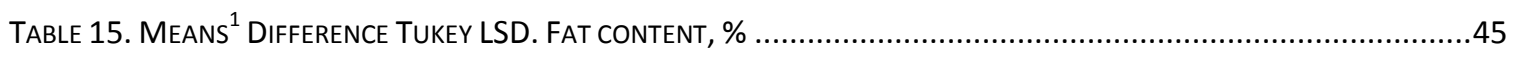

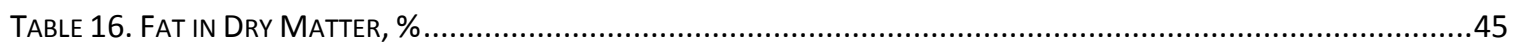

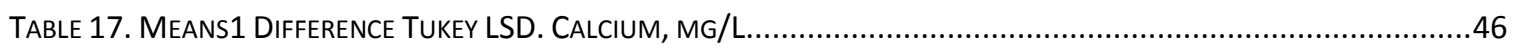

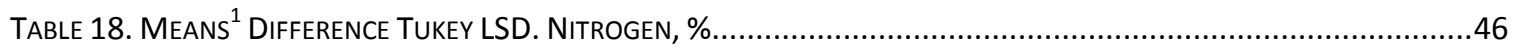

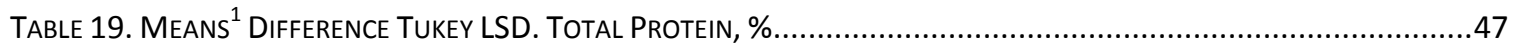

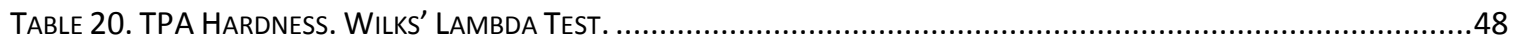

TABLE 21. TPA HARDNESS. TUKEY LSD MEANS ${ }^{1}$ FOR ALL TREATMENTS DURING RIPENING.......................................50

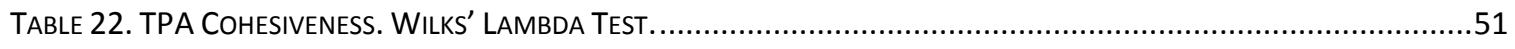

TABLE 23. TPA COHESIVENESS. TUKEY LSD MEANS1 FOR ALL TREATMENTS DURING RIPENING...................................52

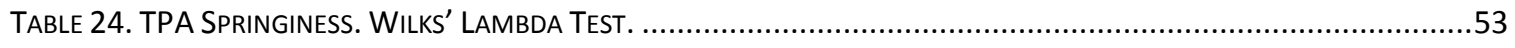


TABLE 25. TPA SPRINGINESS. TUKEY LSD MEANS ${ }^{1}$ FOR ALL TREATMENTS DURING RIPENING. ....................................54

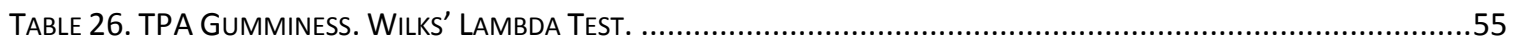

TABLE 27. TPA GUMMINESS. TUKEY LSD MEANS ${ }^{1}$ FOR ALL TREATMENTS DURING RIPENING.......................................57

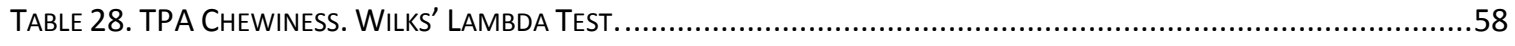

TABLE 29. TPA CHEWINESS. TUKEY LSD MEANS ${ }^{1}$ FOR ALL TREATMENTS DURING RIPENING.........................................59

Table 30. Water Soluble Nitrogen (WSN) Content. Wilks' Lambda TeSt ..................................................63

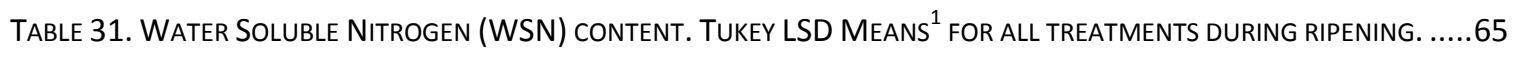

Table 32. Dietary Reference Intake Values for Calcium by Life-Stage Group for U.S. AND CanadA ${ }^{A} \ldots \ldots . . . . . . . . . . . .73$ 


\section{LIST OF FIGURES}

Figure 1. Cheddar First And Second grade composition RANGeS (Fox et AL., 2004B) ....................................

FigurE 2. CALCIUM-ION AS A FUNCTION OF CONCENTRATION OF SALTS (DE KORT ET AL., 2011). ................................14

FIGURE 3. EFFECT OF DISODIUM CITRATE ON RENNET GEL STRENGTH. ............................................................ 17

FIGURE 4. EFFECT OF DISODIUM EDTA AND CA DISODIUM AFTER RENNET ....................................................20

FIGURE 5. FLOW DIAGRAM OF EXPERIMENTAL DESIGN OF FFC, 3NA, EDTA AND LFC CHEDDAR CHEESES. .......................23

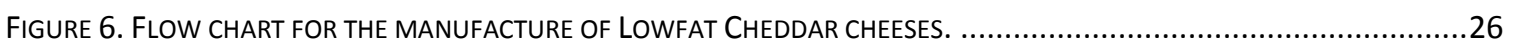

FiguRE 7. Flow CHART OF MANUfACTURE OF FFC USING THE MILLED-CURD METHOD. ........................................28

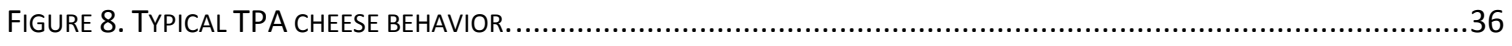

FIGURE 9. TPA HARDNESS. LEAST SQUARE MEANS OF LOWFAT AND FFC CHEESES DURING 120 DAYS OF RIPENING.............48

FIGURE 10. TPA COHESIVENESS. LEAST SQUARE MEANS OF LF CHEESES AND FFC DURING 120 DAYS RIPENING. ...............51

FIGURE 11. TPA SPRINGINESS. LEAST SQUARE MEANS OF LF CHEESES AND FFC DURING 120 DAYS RIPENING..................53

FIGURE 12. TPA GUMMINESS. LEAST SQUARE MEANS OF LFC AND FFC DURING RIPENING. ....................................56

FIGURE 13. TPA CHEWINESS. LEAST SQUARE MEANS OF LFC AND FFC DURING RIPENING.....................................58

FIgURE 14. PolyACRYLAMIDE GEL ELECTROPHORESIS OF LFC AND FFC AFTER 7 AND 30 DAYS OF RIPENING.....................61

FIGURE 15. PolyACRYLAMIDE GEL ELECTROPHORESIS OF LFC AND FFC CHEESES AFTER 60 AND 90 dAYS OF RIPENING.........62

FiguRE 16. PolyaCRYLAMIDE GEL ELECTROPHORESIS OF LFC AND FFC AFTER 120 DAYS OF RIPENING. ..........................63

Figure 17. WATER Soluble Nitrogen (WSN) CONTENT. LEAST SQUARE MEANS OF LFC AND FFC DURING RIPENING. .......64 


\section{INTRODUCTION}

Obesity is a major public health problem in the United States (Baskin et al., 2005). The prevalence of overweight and obesity in the population is of medical concern because it increases the risk for several diseases, particularly cardiovascular diseases (CVDs) and diabetes mellitus (Panel, 1998). With consumers becoming more conscious about their health conditions, the desire for food products that deliver nutritional and functional benefits has increased (Childs and Drake, 2009). For the past 20 years, in developed countries, trends within consumers have shown an avoidance of high calorie foods (Mistry, 2001). Several efforts to provide in good health options to the consumers have been led by the government (Childs and Drake, 2009). In the United States, for example, the recommended caloric intake from fat is not more than $30 \%$ of total calories (McMahon, 2010; Jacobs, 1993) . Cheese is a nutritionally valued dairy product of significant economic interest; nearly a third of all global milk production is consumed as cheese (Kethireddipalli et al., 2010). Even though cheese is considered a nutrient-dense food that is a good source of calcium, phosphorus, and protein, the consumer also perceived this product as high in fat and sodium (Johnson, 2009). During the past 15 years, the demand for reduced and lowfat cheese has increased dramatically (Drake \& Swanson, 1995). In the dairy industry, the interests of low calorie foods have given the opportunity to new markets. This incentive has been followed by the dairy industry represented such as Dairy Management Inc. (DMI) that launched several research projects. One of those major efforts is going towards the improvements of LF cheeses. A research conducted through DMI reveals that 16 percent of adults around 20 to 54 years old are cheese restrictors. Fifty percent of the cheese restrictors also say that they might 
be willing to buy LF Cheddar cheese if the product with less fat does not compromise on flavor, texture or meltability (Inc, March, 2009). LF cheeses are usually characterized as having poor body, flavor, and functional properties because of high moisture and low salt. Successfully producing lower fat cheese requires mimicking the role of fat in texture, performance, flavor and color of cheese, as well as compensating for the lower salt-in-moisture concentration when moisture content is increased (McMahon, 2010). Procedures developed to improve the texture and flavor attributes of LF cheeses have been modified to simulate the properties of a FFC (Drake et al., 1996). Changes during the manufacture of LF Cheddar cheeses include variation of processing techniques, starter culture selection, and use of additives (Johnson et al., 2009). Significant advances in understanding the biochemical and physicochemical characteristics of LF variants in the past decade have led to novel technological developments (Banks, 2004). Different methods and technology have been developed, for the past 20 years, creating more than 50 patents (Mistry, 2001). Studies on the influence of fat on flavor and flavor development in Cheddar cheese had been reported (Drake et al., 2010). In recent years with the aim to improve quality of LF Cheddar cheeses, researches have been examined unconventional the addition of chelating agents to reduce the calcium colloidal phosphate (CCP) (Pastorino et al., 2003) or increasing total solids using microfiltration (McGregor and White, 1990a, b). Addition of emulsifying salts (Hoffmann et al., 2012), thickening agents (Dabour et al., 2006) and fat mimetics have been implemented (Banks, 2004; Mistry, 2001; Drake 1996) during processing to replace the fat removed, increase the moisture retention and decrease acid accumulation. 


\section{LITERATURE REVIEW}

\section{Cheese}

Cheese is the generic name for a group of fermented milk-base food products (Fox et al., 2000) and is one of the classical examples of food preservation that uses lactic acid fermentation, and reduction of water activity through removal of water and addition of $\mathrm{NaCl}$ (Fox et al., 2004a). Cheese is a very versatile product with many diverse flavors and texture that can be used as a snack or as part of a dish or prepackaged convenience food (Farkye, 2004). Although traditional cheeses have a rather high fat content, they are rich in protein and in most, cases of calcium and phosphorous and have anticarigenic properties (Fox and McSweeney, 1998). Cheese can be classified according to texture, fat content, ripening method or country of origin. The US Code of Federal Regulations classification of cheese is based on moisture and fat content. Content of fat is usually expressed as fat-in-dry matter (FDM) (Farkye, 2004). FDM is the ratio between the $\%$ fat and $\%$ total solids multiplied by 100 . This value is important because it remains constant and excludes variations of water evaporation, especially for ripened cheeses such as cheddar (Fox et al., 2004b). Table 1 shows a classification of cheeses based on moisture content. 
Table 1. Classification of cheese based on moisture content (Farkye, 2004).

\begin{tabular}{lcc}
\hline \multicolumn{1}{c}{ Consistency } & Maximum moisture (\%) & Minimum FDM (\%) \\
\hline \hline Hard grating & 34 & 32 \\
Hard & 39 & 50 \\
Semisoft & $50(>39)$ & 50 \\
Semisoft, part skim & 50 & $45(<50)$ \\
Soft & Not specified & 50
\end{tabular}

Cheese manufacture essentially involves gelation of the casein via isoelectric point (acid) or enzymatic (rennet) coagulation. Cheeses produced by acid coagulation possess a short shelf life and are usually consumed fresh while the rennet cheeses are almost always matured before consumption (Fox et al., 2004a).

The production of rennet coagulated cheeses can be described in two steps:
A. Conversion of milk into curds
B. Ripening of curds

The conversion of milk into curds (A) or coagulation process due to enzymatic reactions can be divided into two phases.

1) First phase is represented by the hydrolysis of $\kappa$-casein by rennet that claves at the Phe105-Met106 bond. As result a molecule of para- $\kappa$-casein (hydrophobic) and macropeptides (hydrophilic) are produced as the reaction below. Fat does not participate in this stage.

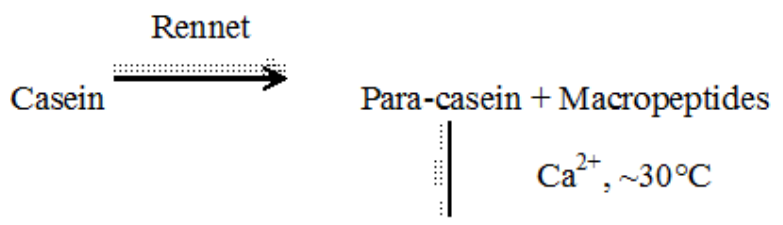

Gel 
2) Second phase starts when at least $85 \%$ of the total $\kappa$-casein has been hydrolyzed and micelles begin to aggregate into a gel. Table 2 resumes the grade of participation of factors at first and second stage.

Table 2. Principal factors affecting the rennet-coagulation time of milk (Fox and McSweeney, 1998).

\begin{tabular}{lll}
\hline \hline Factor & First phase & Second phase \\
\hline \hline Temperature & + & ++ \\
$\mathrm{pH}$ & +++ & - \\
$\mathrm{Ca}$ & - & +++ \\
Pre-heating & ++ & ++++ \\
Rennet concentration & +++ & - \\
Protein concentration & + & ++++ \\
\hline
\end{tabular}

During ripening of curds (B) three principal events take place:

1) Glycolysis: $98 \%$ of lactose in milk is separated as lactic acid from the curd and $2 \%$ remaining is metabolized by nonstarter lactic acid bacteria (NSLAB).

2) Degradation of lipids to fatty acids is called lipolysis that directly contributes to cheese flavor development.

3) Proteolysis or break down of proteins is the most complex event during ripening. This process gives the texture and flavor profile to a cheese (Fox and McSweeney, 1998).

\section{Cheddar cheese}

Cheddar cheese is a rennet-coagulated cheese with a firm texture. Cheddar cheese can be classified as a First or Second grade according to the composition of the cheese. 
Figure 1 suggests ranges of salt in moisture $(\mathrm{S} / \mathrm{M})$, moisture in non-fat substance (MNFS), FDM and pH for First and Second Grade.

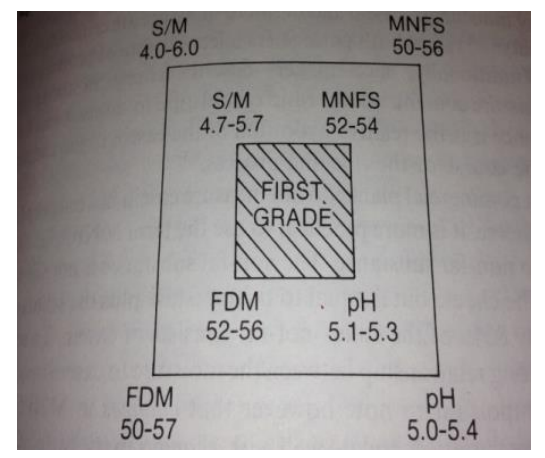

Figure 1. Cheddar First and Second grade composition ranges (Fox et al., 2004b)

\section{Standards of identity for low and full fat Cheddar cheese}

Full fat Cheddar cheese is defined under standards of identity as containing not more than $39 \%$ moisture, unless labeled properly as excess of moisture cheese, and not less than 50\% FDM (Kosikowski and Mistry, 1997).

According to the U.S Code of Federal Regulations (2005), lowfat cheeses have strict legal definitions. Lowfat refers to cheese containing no more than $6 \%$ fat based on definition 21CFR101 - Section 101.62(b)(2)(i). Cheese can be labeled as lowfat food if the fat content has been reduced by $50 \%$ or more, such that it contains less than $3 \mathrm{~g}$ fat per serving (28g) (Drake and Swanson, 1995). 


\section{Consumption of Cheddar cheese}

U.S. per capita consumption of natural cheese increased by 0.36 pounds over the 2010 amount, reaching a level of 33.50 pounds, the second highest amount on the U.S. record (2012). Even though in 2011 the consumption of American-type cheese consumption dropped by 0.14 pounds to 13.18 pounds per person, Cheddar cheese still remains the second most consumed cheese in the U.S. after mozzarella.

According to the International Dairy Foods Association (IDFA), the sales of natural cheese represented a value of over $\$ 11$ billion dollars. The largest volume sales were Cheddar (36.7\%), Mozzarella (20.9\%) and Colby Jack (9.3\%). While mozzarella is the most consumed cheese, sales in billions dollars of Cheddar remain the highest.

\section{Calcium content on a portion of Full fat cheddar}

According to the USDA National Nutrient Database for Standard Reference, a portion of a full fat cheddar cheese is $28.35 \mathrm{gr}(1 \mathrm{oz})$ that should contain about $204 \mathrm{mg}$ of Calcium.

Adequate calcium intake recommendations were set at levels associated with desirable retention of body calcium since high bone density is known to be less susceptible to fractures. Recommended intake for adults is 1000 to $1200 \mathrm{mg} /$ day (Bryant et al., 1999). Dairy foods have indisputably been the highest contributor of dietary calcium; thus, it is no surprise that this group remained the top-ranked source of calcium (Cook and Friday, 2003). 


\section{Problems in the manufacture of $L F$ cheddar cheese.}

The level of fat influences several aspects of cheese, including composition, biochemistry, microstructure, yield, rheological, textural proprieties, and cooking properties. It is well accepted that Cheddar cheese made from skimmilk does not develop a characteristic flavor and texture. Cheese with a FDM less than $50 \%$ did not develop a Cheddar profile (Fox et al., 2004b).

\section{Texture of cheddar cheese}

The texture of Cheddar cheese is of importance to consumers yet, it is difficult to explain and describe due to its complexity. There are many factors that play a big role developing texture of Cheddar cheese. Table 2 above describes the most important factors during the first phase of rennet-coagulation.

Bovine milk contains 30-35 g protein/L. About $80 \%$ of the protein in milk is caseins represented by 4 gene products: $\alpha_{\mathrm{s} 1}, \alpha_{\mathrm{s} 2}, \beta$, and $\kappa$-caseins (Fox, 1992) that in combination with CCP constitute the casein micelles (Lucey et al., 1997)

Natural rennet-curd cheese is essentially a calcium-phosphate-paracasein matrix. In cheese, a dynamic equilibrium exist between concentrations of $\mathrm{Ca}^{2+}$ and inorganic phosphate in the paracasein matrix and the cheese serum influenced by $\mathrm{pH}$ and other factors such as concentrations of $\mathrm{Na}^{+}$(Fox et al., 2000).

Various studies affirm that the characteristics of cheese structure depends upon $\mathrm{pH}$ changes more than any other factor, although the general tendency for the cheese is to become less firm as the calcium content decreases during cheese making, as $\mathrm{pH}$ decreases 
towards the casein isoelectric point of paracasein, the protein assumes an increasingly more compact conformation and the cheese becomes shorter in texture and fractures at a smaller deformation (Fox et al., 2004b).

Salt plays a major role in cheese texture. Enzyme activity, solubility of protein break down, hydration of the protein network, and interactions of calcium with the paracaseinate complex in cheese are influenced by salt concentration (Fox et al., 2004b).

Proteolysis is the most complex, and perhaps most important event during ripening because it is responsible for textural changes during maturation. Small peptides are responsible for the flavor qualities of the cheese depend on this phenomenon (Fox, 1992).

\section{Impact of fat removal on cheese texture}

During the past few decades, consumption of low fat products has grown steadily because of consumer awareness about health associated with obesity (Dabour et al., 2006). Although lowfat cheese may allow for those who want to eat cheese but would like to reduce fat and calorie intake, the removal of fat causes changes in cheese flavor and texture that may be unacceptable to consumers (Childs and Drake, 2009), (Banks, 2004).

The gelation of milk is characterized by the aggregation of the rennet-altered casein micelles into interconnected clusters and forming a network in which fat globules are interspersed as loose inclusions. Continued aggregation of the para-casein, and expulsion of whey leads a gradual fusion of the protein gel network around fat globules (Fox and McSweeney, 2006). 
Cheese texture is a sensory characteristic that can be measured using sensorial analysis (Fox et al., 2000) mechanically measured using a Texture Analyzer.

\section{Colloidal Calcium phosphate role in cheese texture}

$\mathrm{Ca}^{2+}$ ions play a major role in the stability of milk proteins and their functional properties during milk processing but the role of ionic calcium in causing coagulation of milk proteins during heat treatment is still unclear. (Ramasubramanian et al., 2013). The amount and the state of the retained calcium influences the physical characteristics of cheese during ripening (Johnson and Lucey, 2006). Calcium content of Cheddar cheese has an important effect on both texture and long term keeping quality. Some of the factors that influence the calcium content of cheese are:

1. Quantity of the rennet used. The proportion of rennet added should be the minimum necessary to give a firm coagulum. During the manufacture of full fat Cheddar cheese using the milled curd the relation of rennet to $\mathrm{kg}$ of milk is 100 $\mathrm{ml} / 1000 \mathrm{~kg}$. In addition to rennet, a small concentration of $\mathrm{CaCl}_{2}$ is added $(0.06 \%$ w/w of milk). Addition of Ca reduces the rennet coagulation time of milk that is due to the neutralization of negatively charged residues on casein, which increases the aggregation of renneted micelles. Addition of low concentrations of $\mathrm{Ca}$ also increases gel firmness (Lucey and Fox, 1993), For the manufacture of lowfat Cheddar the concentration of rennet is considerably reduced to $34 \mathrm{ml} / 1000 \mathrm{~kg}$ of milk due to the increase of protein content and the reduction of fat globules. The efficacy of the enzyme is inversely proportioned to protein content. For the 
purposes of this study, chelating agents have been added in order to reduce calcium colloidal phosphate (CCP) as a novel method to soften the curd strength.

Set time during manufacture after adding rennet. Whey drainage $\mathrm{pH}$ is considered the most important factor because it determines the mineral content in the curd as well as the residual concentration of rennet and plasmin in cheese. It also defines the final $\mathrm{pH}$ and moisture to casein ratio (Fox et al., 2004b). Decreasing the $\mathrm{pH}$ of the whey at draining increases the level of nonmicellar calcium and lowers the $\mathrm{Ca}^{2+}$ content of cheese (Metzger et al., 2000).

All of the factors mentioned have an impact in the Calcium retention in the cheese matrix. Changes in the physical properties of cheese during ripening occur in two stages:

1. Changes in the insoluble calcium content led by $\mathrm{pH}$ and changes that takes place within a short period after cheesemaking.

2. The second stage is governed by the extent of proteolysis of intact casein that occurs throughout cheese ripening (Johnson and Lucey, 2006).

Removal of colloidal calcium phosphate (CCP) at milk pH has been done successfully in the past using dialysis of skimmilk reducing CCP concentration and demonstrating the importance for micellar integrity (Fox, 1992). In addition, if the $\mathrm{pH}$ of milk is lowered by acid addition prior to rennet coagulation, a portion of the micellar calcium is solubilized and this will lower the calcium content of cheese.

Increasing the temperature of acidified milk prior to rennet addition should cause some of the casein to go back into the micelles because of increased hydrophobic attraction among caseins (Metzger et al., 2000). 


\section{Chelating agents definition}

Chelating agents, in some cases called emulsifier salts, play an important role in food preservation. They are molecules designed to inactivate oxidative degradation that impact quality, shelf-life, and nutritional content of food products, especially of packaged foods. When trace metals are present in foods; they initiate degradation of nutritional compounds such as unsaturated fatty acids, carotenoids, antioxidants, phytosterols, and many vitamins. In consequence, chelating agents are designed to sequestrate metal ions.

\section{Uses of Chelating agents in the dairy industry}

Emulsifying salts such as disodium citrate are widely used in the dairy industry for processed cheese manufacture to control melting, texture and free oil formation (Mizuno and Lucey, 2005). Processed cheese is produced by blending shredded natural cheeses of different types and degrees of maturity with emulsifying agents, and by heating the blend under a partial vacuum with constant agitation until a homogeneous mass is obtained. In addition to natural cheeses, other dairy and non-dairy ingredients may be included in the blend (Carić and Kaláb, 1993).

Sodium phosphates, polyphospates and citrates are emulsifying salts most commonly used in the manufacture of process cheese either alone or in mixtures. Their role during processing is to sequester calcium in the natural cheese, to solubilize protein and increase its hydration and swelling, to facilitate emulsification of fat, and to adjust and stabilize pH (Carić and Kaláb, 1993). 
Chelators such as EDTA can be added to inhibit metal-promoted oxidation, however there is significant consumer and industry demand to eliminate EDTA from product formulations (Goddard et al., 2012).

\section{Chelating agents used for Lowfat Cheddar cheese manufacture}

Effect of sodium citrate on structure and function relationships of Cheddar cheese have been already investigated (Pastorino et al., 2003). Using high pressure injection, a buffer (pH 5.27) containing 40\% (wt/wt) citric acid and trisodium dehydrated and $6.25 \%$ (wt/wt) anhydrous citric acid from zero (control) to five times successive injections performed $24 \mathrm{hrs}$ apart. Citric acid increased from 0.22 (control) to $1.39 \%$ (after five injections). As result, a reduction on the bound phosphate content on cheese decreased from $0.54 \mathrm{mmol} / \mathrm{g}$ protein (control) to $0.45 \mathrm{mmol} / \mathrm{g}$ protein (after 5 injections) increasing phosphate solubilization and possibly the ionic $\mathrm{Ca}^{2+}$ content decreased resulting in expansion of the protein matrix and increasing hardness.

\section{Chelating agents and the impact on Texture of cheese}

Calcium chelators such as EDTA, citrate, phosphate are often used to improve the heat stability on dairy products influencing changes in the casein micelles decreasing calcium ions and depletion of CCP (De Kort et al., 2011). In this study, the calcium ion activity was decreased upon the addition of 4 different types of salts in the following order: SHMP (sodium hexametaphosphate), SP (sodium phytate), TSC (trisodium citrate) and $\mathrm{Na}_{2} \mathrm{HPO}_{4}$. SHMP caused the most reduction in $\mathrm{Ca}^{2+}$ activity. Figure 2 shows efforts of various cheating agents on the decrease of $\mathrm{Ca}^{2+}$ ions activity of casein micelles. 


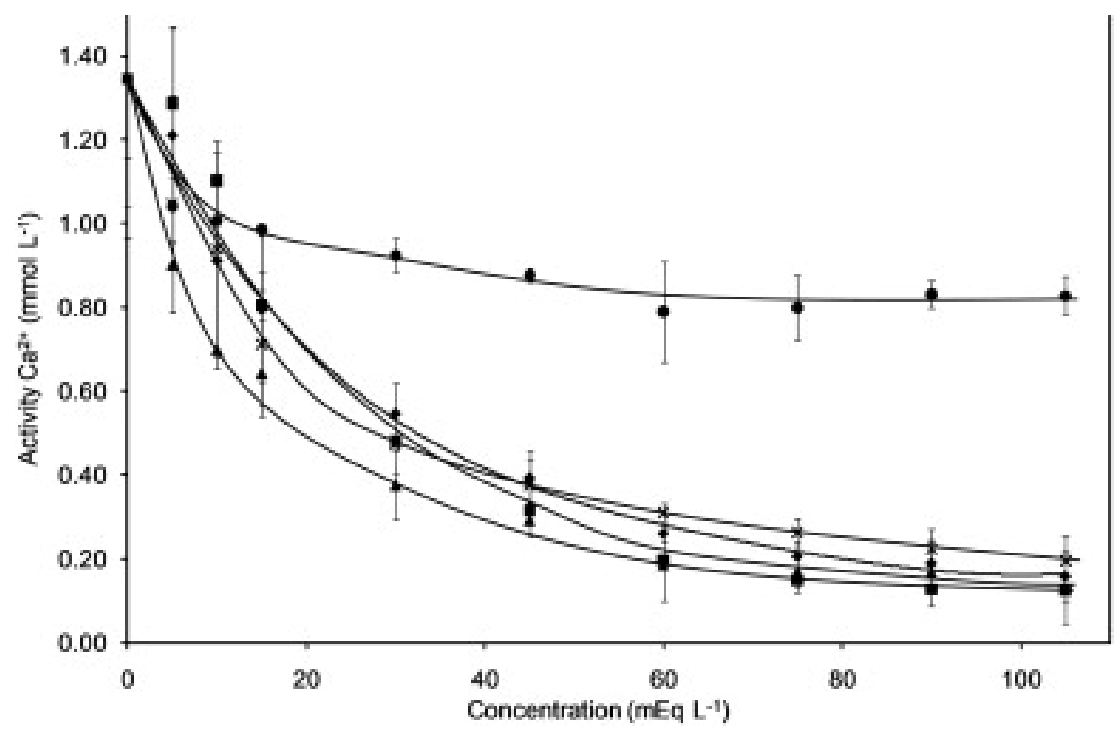

Figure 2. Calcium-ion as a function of concentration of salts (De Kort et al., 2011).

(•) Na2UMP; (•) Na2HPO4; (ø) SHMP (sodium hexametaphosphate); (^) SP (sodium phytate); (x) TSC (trisodium citrate) 


\section{PRELIMINARY STUDIES ON COAGULATION USING CHELATING AGENTS}

\section{Brief outline}

If the total $\mathrm{Ca}^{2+}$ content of cheese is reduced, then the amount of cross-linking between casein polymers is reduced and the cheese becomes softer (Metzger et al., 2000).

Effects of sodium citrate using high pressure injection was reported (Pastorino et al., 2003) demonstrating an increase on phosphate solubilization, and possible decreased ionic calcium content. The aim of this study is to analyze the effect of the addition of sodium citrate and EDTA to improve the texture of lowfat natural Cheddar.

Disodium citrate and disodium EDTA were selected due to their ability to work well in dairy systems (De Kort et al., 2011).

\section{Determination of disodium citrate concentration and coagulation time}

\section{Objectives}

Determine the adequate concentration of the disodium citrate to act as a $\mathrm{Ca}^{2+}$ chelating agent.

\section{Procedure}

Five liters of pasteurized skimmed milk ( $0.19 \%$ fat) was collected from the California Polytechnic State University Creamery and stored at $4^{\circ} \mathrm{C}$ over night. Two hundred $\mathrm{ml}$ of skimmilk was transferred into $250 \mathrm{ml}$ beakers. Each beaker was previously labeled with different times $(5,10,15$ and $20 \mathrm{~min})$ and concentrations of sodium citrate $(0,0.1,0.15$, 
0.2, 0.25 and $0.3 \% \mathrm{w} / \mathrm{w}$ ) and placed into a water bath (ISOTEMP 210, Fisher Scientific) until the milk temperature reached $\sim 31{ }^{\circ} \mathrm{C} .10 \%$ phosphoric acid was added and mixed until the $\mathrm{pH}$ was reduced to 6.2 . Rennet was added at the rate of $100 \mathrm{ml} / 475 \mathrm{~kg}$ of milk leaving 5 minutes between samples to prevent overlap texture measurements. A timer was set to beep every 5 minutes after rennet addition. The beakers were taken out to measure the curd hardness using TA-XT2 Texture Analyzer using the same setting as yogurt (based on the product similarities). The settings for this measurement are described on Table 4.

Table 3. Texture Analysis Settings. Specific settings selected for yogurt using TA-XT2 Texture Analyzer.

\begin{tabular}{lc}
\hline \hline \multicolumn{1}{c}{ Parameter } & Selected Settings \\
\hline Test Mode & Yogurt \\
Pre Test Speed & $1.2 \mathrm{~mm} / \mathrm{s}$ \\
Post Test speed & $1.2 \mathrm{~mm} / \mathrm{s}$ \\
Distance & $80 \mathrm{~mm}$ \\
Compression & $50 \%$ \\
Time & $5 \mathrm{~s}$ \\
Force & $5 \mathrm{~g}$ \\
Probe & $40 \mathrm{~mm}$ \\
\hline
\end{tabular}

\section{Results and Conclusions}

In the case of LF Cheddar cheese manufacture, the set time after rennet addition before curd cutting is reduced to 20 minutes due to a reduction of fat content compared to a FFC set time (30 min) (Kosikowski and Mistry, 1997). In consequence, during the preliminary studies and LF cheese manufacture we maintained this time as a constant.

Figure 3 shows the development of the coagulum hardness of milk containing added sodium citrate after rennet addition. At this point we obtain a curd with a force $\sim 150 \mathrm{~g}$ 
which makes possible to get a soft curd but still obtain cheese out of it. At 0.025 or 0.3 $\% w t / w t$ the curd was too soft and was unacceptable for cheese making.

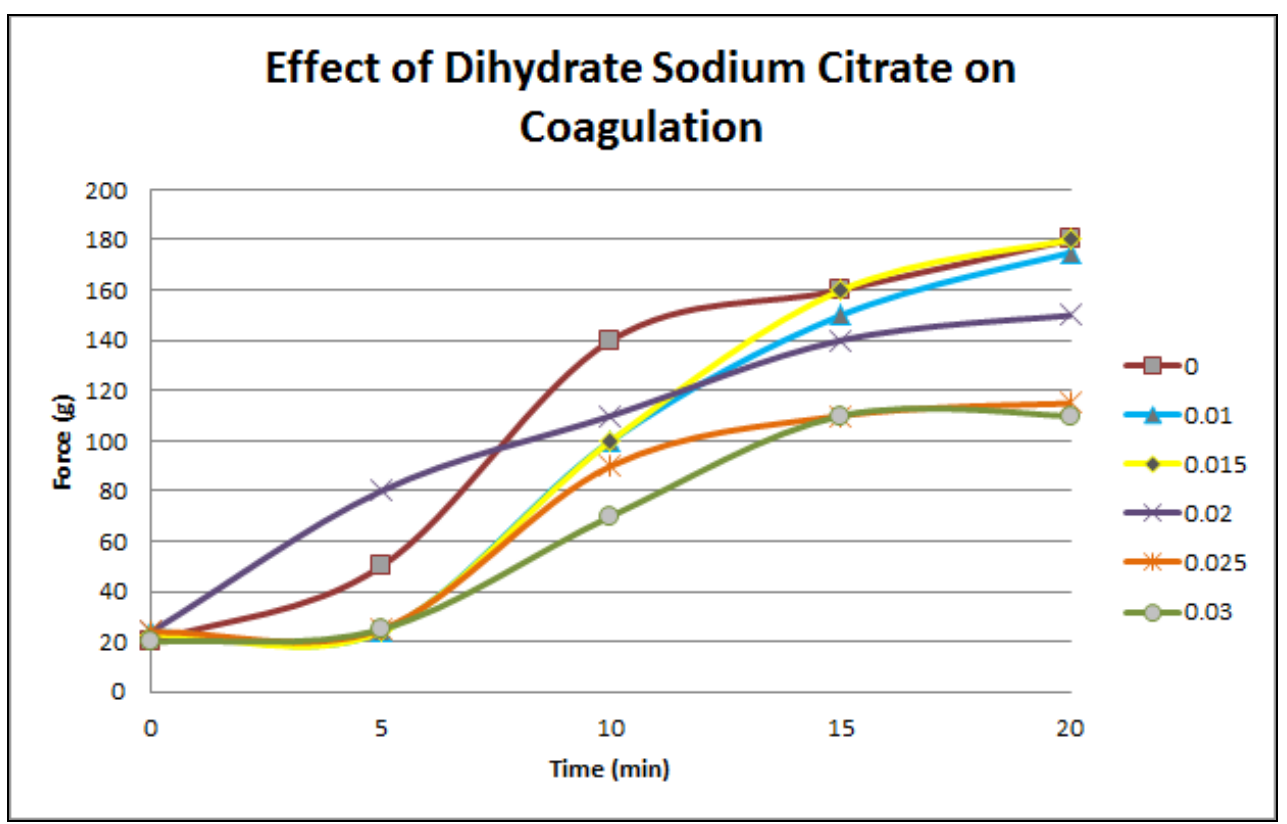

Figure 3. Effect of Disodium Citrate on rennet gel strength.

\section{Calcium EDTA and Disodium EDTA chemical properties described by manufacture company}

In the invention dilute aqueous sodium hypochlorite is stabilized against decomposition during storage by incorporating in it a small proportion of the chelate of disodium ethylenediaminetetraacetic (EDTA). Thus stabilized even at high dilutions the hypochlorite retains nearly its initial strength for many when intended for disinfecting surfaces on considerable organic matter is present the diluted hypochlorite may be formulated to contain also a detergent and an alkaline builder (Burton, 1990). 
VERSENE is the provider of the two types of EDTA. They vary on the $\mathrm{pH}$ range of action. According to the product specifications VERSENE CA Chelating Agent is more efficient in foods with a $\mathrm{pH}$ between 6.5-7.5 (1 wt\% solution).VERSENE Disodium EDTA best pH environment falls between 4.3-4.7 (1 wt\% solution) and 4.0-6.0 (5 wt\% solution).

\section{Selecting the appropriate EDTA for cheese making purposes}

\section{Objectives}

The purpose of this experiment is to define which type of EDTA (calcium or disodium) was most effective for rennet curd formation.

\section{Procedure}

Five liters of fresh raw whole milk was obtained from the Cal Poly dairy farm and storaged at $4{ }^{\circ} \mathrm{C}$ over night. The cold milk was transferred into a $250 \mathrm{ml}$ and flasks and centrifuged for $25 \mathrm{~min}$ at 10,000 rpm to separate the fat from the milk. Skim milk $0.17 \%$ fat was obtained after centrifugation. $200 \mathrm{ml}$ of skim milk were transferred into $250 \mathrm{ml}$ beakers. The beakers were previously labeled with different concentrations of $\mathrm{Ca}$ disodium EDTA and disodium EDTA at different concentrations and placed into a water bath (ISOTEMP 210, Fisher Scientific). When milk temperature reached $\sim 31^{\circ} \mathrm{C}, 10 \%$ phosphoric acid was added as well as the chelating agents and mixed until the $\mathrm{pH}$ was reduced to 6.2. Rennet was added at the rate of $100 \mathrm{ml} / 475 \mathrm{~kg}$ milk. The samples were staggered 5 min apart to prevent overlap texture measurements. After 20 minutes of adding rennet, each beaker was taken out to measure the curd hardness using TA-XT2 
Texture Analyzer using the same setting as yogurt (based on the product similarities).

The settings for this measurement are described on Table 5.

Table 4. Texture Analysis Settings. Specific settings selected for yogurt using TA-XT2 Texture Analyzer.

\begin{tabular}{lc}
\hline \hline \multicolumn{1}{c}{ Parameter } & Selected Settings \\
\hline \hline Test Mode & Yogurt \\
Pre Test Speed & $1.2 \mathrm{~mm} / \mathrm{s}$ \\
Post Test speed & $1.2 \mathrm{~mm} / \mathrm{s}$ \\
Distance & $80 \mathrm{~mm}$ \\
Compression & $50 \%$ \\
Time & $5 \mathrm{~s}$ \\
Force & $5 \mathrm{~g}$ \\
Probe & $40 \mathrm{~mm}$ \\
\hline
\end{tabular}

\section{Results and Conclusions}

According to the results obtaining by changing the concentration of the two types of EDTA (Table 6), the most appropriate chelating agent for this experiment is the disodium EDTA. 
Table 5. Concentration of Ca Disodium EDTA and Disodium EDTA and force.

\begin{tabular}{cccc}
\hline $\begin{array}{c}\text { Ca Disodium EDTA Chelating } \\
\text { Agent (\%) }\end{array}$ & Max. Force (g) & $\begin{array}{c}\text { Disodium EDTA Chelating } \\
\text { Agent (\%) }\end{array}$ & Max. Force (g) \\
\hline \hline 0.03 & 210 & 0.03 & 200 \\
0.1 & 200 & 0.1 & 200 \\
0.2 & 200 & 0.2 & 180 \\
1 & 200 & 1 & 80 \\
2 & 200 & 2 & 55 \\
3 & 200 & 3 & 25 \\
5 & 200 & & \\
7 & 190 & & \\
10 & 180 & & \\
\hline
\end{tabular}

Using Ca Disodium EDTA at 10\% w/w did not affect curd firmness.

As result of this experiment, the emulsifying agent selected is disodium EDTA at $0.2 \% \mathrm{w} / \mathrm{w}$ because it gave similar curd characteristics as the disodium citrate after $20 \mathrm{~min}$ of rennet addition (Figure 4).

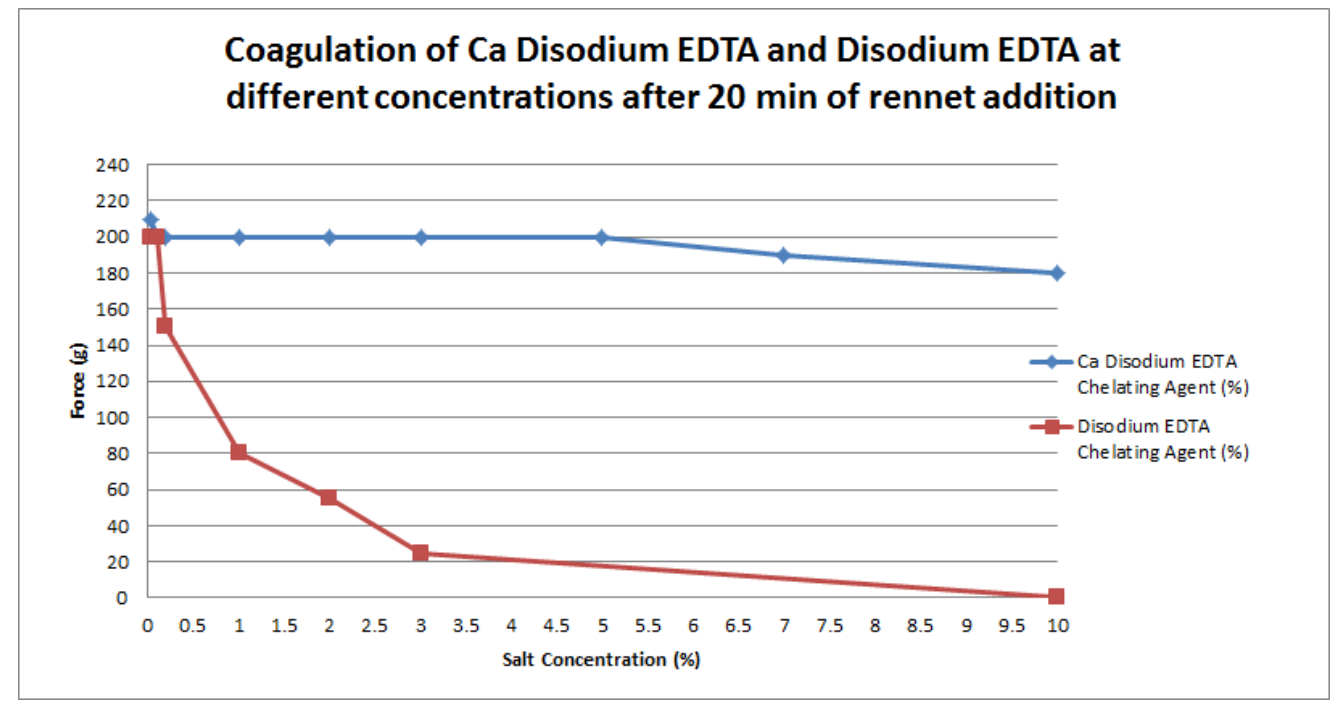

Figure 4. Effect of disodium EDTA and Ca disodium after rennet. 


\section{MATERIALS AND METHODS}

\section{Ingredients}

\section{Milk}

Pasteurized whole milk from containing $3.97 \%$ fat and $3.5 \%$ protein was obtained from California Polytechnic State University Creamery. The majority of the milk was skimmed to $0.16 \%$ fat and mixed with whole milk to obtain mixed milk for cheese making of $0.59 \%$ fat.

\section{Rennet}

CHY-MAX ${ }^{\circledR}$ by Chr. Hansen's, (Milwaukee, WI) was used for milk clotting. ChyMax is a $100 \%$ pure chymosin produced by fermentation.

\section{Starter cultures}

A blend of three types of mesophilic commercial cultures of lactic acid bacteria were used; 850, DSH-hb, and LH32, from Chr. Hansen's, (Milwaukee, WI).

\section{4. $10 \%$ Phosphoric acid}

Food grade phosphoric acid (Innophop, Cranbury, NJ) solution was used to preacidify the mixed milk.

\section{Disodium EDTA}

Food grade EDTA was obtained from Dow Chemical Company, (Midland, MI)

\section{Disodium Citrate}

Food grade disodium citrate 


\section{Standarization}

The milk used for experimental lowfat Cheddar cheeses was HTST pasteurized at $72^{\circ} \mathrm{C}$ for $16 \mathrm{~s}$, cooled to $4^{\circ} \mathrm{C}$, and stored at $4^{\circ} \mathrm{C}$ overnight until used for cheese manufacture the following day.

Milk for lowfat cheese was standardized to $0.53 \%$ fat by adding $14.3 \mathrm{~kg}$ whole milk to $135 \mathrm{~kg}$ skim milk. Full fat Cheddar cheese $(4.5 \mathrm{~kg})$ manufactured by Cal Poly Creamery from the same lot of whole milk was obtained as full fat cheese was not standardized.

\section{Experimental Design}

The project was designed using randomized complete block designed. LF cheese variants and FFC where produced in 5 different occasions. The milk collected for every cheese making was taken from different lots. Cheese milk was divided into three lots (A, B \& C). Sodium citrate ( $3 \mathrm{Na}$ ) and disodium EDTA (EDTA) were added to vat A \& B at the rate of $0.02 \%$ and $0.2 \%$ respectively. C served as control (LFC). Full fat cheddar (FFC) was manufactured at Cal Poly using the milled curd method and from the cheeses was made from the same batch of milk to avoid variation. Figure 5 summarizes the experimental design for this project. 


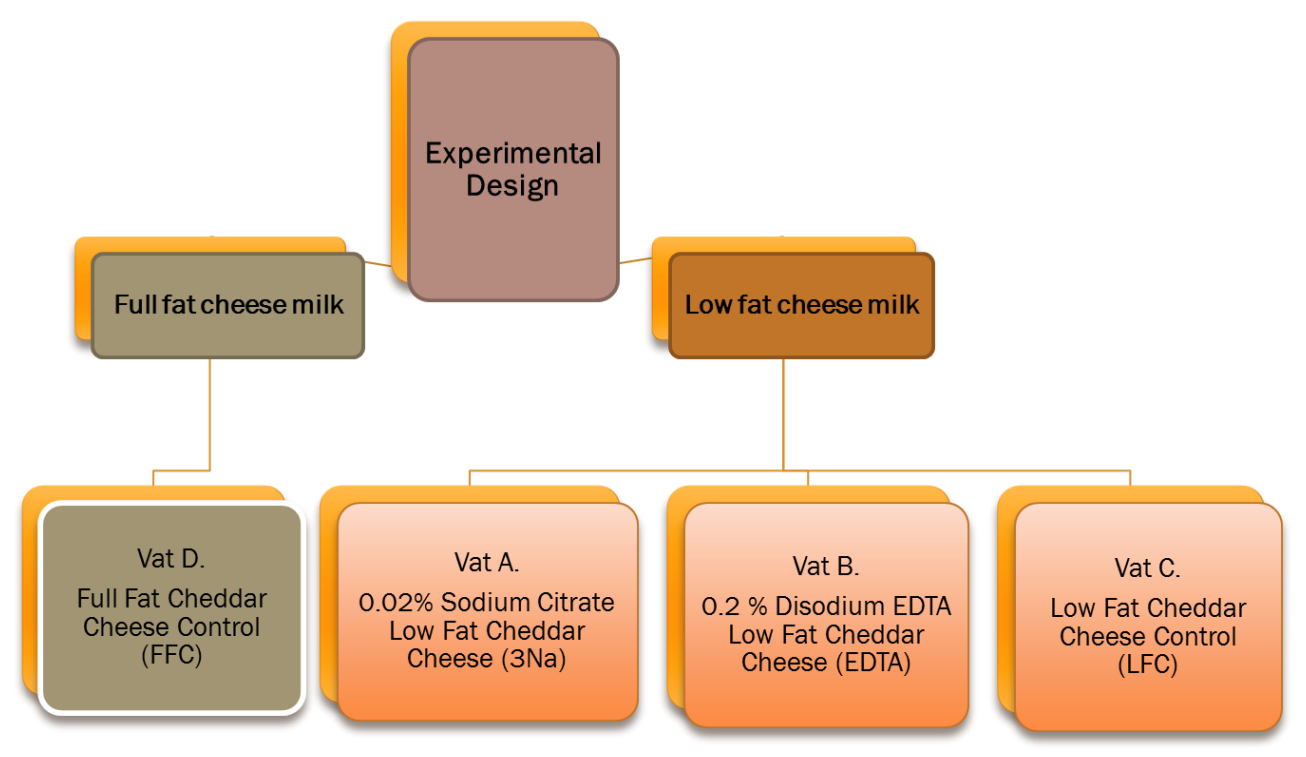

Figure 5. Flow diagram of experimental design of FFC, 3Na, EDTA and LFC Cheddar cheeses.

\section{Statistical Analysis}

A randomized complete block design with one observation per treatment/block combination was used for the purposes of this work. Both, ANOVA and MANOVA models were used to compare treatment means. The specific model parameterization for the MANOVA is shown below. Statistic model nomenclature has been defined in Table 7. A univariate version of the model shown below was used for the ANOVA models.

$$
\mathbf{y}_{i j}=\boldsymbol{\mu}+\boldsymbol{\tau}_{i}+\boldsymbol{\beta}_{j}+\varepsilon_{i j}
$$


Table 6. Single factor MANOVA with blocks terminology definition. Temporal vectors are for ripening measurement times $(7,30,60,90$ and 120 days)

\begin{tabular}{|c|c|}
\hline \multicolumn{2}{|c|}{ Single-factor MANOVA terminology } \\
\hline Parameter & Definition \\
\hline $\mathbf{y}_{i j}$ & $\begin{array}{l}\text { Temporal vector response from } \mathrm{j}^{\text {th }} \\
\text { experiment associated with treatment } \mathrm{i} \text {. }\end{array}$ \\
\hline$j=1,2,3,4,5$ & 5 cheese making trials \\
\hline$i=1,2,3,4$ & Treatments $=$ FFC, LFC, EDTA, 3Na \\
\hline$\mu$ & Overall mean temporal vector \\
\hline$T$ & Treatment effect vector \\
\hline $\boldsymbol{B}$ & Experiment (block) effect vector \\
\hline$\varepsilon_{i j}$ & Random error vector \\
\hline
\end{tabular}

Post-hoc comparisons of individual treatment means following ANOVA analysis were analyzed using Tukey's Method (HSD). Tukey’s HSD is more conservative than some other methods such as Fisher's LSD, meaning that we are less likely to declare pairs of means to be statistically significantly different. However, Tukey's HSD is less likely to report erroneous significant differences. As a conservative method, HSD also produces wider confident intervals (CI) for the pairwise differences than Fisher's LSD.

All statistical analysis was performed using JMP (JMP, Version 10. SAS Institute Inc.,Cary, NC). All reported intervals are at the $95 \%$ level of confidence.

\section{Manufacture of low fat Cheddar cheese}

Raw milk from the Dairy California Polytechnic University dairy farmwas collected and transported to the Creamery of the same institution for further pasteurization. A sample of the milk was analyzed for fat content by the Babcock method (Standards Methods for the Examination of Dairy Products \# 15.083, 2004). Part of the whole pasteurized milk was skimmed and the fat content was determinate using the same 
protocol. In order to obtain low fat cheese milk, a mass balance using the Pearson Square was performed. Consequently, about 7 parts of skimmed milk was mixed with 1 part of whole milk for each of the three vats LF cheese (A, B \& C). The standardized cheese milk contained $\sim 0.57 \%$. The temperature of the standardized cheese milk for all vats was elevated to $31.1^{\circ} \mathrm{C}$. Cheese milk was acidified to $\mathrm{pH} 6.5$ by circulative $10 \%$ phosphoric acid using a pump. Then sodium citrate (3Na) and disodium EDTA (EDTA) were added to vats $\mathrm{A} \& \mathrm{~B}$ at the rates of $0.02 \%$ and $0.2 \%(\mathrm{w} / \mathrm{w})$ respectively, after which additional phosphoric acid was added such that the final $\mathrm{pH}$ prior renneting was 6.2. Arnatto was also used to provide color to the cheese $(100 \mathrm{ml} / 454 \mathrm{~kg}$ milk). Three types of commercial DVS starter cultures (DSG-hb, LH32, 850) were added $0.0028 \%, 0.0028 \% \& 0.02 \%$ (w/w of milk), respectively. The milk was ripened for 30 min with manual agitation Chymosin rennet (35 ml/1000 kg of milk) was added to the milk, which was held quiescently until a coagulum formed ( $20 \mathrm{~min})$. The coagulum was cut using 5/8 knives and healed for 5 minutes. Then, the temperature was slowly raised to $35.5^{\circ} \mathrm{C}$ in 30 minutes with continuous manual agitation. The whey was drained at $\mathrm{pH} 5.98$. The cheese was immediately hand milled including an extra wash step. The wash water temperature was $\sim 21^{\circ} \mathrm{C}(20 \% \mathrm{w} / \mathrm{w}$ of milk) and held for 10 minutes. Cheese curd was salted in three installments 5 minutes apart $(2.8 \%$ w/w of curd $)$. Curds were placed into a $10 \mathrm{~kg}$ Wilsonstyle stainless steel hoop that was pressed overnight at $276 \mathrm{Kpa}$. Pressed cheese was packed in polyethylene bags and ripened at $8^{\circ} \mathrm{C}$. The flow diagram is shown in Figure 6 . 
Pasteurized standardized milk

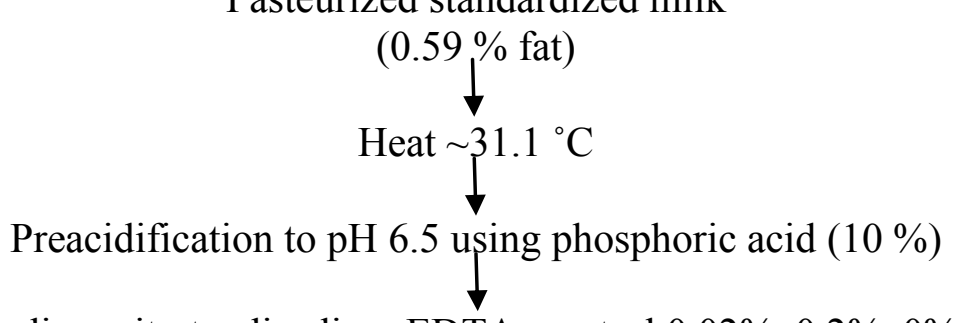

Vat A, B \& C sodium citrate, disodium EDTA, control $0.02 \%, 0.2 \%, 0 \%$ (w/w of milk), respectively

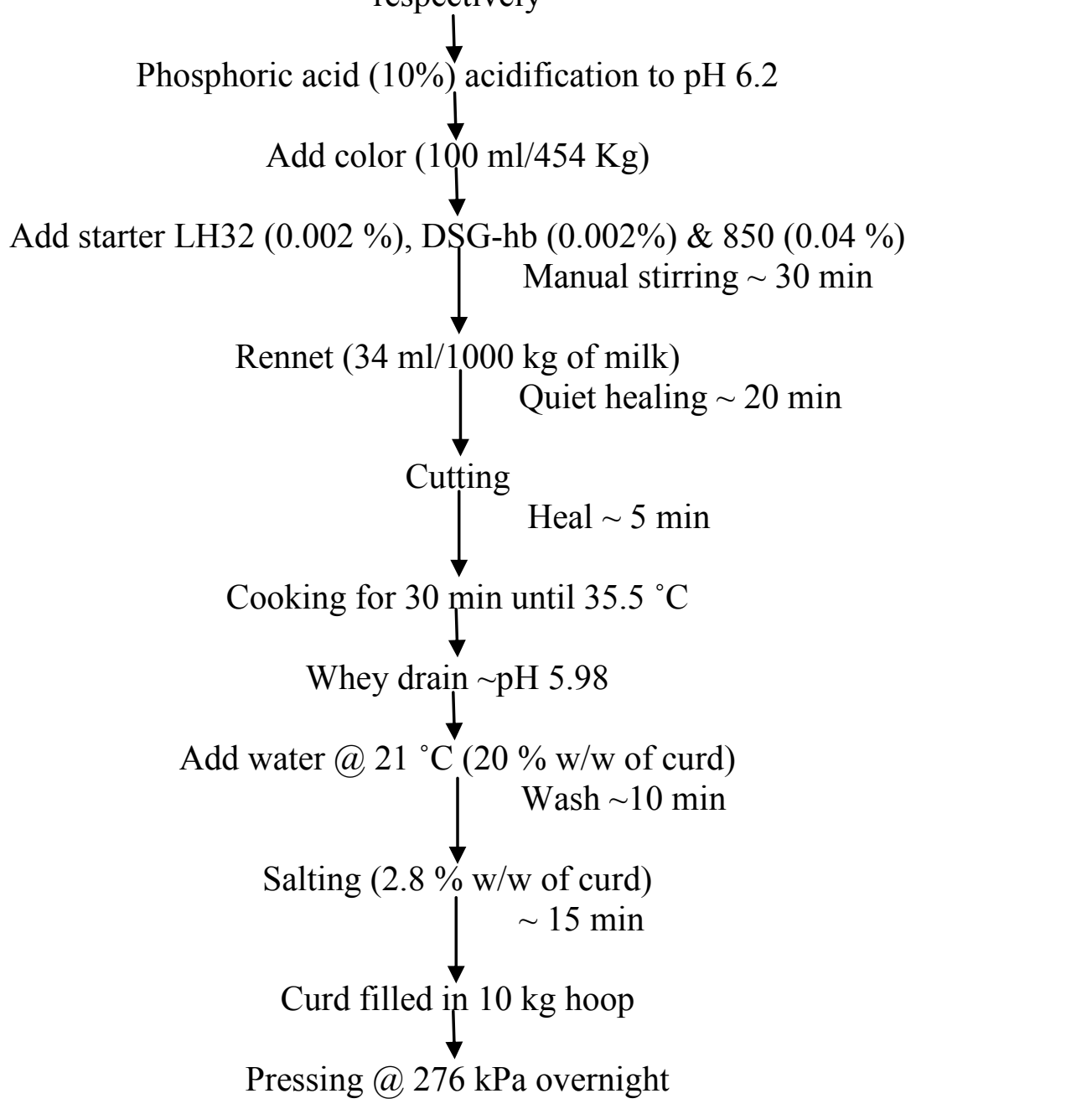

Figure 6. Flow chart for the manufacture of Lowfat Cheddar cheeses. 


\section{Manufacture of full fat Cheddar cheese}

Commercial FFC cheese ( $4.5 \mathrm{~kg}$ ) was acquired from Cal Poly on five different occasions. The FF Cheddar cheese was manufactured using the milled curd method using the same batch of milk employed to manufacture LF cheddar cheeses and has been described below.

Pasteurized cheese milk containing $\sim 4.0 \%$ was tempered at $35.5^{\circ} \mathrm{C}$. Starter bacteria, DVS850, R604 and LH-32 were added at $0.06 \%, 0.06 \%$ and $0.001 \% \mathrm{w} / \mathrm{w}$ of milk, respectively. $\mathrm{CaCl}_{2}$ and color (Arnnatto) were added at $0.06 \%$ and $0.1 \% \mathrm{w} / \mathrm{w}$ of milk, respectively. After 30 minutes of culture addition, chymosin was added $(100 \mathrm{ml} / 1000 \mathrm{~kg}$ milk) and stired for $2 \mathrm{~min}$. Then the agitator and pump were turned off to allow coagulation. The coagulum was cut in $30 \mathrm{~min}$ followed by 5 min healing. Stirring begun and steam went on to start cooking the curd for 30 min until temperature reached $39^{\circ} \mathrm{C}$. Whey was drained at pH 6.1 and the curd was pushed to both sides to let the curds fuse together. Cheddaring process was done over two hours keeping the vat temperature at $39^{\circ} \mathrm{C}$ and turning curd cheese piles every $15 \mathrm{~min}$ until a pH of 5.4 was reached. Cheese was milled and salt was posterior added at $2.5 \% \mathrm{w} / \mathrm{w}$ of curd in three installments 5 minutes apart. Curds were placed into a $20 \mathrm{~kg}$ stainless steel Wilson-style hoop that was pressed overnight at $276 \mathrm{Kpa}$. Pressed cheese was packed in polyethylene bags and ripened at $8^{\circ} \mathrm{C}$. The flow diagram is showed in Figure 7 . 
Pasteurized cheese milk. Vat D

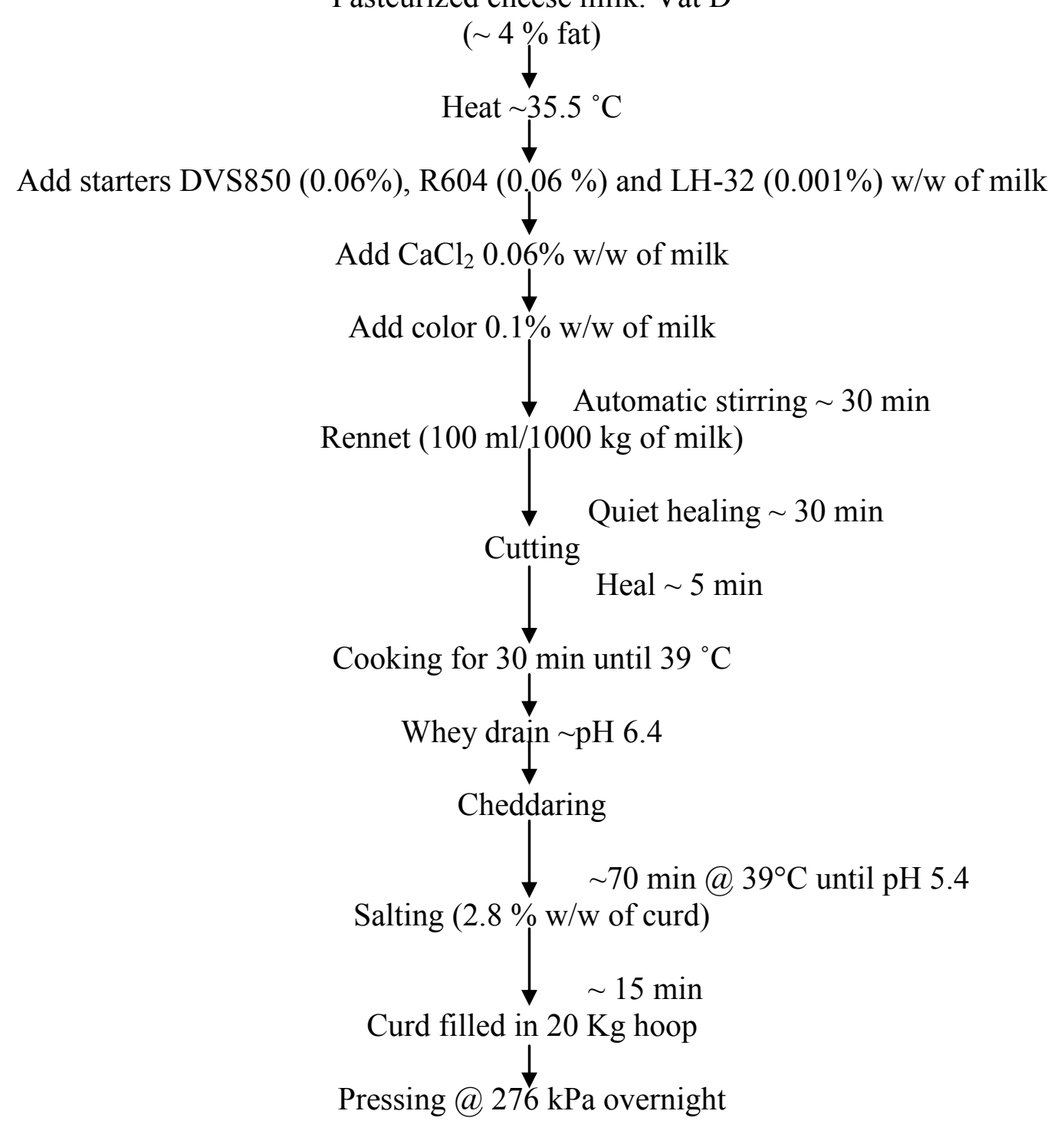

Figure 7. Flow chart of manufacture of FFC using the Milled-curd method. 


\section{Compositional Analysis}

Compositional analysis was performed for the five trials at different time points (Table 8) during 120 days of ripening.

Table 7. Parameters considered over time for all trials.

\begin{tabular}{|c|c|c|c|c|c|}
\hline Parameter & $\begin{array}{l}7 \\
\text { days }\end{array}$ & $\begin{array}{l}30 \\
\text { days }\end{array}$ & $\begin{array}{l}60 \\
\text { days }\end{array}$ & $\begin{array}{l}90 \\
\text { days } \\
\end{array}$ & $\begin{array}{l}120 \\
\text { days } \\
\end{array}$ \\
\hline $\mathrm{pH}$ & & $\mathrm{x}$ & & & \\
\hline Moisture & & $\mathrm{x}$ & & & \\
\hline Total solids & & $\mathrm{x}$ & & & \\
\hline Fat & & $\mathrm{x}$ & & & \\
\hline WSN (Secondary proteolysis) & $\mathrm{x}$ & $\mathrm{x}$ & $\mathrm{x}$ & $\mathrm{x}$ & $\mathrm{X}$ \\
\hline Total protein & $\mathrm{x}$ & & & & \\
\hline Total nitrogen & $\mathrm{x}$ & & & & \\
\hline $\begin{array}{l}\text { Urea-Page Gel (Primary } \\
\text { proteolysis) }\end{array}$ & $\mathrm{x}$ & $\mathrm{x}$ & $\mathrm{x}$ & $\mathrm{x}$ & $\mathrm{x}$ \\
\hline Texture Analysis & $\mathrm{x}$ & $\mathrm{x}$ & $\mathrm{x}$ & $\mathrm{x}$ & $\mathrm{x}$ \\
\hline Insoluble Calcium content & & $\mathrm{x}$ & & & \\
\hline
\end{tabular}

pH measurement.

$\mathrm{pH}$ was measured in duplicate by weighing $10 \mathrm{~g}$ of Cheddar cheese and $10 \mathrm{ml}$ of deionized water into a $100 \mathrm{ml}$ blender. Using medium speed, the mix was blended for $30 \mathrm{~s}$. $\mathrm{pH}$ electrode was measured using Oakton waterproof spear tip double junction $\mathrm{pH}$ electrode (model WD-35634-40, Oakon Instruments, Vernon Hills-IL). Certified buffers

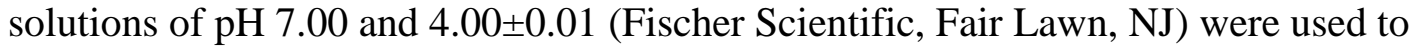
calibrate the electrode. This measurement was carried out in duplicate on the $30^{\text {th }}$ day of ripening. 


\section{Moisture and total solids content.}

Moisture analyses of the cheese samples were performed using CEM microwave oven model Labwave ${ }^{\mathrm{TM}} 9000$ (CEM Corp., Matthews, NC) AOAC \# 926.08 (16 ${ }^{\text {th }}$ ed., vol. 2, 1995) official method was used. A slight modification in the sample weight was done by using $3 \mathrm{~g}$ of hand grated cheese instead of $10 \mathrm{~g}$. The total solids of the sample were calculated and subtracted from 100 to give $\%$ moisture. This measurement was carried out in duplicate on the $30^{\text {th }}$ day of ripening.

\section{Salt Analysis using Chloride Method}

$\mathrm{NaCl}$ content was measured in duplicate by chloride analysis using the Corning 926 Analyzer Salt Analyzer (Corning Medical and Scientific Glass Works). Five grams of cheese were grated and DI water was added to yield a total of $100 \mathrm{~g}$. The water adjustment was determinate by using the next equation:

$$
100-(\text { samplewt. in grams }) *(\% \text { moisture in sample })
$$

The cheese sample and the additional deionized (DI) water was added to a Whirlpak bag and homogenized using a Stomacher ${ }^{\mathrm{TM}}$ for three min. for three minutes. The content of the bag was filtered through a Whatman ${ }^{\mathrm{TM}}$ No. 41 paper. The Chloride Analyzer was adjusted by adding $250 \mathrm{ml}$ of chloride meter standard (200 $\mathrm{mg} / \mathrm{L} \mathrm{Cl}$, Sherwood) to the

combined acid buffer (cat\# 131-3751, Nelson James, Inc.). Calibration reading had to be between 97 and 103 for three repeated times. After calibration, $250 \mathrm{ml}$ of filtrate was added to the combined acid buffer to get a reading. The conversion factor used to obtain 
the percentage of salt in sample was 0.04 multiplied by the $\mathrm{mg} / \mathrm{L}$ registered on the Analyzer.

\section{Fat Content of milk}

Fat concentration in milk was measured using the Mojonnier ether extraction modified official method \# 989.05 - AOAC $16^{\text {th }}$ ed., vol. 2, 1995). This method was the most reliable for milk because the fat content in the samples were expected to be low ( 4.5 to $0.16 \%$ ). This measurement was carried out in duplicate the day previous of the cheese manufacture.

\section{Fat Content in LF cheeses}

Fat concentration in LF Cheddar cheeses was measured using the Mojonnier ether extraction modified official method \# 989.05 (AOAC, $16^{\text {th }}$ ed., vol. 2,1995 ), due to an expected low fat content that could be better reported using this procedure. A slight modification during sample preparation was done. One gram of cheese was introduced into a Mojonnier flask and mixed with $8 \mathrm{ml}$ of water at boiling point instead of room temperature. Samples were shaken and cooled prior to adding $3 \mathrm{ml}$ of ammonium hydroxide. The ammonium reagent was mixed with the sample and Mojonnier flasks where placed into a water bath at $70^{\circ} \mathrm{C}$ for 5 min, rocking by hand every minute. The method was modified due to a poor dilution of the cheese components, mainly caseins. This measurement was carried out in duplicate on the $30^{\text {th }}$ day of ripening and was reported as Fat Dry Matter (FDM). 


\section{Fat content in FFC}

The fat content was determined by the Babcock Method described in Standard Methods for the Examination of Dairy Products \# 15.083 for cheese (Wehr et al., 2004). This measurement was carried out in duplicate on the $30^{\text {th }}$ day of ripening. Fat conternt in cheese was expressed as FDM.

\section{Total Nitrogen Content}

The total $\mathrm{N}$ of all the samples was determined by using $1 \mathrm{~g}$ sample using the Kjeldahl Method \# 920.123 (AOAC, 1995) using a the Tecator ${ }^{\mathrm{TM}} 2020$ Digestor (Perstorp Analytical Company, Höganäs, Sweeden) and a distillation unit Kjeltec ${ }^{\text {TM }} 2200$ (FOSS Instruments Höganäs, Sweeden). Measurements were performed in duplicate for each cheese sample after 30 days of ripening.

\section{Total Protein Analysis.}

Total Protein percent was determinate by multiplying total N (\%) by the conversion factor 6.38 .

$$
\% \text { protein }=\% N^{*} 6.38
$$

\section{Water Soluble Nitrogen (WSN) Analysis.}

Secondary Proteolysis. Water Soluble Nitrogen (WSN) content was determined by weighing $15 \mathrm{~g}$ cheese sample and placed into a Whirlpack bag and $30 \mathrm{ml}$ of DI water was added. Samples were homogenized using a Stomacher ${ }^{\mathrm{TM}}$ for three minutes. The content 
of the bag was filtered through a Whatman ${ }^{\mathrm{TM}}$ No. 41 with a glass wool in the bottom. The filtrate was collected into a $50 \mathrm{ml}$ falcon tube, labeled and storage in the freezer until further nitrogen content analysis by the Kjeldahl method. Kjeldahl procedure used for WSN determination is the same described above for the nitrogen analysis of cheese. For this analysis instead of using $1 \mathrm{~g}$ of cheese as sample, $1 \mathrm{~g} \mathrm{WSN}$ extract was used. The titrant concentration used for this procedure was $0.01 \mathrm{~N} \mathrm{HCl}$ (cat\# SA54-20, Fisher Scientific) instead of $0.1 \mathrm{~N} \mathrm{HCl}$ due to a low nitrogen content of the samples.

\section{Urea-Polyacrylamide Gel Electrophoresis}

Electrophoresis, urea-PAGE, is particularly appropriate for monitoring primary proteolysis. Primary proteolysis was analyzed using urea-PAGE performed on all cheeses in duplicate. The analysis was done at 7, 30, 60, 90 and 120 days of ripening in order to identify the breakdown of caseins.

The preparation described is for two gels. Stacking gel (top part) was done by mixing $5.0 \mathrm{ml}$ of $40 \%$ acrylamide solution (cat\# 161-0148, Bio-Rad), $0.100 \mathrm{~g}$ of N, N' methylene bisacrylamide (cat\# M7256-100G, SigmaAldrich) and $14.0 \mathrm{ml}$ of separating gel buffer in a $50 \mathrm{ml}$ falcon tube. To catalyze polymerization, $10 \mu \mathrm{l}$ of N,N,N',N'tetramethylethylenediamine or TEMED (cat\# 161-800, Bio-Rad) was added with $75.2 \mu 1$ of $10 \%$ (wt./vol.) ammonium persulfate or APS (cat\# A7460-500G, Sigma-Aldrich). 7 ml of the stacking gel was pipetted into glass plates. DI water was pipetted on top of the gel to even the surface. 30 min were allowed for polymerizartion catalysis. The separating gel buffer was prepared by mixing $32.15 \mathrm{~g}$ of Tris (hydroxymethyl) methylamine (cat\# 42457-5000, ACROS), 192.85 g Urea (BP169-212, Fisher Scientific), $2.86 \mathrm{ml}$ of 
concentrated $\mathrm{HCl}$ (cat\# SA49, Fisher Scientific), and $500 \mathrm{ml}$ DI water using a $50 \mathrm{ml}$ falcon tube. $\mathrm{pH}$ was adjusted to 8.9 .

The separating gel (bottom part) was prepared by adding $1.0 \mathrm{ml}$ of $40 \%$ acrylamide solution, $0.020 \mathrm{gr}$ of $\mathrm{N}, \mathrm{N}^{\prime}$ methylene bisacrylamide, and $9.0 \mathrm{ml}$ of stacking gel buffer. The separatin gel buffer was prepared by mixing $4.15 \mathrm{~g}$ of Tris (hydroxymethyl) methylamine, $150 \mathrm{~g}$ of Urea, and $2.2 \mathrm{ml}$ of $\mathrm{HCl}$, dissolving to $500 \mathrm{ml}$ with deionized water and adjusting the $\mathrm{pH}$ to 7.6. Polymerization was catalyzed with $5 \mu$ l of TEMED and $60 \mu \mathrm{l}$ of $10 \%$ (wt./vol.) ammonium persulfate (APS). Water from the surface of the gel was soaked and separating gel was pipetted to the top. $1.5 \mathrm{~mm}$ combs were inserted into gel and sat for 15 min to polymerization.

For the electrode buffer, $3.0 \mathrm{~g}$ Tris(hydroxymethyl)methylamine or Tris Base and 14.6 g glycine (cat\# G8898-1KG, Sigma Aldrich) were dissolved in DI water and made up to1L and adjusted to a $\mathrm{pH} 8.4$.

Gels were placed into gel holder and inserted into mini gel tank, filled with electrode buffer and the combs were removed. The rest of the tank was filled with $\sim 850 \mathrm{ml}$ of electrode buffer. To pre-equilibrate, gels were run at $120 \mathrm{~V}$ for $10 \mathrm{~min}$.

Then, the gels were loaded at equivalent protein level for each sample because were expected to have higher protein content than FFC, $4 \mu 1$ of LF cheese samples were loaded while FFC load was $\sim 4.3 \mu$. The sample was a mixture containing $10 \mathrm{mg}$ cheese and 1 $\mathrm{ml}$ sample buffer. The sample buffer consisted of $0.75 \mathrm{~g}$ Tris (hydroxymethyl) methylamine, $49 \mathrm{~g}$ Urea, $0.4 \mathrm{ml}$ of concentrated $\mathrm{HCl}, 0.7 \mathrm{ml} \beta$-mercaptoethanol (cat\# BP176-100, Fisher Scientific), $0.15 \mathrm{~g}$ of Bromophenol Blue (cat\# BP115-25, Fisher Scientific) dissolved to $100 \mathrm{ml}$ with deionized water. 
The gels were run at $150 \mathrm{~V}$ until Bromophenol blue tracking dye was seen at the bottom of the slab, which took between 90 and 120 min.

Gel stain solution was prepared by mixing $250 \mathrm{ml}$ of ( $0.2 \%$ wt./vol $)$ Coomassie Brilliant G250 (cat\# BP100-25, Fisher Scientific) and $250 \mathrm{ml}$ of $1 \mathrm{M} \mathrm{H}_{2} \mathrm{SO}^{4} .1 \mathrm{M} \mathrm{H}^{2} \mathrm{SO}^{4}$ was prepared by mixing $13.9 \mathrm{ml}$ concentrated $\mathrm{H}_{2} \mathrm{SO}_{4}$ (cat\# A300SI-212, Fisher Scientific) with $236.1 \mathrm{ml}$ of DI water. Coomassie and $1 \mathrm{M} \mathrm{H}_{2} \mathrm{SO}_{4}$ where combined and held overnight. Next day the mixture was filtered through Whatman ${ }^{\mathrm{TM}}$ No. 541 paper. Then $55.5 \mathrm{ml}$ of $10 \mathrm{M} \mathrm{KOH}$ prepared by mixing $31.14 \mathrm{~g} \mathrm{KOH}$ pellets (cat\# P250-500, Fisher Scientific) to $24.4 \mathrm{ml}$ of DI water and added to the filtrate. $66.66 \mathrm{~g}$ trichloroacetic acid powder (cat\# A322-500, Fisher Scientific) was added into the previous solution. Gels were stained overnight. The Gel-Doc (Bio-Rad) and Quantity One® software v.4.6.3 (Bio-Rad) were used to capture gel images.

\section{Texture Analysis for Cheese Samples}

Cheese texture is a sensorial characteristic ultimately expressed in sensory descriptors defined by a trained texture panels Table 9 . However, to establish and maintain a trained panel could be very costly and time consuming. For this reason, instrumentals methods based on force-compression have been designed to simulate compression of cheese between molars during chewing (Fox et al., 2000).

Test Model used for cheese texture examination was the Texture Profile Analysis (TPA). This method measure specific attributes for solid and semi-solid products such as hardness, cohesiveness, adhesiveness, springiness, gumminess, and chewiness. Figure 9 
is a typical cheese TPA graph which includes the areas of compression and lengths in order to calculate the 5 principal texture parameters in cheese (Chen et al., 1979).

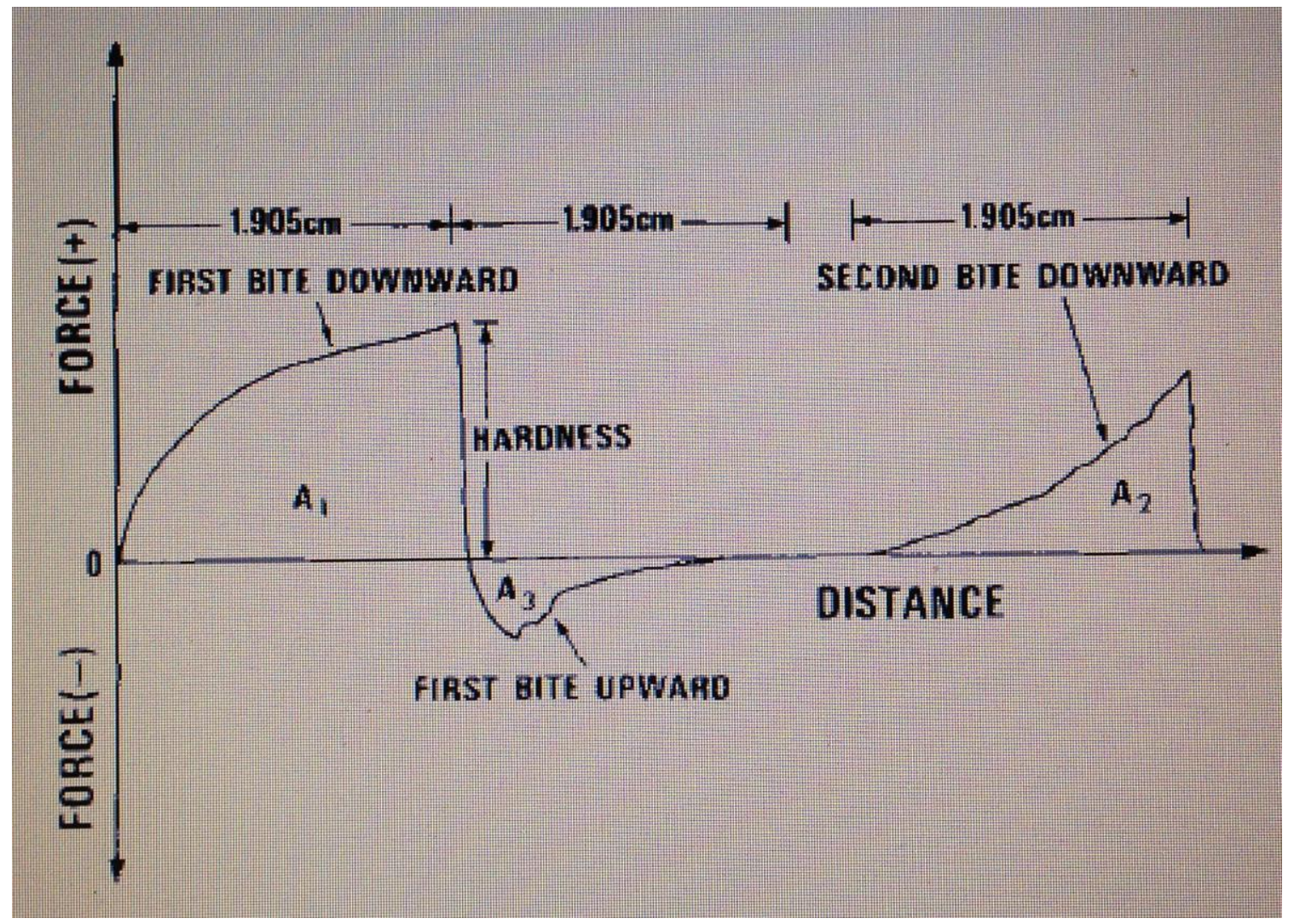

Figure 8. Typical TPA cheese behavior.

Table 9 provides the definition of Texture Parameters that are the most used to analyze semisolid products like cheese. TPA have been extensively used in literature (Bourne, 1978, Chen et al., 1979, Bryant et al., 1995, Pons and Fiszman, 1996, Szczesniak, 2002). 
Table 8. Definition of Texture Parameters. (Bourne, 1978).

\section{Texture Terminology}

\begin{tabular}{l|l}
\hline \hline Hardness & $\begin{array}{l}\text { The hardness value is the peak force of the first compression of the } \\
\text { product. Typically is the deepest compression for most products and is } \\
\text { known as "first bite" } \\
\text { Cohesiveness is how well the product withstands a second deformation }\end{array}$ \\
Cohesiveness & $\begin{array}{l}\text { relative to how it behaved under the first deformation. Cohesiveness is the } \\
\text { extent to which a material can be deformed before it ruptures. } \\
\text { Cohesiveness = Area } 2 / \text { Area } 1\end{array}$ \\
Springiness & $\begin{array}{l}\text { Springiness is how well a product physically springs back after it has been } \\
\text { deformed during the first compression. Springiness = Length } 2 / \text { Length } 1\end{array}$ \\
Chewiness & $\begin{array}{l}\text { Chewiness only applies for solid products and is the energy required to } \\
\text { masticate a product to a state ready for swallowing. Chewiness }= \\
\text { Gumminess * Cohesiveness } \\
\text { Gumminess only applies to semi-solid products and is the energy required } \\
\text { to disintegrate a semi-solid product to a state ready for swallowing. } \\
\text { Gumminess = Hardness/Cohesiveness }\end{array}$ \\
\hline Gumminess
\end{tabular}

TA-XT2 ${ }^{\circledR}$ Texture Analyzer (Texture Technology Corp., Scarsdale, NY) was used to analyze texture parameters on all cheese samples at 7, 30, 60, 90 and 120 days of ripening. Expert Version 1.22 software (Stable Micro Systems, Scarsdale, NY) was utilized for this purpose.

Eight cheese cubes per samples were prepared by cutting $20 \mathrm{~mm}$ cubes; only cheese inside of the block was analyzed. Cheese samples were placed in weight boats, wrapped with foil, labeled and placed in the refrigerator for $3 \mathrm{~h}$. Each weightboat was taken out of the refrigerator, the foil was removed and samples were sitting at room temperature for 30 min. 15 min gap was given between weightboats taking out of the refrigerator. Texture Analyzer Settings are described in Table 10. 
Table 9. Texture Analysis Settings. Specific settings selected for TPA with the TA-XT2 Texture Analyzer.

\begin{tabular}{ll}
\hline \multicolumn{1}{c}{ Parameter } & \multicolumn{1}{c}{ Selected Settings } \\
\hline Test Mode & T.P.A \\
Pre Test Speed & $1.2 \mathrm{~mm} / \mathrm{s}$ \\
Post Test speed & $1.2 \mathrm{~mm} / \mathrm{s}$ \\
Distance & $10 \mathrm{~mm}$ \\
Compression & $50 \%$ \\
Time & $5 \mathrm{~s}$ \\
Force & $5 \mathrm{~g}$ \\
Probe & $40 \mathrm{~mm}$ \\
\hline
\end{tabular}

\section{Calcium Determination}

Calcium was determined by an atomic absorption spectroscopy. Ash content of cheese samples were determined by official method \# 935.42 (AOAC, 1995). One gram cheese was weighed into a crucible and dried for an hour at $100^{\circ} \mathrm{C}$ and immediately placed in a Isotemp Programmable Forced-Draft Furnace at $525^{\circ} \mathrm{C}$ for at least $16 \mathrm{~h}$. Samples were cooled down in a desiccator. Once the samples were cool, the ash was dissolved in $1.0 \mathrm{ml}$ of $\mathrm{HNO}_{3}$ and a small amount of DI water was added. The solution was transferred to a $250 \mathrm{ml}$ volumetric flask and filled with DI water to the mark on the flask. $10 \mathrm{ml}$ of diluted sample was pipetted into a $100 \mathrm{ml}$ volumetric flask and $10 \mathrm{ml}$ of $1 \%$ lanthanum oxide were added and topped with DI water to the mark. $45 \mathrm{ml}$ of the solution was saved into a $50 \mathrm{ml}$ falcon tube labeled and ready to analyze at the Soil Sciences department at California Polytechnic University- San Luis Obispo. The absorption spectrophotometer model Spectr ${ }^{\mathrm{TM}} \mathrm{AA} 55 \mathrm{~B}$ (Varian Analytical Instruments, 
Palo Alto, CA). The atomic absorption standard curve and sample were prepared according to the AOAC Official Method \# 991.25 (AOAC, 1995).

$1 \%$ lanthanum oxide was preparing by measuring $11.73 \mathrm{~g}$ of $\mathrm{La}_{2} \mathrm{O}_{3}$ in $25 \mathrm{ml} \mathrm{HNO}_{3}$ diluted into $1 \mathrm{~L}$ of DI water.

To convert the concentration of calcium $\mathrm{Ca}^{2+}$ in the cheese (ppm) to $\mathrm{mg}$ per portion we used the following equation:

$$
\frac{p p m}{4}=\frac{\% C a}{100} \times \frac{28 g}{\text { portion }} \times \frac{1000 m g}{g}=\frac{m g}{\text { portion }}
$$




\section{RESULTS AND DISCUSSION}

\section{Milk Composition}

Milk was collected in 5 different occasions for LF Cheddar cheeses and FFC manufacture. Milk for LF cheeses were separated in 3 vats A, B, C (3Na, EDTA and LFC, respectively), was standardized (refer to standardization) with a fat content $\sim 0.59 \%$ obtained by blending skimmilk standarized and whole milk. There was no evidence (Tukey adjusted $\mathrm{P}>0.05$ ) that fat content of mix milk for LFC differed between the 5 trials. Whole milk used for FFC was not standardized but the $\%$ fat $\sim 4.0$ between trials did not showed significant differences in the means according to Tukey LSD ( $\mathrm{P}>0.05)$. A summary of fat contents of whole milk and standarized milks used for FFC and LF cheeses is shown in Table 11.

Table 10. Means ${ }^{1}$ Difference Tukey LSD for cheesemaking milk.

\begin{tabular}{c|cc}
\hline \hline \multicolumn{3}{c}{ Type of milk } \\
\hline \hline Trial & \% fat mix milk & \% fat whole milk \\
7 & $0.6 \mathrm{a}$ & $4.17 \mathrm{a}$ \\
5 & $0.59 \mathrm{a}$ & $4.10 \mathrm{a}$ \\
4 & $0.59 \mathrm{a}$ & $4.07 \mathrm{a}$ \\
6 & $0.58 \mathrm{a}$ & $3.99 \mathrm{a}$ \\
Means within the same column with different superscripts differ significantly $(\mathrm{P}<0.05)$ \\
${ }^{1}$ Mean of duplicate determination of five cheesemaking trials.
\end{tabular}

Since the only source of fat is located in the cream portion of the milk, during the manufacture of LF Cheddar cheese variants milk was standardized using a mixture of skim and full fat milk to a $0.59 \%$ fat content. 


\section{Cheese Composition}

The composition of the cheeses was analyzed to identify changes in the batches.

1. $p H$

Table 11. Means ${ }^{1}$ Difference Tukey LSD pH.

\begin{tabular}{ccclcc}
\hline \hline Treatment & Mean & Std Dev & Std error & F & P \\
\hline \hline 3NA & $4.62^{\mathrm{b}}$ & 0.2448 & 0.1095 & & \\
EDTA & $4.568^{\mathrm{b}}$ & 0.2039 & 0.0912 & 9.1306 & 0.002 \\
FFC & $4.876^{\mathrm{a}}$ & 0.2023 & 0.0905 & & \\
LFC & $4.662^{\mathrm{b}}$ & 0.2145 & 0.0959 & & \\
\hline
\end{tabular}

Means within the same column with different superscripts differ significantly $(\mathrm{P}<0.05)$

${ }^{1}$ Mean of duplicate determination of five cheesemaking trials.

3NA = Lowfat Cheddar disodium citrate

EDTA = Lowfat Cheddar disodium EDTA

$\mathrm{FFC}=$ Full fat Cheddar control

LFC $=$ Lowfat Cheddar control

Table 12 summarizes the $\mathrm{pH}$ values obtained during the five trials, measured at day 7 and shows a significant evidence $(\mathrm{P}=0.002)$ among treatments between $\mathrm{FFC}$ and all $\mathrm{LF}$ cheeses. These results show no evidence that the addition of chelating agents effect the $\mathrm{pH}$ of the LF cheeses. Figure 13 shows the least square means plot of the LF Cheddar cheeses and FFC. Differences on the cheese making procedure reducing $\mathrm{pH}$ with $10 \%$ phosphoric acid and the addition of chelating agents resulted in a variation of the final $\mathrm{pH}$ between all LF Cheddar cheeses and FFC. 
2. Total Solids (TS)

Table 12. Means ${ }^{1}$ Difference Tukey LSD. Total Solids (TS)

\begin{tabular}{cccccc}
\hline \hline Treatment & Mean & Std Dev & Std error & F & P \\
\hline \hline 3NA & $46.04^{\text {bc }}$ & 1.8128 & 0.8107 & & \\
EDTA & $44.178^{\mathrm{c}}$ & 1.0205 & 0.4564 & 186.75 & $<0.0001$ \\
FFC & $63.786^{\mathrm{a}}$ & 1.4409 & 0.6444 & & \\
LFC & $48.05^{\mathrm{b}}$ & 0.8911 & 0.3985 & & \\
\hline
\end{tabular}

Means within the same column with different superscripts differ significantly $(\mathrm{P}<0.05)$

${ }^{1}$ Mean of duplicate determination of five cheesemaking trials.

3NA = Lowfat Cheddar disodium citrate

EDTA $=$ Lowfat Cheddar disodium EDTA

$\mathrm{FFC}=$ Full fat Cheddar control

LFC $=$ Lowfat Cheddar control

$\%$ TS among samples show a significant difference $(\mathrm{P}=0.0001)$ between FFC and all

LF Cheddar cheeses. The reduction in fat content resulted in increased moisture content in the LF cheeses versions. Of the LF varieties, $3 \mathrm{Na}$ and LFC show had a significantly higher $(\mathrm{P}>0.05)$ moisture than EDTA.

\section{Moisture}

An increase of moisture between FFC and the LF Cheddar cheeses are evident showing a significant difference $(\mathrm{P}>0.05)$. Increase of moisture in the LF Cheddar cheese samples are due to some procedure modifications having the FFC milling manufacture as control.

1) Removal on fat content of the cheesemilk from 4 to $0.6 \%$.

2) Reduction of the temperature during the heating from $35.5^{\circ} \mathrm{C}$ on $\mathrm{FFC}$ to $31.1^{\circ} \mathrm{C}$ of LF Cheddar cheese. 
3) Reduction of the cooking temperature from $39.5^{\circ} \mathrm{C}$ for $\mathrm{FFC}$ to $31.1^{\circ} \mathrm{C}$ for $\mathrm{LF}$ Cheddar cheese.

4) Addition of a washing step for LF Cheddar cheeses.

The removal of fat from the cheese matrix has resulted in research to find methods to replace the low content of fat for moisture. In order to aid moisture absorption, measures listed above were taken in this regard. It has been proven that higher cooking temperature produced cheese with at lower moisture and decreased proteolysis during 50 days of storage at $4{ }^{\circ} \mathrm{C}$ (Yun et al., 1993). Studies highlighted the important processing parameters for manufacturing LF cheddar cheeses which includes low temperature cooking and high $\mathrm{pH}$ at drain and milling (Mistry, 2001).

A wash step before hopping and pressing the curds was done using water at $21^{\circ} \mathrm{C}(20$ $\% \mathrm{w} / \mathrm{w}$ of curd) for 10 minutes to help moisture increase.

In addition, a significant difference $(\mathrm{P}>0.05)$ between LFC and EDTA was detected.

Table 13. Means ${ }^{1}$ Difference Tukey LSD. Moisture, $\%$

\begin{tabular}{cccccc}
\hline \hline Treatment & Mean & Std Dev & Std error & F & P \\
\hline \hline 3NA & $53.96^{\text {ab }}$ & 1.8128 & 0.8107 & & \\
EDTA & $55.822^{\mathrm{a}}$ & 1.0205 & 0.4564 & 186.74 & $<0.0001$ \\
FFC & $36.214^{\mathrm{c}}$ & 1.4409 & 0.6444 & & \\
LFC & $51.95^{\mathrm{b}}$ & 0.8911 & 0.3985 & & \\
\hline
\end{tabular}

Means within the same column with different superscripts differ significantly $(\mathrm{P}<0.05)$

${ }^{1}$ Mean of duplicate determination of five cheesemaking trials.

3NA = Lowfat Cheddar disodium citrate

EDTA $=$ Lowfat Cheddar disodium EDTA

$\mathrm{FFC}=$ Full fat Cheddar control

LFC $=$ Lowfat Cheddar control 


\section{Salt}

Significant differences $(\mathrm{P}=0.0154)$ between FFC and LF Cheddar cheese variants were detected. No significant differences $(\mathrm{P}<0.05)$ among LF sample.

Table 14. Means1 Difference Tukey LSD. Salt, \%

\begin{tabular}{cccccc}
\hline \hline Treatment & Mean & Std Dev & Std error & F & P \\
\hline \hline 3NA & $1.964^{\mathrm{b}}$ & 0.0089 & 0.004 & & \\
EDTA & $1.986^{\mathrm{ab}}$ & 0.0134 & 0.006 & 5.2308 & 0.0154 \\
FFC & $2.012^{\mathrm{a}}$ & 0.0415 & 0.0185 & & \\
LFC & $1.966^{\mathrm{b}}$ & 0.0134 & 0.006 & & \\
\hline
\end{tabular}

Means within the same column with different superscripts differ significantly $(\mathrm{P}<0.05)$

${ }^{1}$ Mean of duplicate determination of five cheesemaking trials.

3NA $=$ Lowfat Cheddar disodium citrate

EDTA $=$ Lowfat Cheddar disodium EDTA

FFC $=$ Full fat Cheddar control

LFC $=$ Lowfat Cheddar control

\section{Fat}

A natural first grade full fat Cheddar cheese should contain \% FDM 52-56 (Fox et al., 2004a). Standards of identity define Cheddar cheese as containing not more than $39 \%$ moisture and not more than 50\% of FDM (Kosikowski and Mistry, 1997). For LF cheddar cheeses, the standard of identity requires a fat content of no more than $6 \%$. As expected, the $\%$ fat and \% FDM contents between LF cheeses and FFC were significantly different $(\mathrm{P}=0.0001)$ (Table $16 \& 17)$. 
Table 15. Means ${ }^{1}$ Difference Tukey LSD. Fat content, $\%$

\begin{tabular}{cccccc}
\hline \hline Treatment & Mean & Std Dev & Std error & F & P \\
\hline \hline 3NA & $5.968^{\mathrm{b}}$ & 0.0277 & 0.0124 & & \\
EDTA & $5.85^{\mathrm{b}}$ & 0.142 & 0.0635 & 12580 & $<0.0001$ \\
FFC & $32.68^{\mathrm{a}}$ & 0.497 & 0.2223 & & \\
LFC & $5.908^{\mathrm{b}}$ & 0.0709 & 0.0317 & & \\
\hline
\end{tabular}

Means within the same column with different superscripts differ significantly $(\mathrm{P}<0.05)$

${ }^{1}$ Mean of duplicate determination of five cheesemaking trials.

3NA = Lowfat Cheddar disodium citrate

EDTA $=$ Lowfat Cheddar disodium EDTA

$\mathrm{FFC}=$ Full fat Cheddar control

LFC $=$ Lowfat Cheddar control

Table 16. Fat in Dry Matter, $\%$

\begin{tabular}{cccccc}
\hline \hline Treatment & \%Fat & \%Moisture & \%TS & \%FDM & P \\
\hline \hline 3NA & 5.97 & 53.96 & 46.04 & $13^{\mathrm{b}}$ & \\
EDTA & 5.85 & 55.82 & 44.18 & $13^{\mathrm{b}}$ & $<0.0001$ \\
FFC & 32.68 & 36.21 & 63.79 & $51.23^{\mathrm{a}}$ & \\
LFC & 6.0 & 51.95 & 48.05 & $12.5^{\mathrm{b}}$ & \\
\hline
\end{tabular}

Means within the same column with different superscripts differ significantly $(\mathrm{P}<0.05)$

${ }^{1}$ Mean of duplicate determination of five cheesemaking trials.

\section{6. $\mathrm{Ca}^{2+}$}

Table 18 shows the calcium concentrations in the four cheeses. FFC is significantly different $(\mathrm{P}<0.05)$ than the $3 \mathrm{Na}$ and EDTA LF cheeses. Therefore, these two LF Cheddar cheeses are expected to have a softer texture because $\mathrm{Ca}^{+2}$ concentrations have decreased, and so, protein interaction happens to a lesser degree. On the other hand $3 \mathrm{Na}$ and EDTA cheeses have similar calcium concentration with the LFC. Thus, these three samples are expected to have similar textures. These results have a correlation with the preacidification using 10\% phosphoric acid step during LF Cheddar cheese making. Examination of preacidification during mozzarella show similar results. At any level of preacidification, the calcium content was reduced. Furthermor, preacidification increased calcium, increased protein, and reduced fat recovery (Metzger et al., 2000). 
Table 17. Means1 Difference Tukey LSD. Calcium, mg/L

\begin{tabular}{cccccc}
\hline \hline Treatment & Mean & Std Dev & Std error & F & P \\
\hline \hline 3NA & $1.91^{\mathrm{b}}$ & 0.4004 & 0.1791 & 9.35 & $<.0018$ \\
EDTA & $2.01^{\mathrm{b}}$ & 0.2897 & 0.1296 & & \\
FFC & $2.924^{\mathrm{a}}$ & 0.3891 & 0.174 & & \\
LFC & $2.494^{\mathrm{ab}}$ & 0.1203 & 0.0538 & & \\
\hline
\end{tabular}

Means within the same column with different superscripts differ significantly $(\mathrm{P}<0.05)$

${ }^{1}$ Mean of duplicate determination of five cheesemaking trials.

3NA $=$ Lowfat Cheddar disodium citrate

EDTA $=$ Lowfat Cheddar disodium EDTA

FFC $=$ Full fat Cheddar control

LFC $=$ Lowfat Cheddar control

\section{Total Nitrogen}

Total nitrogen content in the FFC cheese was significantly different $(\mathrm{P}<0.05)$ than the other LF versions mainly due to the inclusion of fat in cheesemaking, indicating a lower protein concentration (Table 19). Among the LF Cheddar cheeses, the EDTA cheese had significantly lower $(\mathrm{P}=0.0001)$ nitrogen which may be due to more dissociation of caseins and subsequent losses in the whey.

Table 18. Means ${ }^{1}$ Difference Tukey LSD. Nitrogen, $\%$

\begin{tabular}{cccccc}
\hline \hline Treatment & Mean & Std Dev & Std error & F & P \\
\hline \hline 3NA & $5.852^{\mathrm{a}}$ & 0.2972 & 0.1329 & 312.86 & $<.0001$ \\
EDTA & $5.578^{\mathrm{b}}$ & 0.2175 & 0.0973 & & \\
FFC & $4.258^{\mathrm{c}}$ & 0.307 & 0.1373 & & \\
LFC & $5.872^{\mathrm{a}}$ & 0.3227 & 0.1443 & & \\
\hline
\end{tabular}

Means within the same column with different superscripts differ significantly $(\mathrm{P}<0.05)$

${ }^{1}$ Mean of duplicate determination of five cheesemaking trials.

3NA = Lowfat Cheddar disodium citrate

EDTA $=$ Lowfat Cheddar disodium EDTA

$\mathrm{FFC}=$ Full fat Cheddar control

LFC $=$ Lowfat Cheddar control 
Table 19. Means ${ }^{1}$ Difference Tukey LSD. Total Protein, $\%$

\begin{tabular}{ccclcc|}
\hline \hline Treatment & Mean & Std Dev & Std error & F & P \\
\hline \hline 3NA & $37.340^{\mathrm{a}}$ & 1.9001 & 0.8497 & & $<.0001$ \\
EDTA & $35.584^{\mathrm{b}}$ & 1.3958 & 0.6242 & & \\
FFC & $27.182^{\mathrm{c}}$ & 1.9471 & 0.8708 & & \\
LFC & $37.466^{\mathrm{a}}$ & 2.0677 & 0.9247 & & \\
\hline
\end{tabular}

Means within the same column with different superscripts differ significantly $(\mathrm{P}<0.05)$

${ }^{1}$ Mean of duplicate determination of five cheesemaking trials.

3NA $=$ Lowfat Cheddar disodium citrate

EDTA $=$ Lowfat Cheddar disodium EDTA

$\mathrm{FFC}=$ Full fat Cheddar control

LFC $=$ Lowfat Cheddar control

\section{Cheese Texture}

The texture of a cheese is determined primarily by its $\mathrm{pH}$ and the ratio of intact casein to moisture (Lawrence et al., 1987).

\section{Hardness}

If the total calcium content of cheese is reduced, then the amount of cross-linking between casein polymers is reduced and the cheese becomes softer (Metzger et al., 2000). Calcium plays an integral role in cheese texture by cross-linking proteins. As a result, the amount of calcium in cheese has an effect on texture (Metzger et al., 2000). Literature review correlates with the results. Even though calcium was captured by chelating agents as hypothesized, full fat Cheddar cheese remained as the softer after 120 days of ripening. 
Table 20. TPA Hardness. Wilks' Lambda Test.

\begin{tabular}{ccccc}
\hline \hline Hardness & F & df1 & df2 & P \\
\hline \hline Equality & 2.54 & 15 & 22.5 & 0.0223 \\
Parallel & 1.35 & 12 & 24 & 0.26 \\
Overall level & 12.38 & 3 & 12 & 0.0006 \\
\hline
\end{tabular}

Wilks' Lambda Test (Table 21) and the profiles (Figure 9) show that the mean TPA hardness profiles over time are significantly different $(\mathrm{P}=0.0223)$. While there is no evidence that the relative changes in TPA hardness over the ripening are different (i.e., the hardness temporal profiles appear parallel $)(P=0.26)$, they do exhibit significant differences of mean overall TPA hardness $(\mathrm{P}=0.0006)$. Figure 9 shows the changes on hardness of the four treatments during ripening. We can clearly see that overall FFC was the softer variant. EDTA and $3 \mathrm{Na}$ follow a very similar pattern during ripening and LFC remained harder compared to any other treatment.

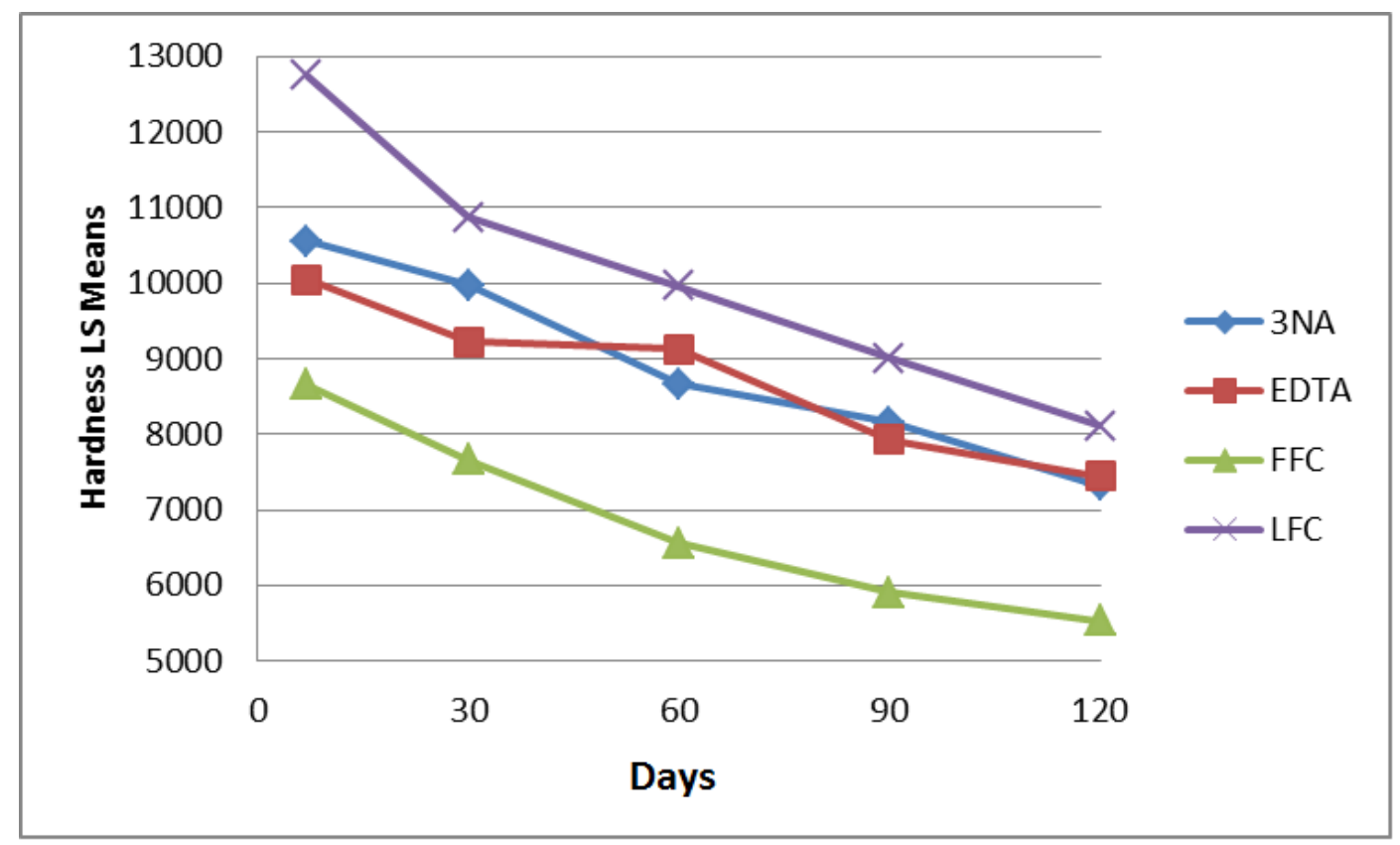

Figure 9. TPA Hardness. Least square means of Lowfat and FFC cheeses during 120 days of ripening. 
However as Table 22 shows, TPA hardness by day 7 between FFC, EDTA and 3Na does not show significant differences $(\mathrm{P}>0.05)$. Results of day 7 , cheeses show that the texture between the FFC and the 3Na and EDTA were similar while LFC had the highest TPA hardness due to lack of chelating agents in the formulation.

After $30 \mathrm{~d}$ ripen significant differences were detected between the TPA hardness of FFC, LFC and $3 \mathrm{Na}(\mathrm{P}=0.0025)$. There was no significant differences in TPA hardness between FFC and LF cheese made with EDTA $(\mathrm{P}>0.05)$.

After 60, 90 and 120 day ripened, significant differences $(P=0.0003,0.00034,0.001$ respectively) were recorded between all the LF Cheddar cheeses and FFC. The FFC had lower mean TPA hardness than all the LF cheeses.

Although no significant differences were detected after 30 days of ripening, Fig 9 shows a decrease on the TPA harness for all cheeses over ripening due to the breakdown of proteins.

An increase in hardness can be due to a more compact protein matrix. Although moisture content was increased in LF Cheddar cheeses it did not soften the cheese after 30 days. Similar results were obtained during texture examination of Cheddar cheeses with different fat content (Bryant et al., 1995). 
Table 21. TPA Hardness. Tukey LSD Means ${ }^{1}$ for all treatments during ripening.

\begin{tabular}{|c|c|c|c|c|c|c|}
\hline Parameter by day & Treatment & Mean & Std Dev & Std error & $F(3,12)$ & $\mathbf{P}$ \\
\hline \multirow{4}{*}{7 Hardness (g) } & $3 \mathrm{NA}$ & $10554^{\mathrm{ab}}$ & 1216.6 & 544.07 & \multirow{4}{*}{7.48} & \multirow{4}{*}{0.0044} \\
\hline & EDTA & $10047^{b}$ & 1668.1 & 746 & & \\
\hline & FFC & $8657.7^{\mathrm{b}}$ & 1069.4 & 478.27 & & \\
\hline & LFC & $12748^{\mathrm{a}}$ & 2102.3 & 940.18 & & \\
\hline \multirow{4}{*}{30 Hardness (g) } & $3 \mathrm{NA}$ & $9970^{\mathrm{a}}$ & 1779.1 & 795.64 & \multirow{4}{*}{8.644} & \multirow{4}{*}{0.0025} \\
\hline & EDTA & $9216.9^{\mathrm{ab}}$ & 2036.4 & 910.69 & & \\
\hline & FFC & $7656.3^{\mathrm{b}}$ & 725.27 & 324.35 & & \\
\hline & LFC & $10863^{\mathrm{a}}$ & 1718.5 & 768.55 & & \\
\hline \multirow{4}{*}{60 Hardness (g) } & $3 \mathrm{NA}$ & $8664.7^{\mathrm{a}}$ & 1490.5 & 666.57 & \multirow{4}{*}{13.7726} & \multirow{4}{*}{0.0003} \\
\hline & EDTA & $9121.4^{\mathrm{a}}$ & 1248.8 & 558.5 & & \\
\hline & FFC & $6562.8^{\mathrm{b}}$ & 534.15 & 238.88 & & \\
\hline & LFC & $9965.2^{\mathrm{a}}$ & 964.96 & 431.54 & & \\
\hline \multirow{4}{*}{90 Hardness (g) } & $3 \mathrm{NA}$ & $8158.9^{\mathrm{a}}$ & 898.58 & 401.86 & \multirow{4}{*}{7.9882} & \multirow{4}{*}{0.0034} \\
\hline & EDTA & $7925.5^{\mathrm{a}}$ & 1470.9 & 657.82 & & \\
\hline & $\mathrm{FFC}$ & $5899.1^{\mathrm{b}}$ & 659.49 & 294.93 & & \\
\hline & LFC & $9003.1^{\mathrm{a}}$ & 1561.5 & 698.35 & & \\
\hline \multirow{4}{*}{120 Hardness (g) } & $3 \mathrm{NA}$ & $7317.7^{\mathrm{a}}$ & 737.06 & 329.63 & \multirow{4}{*}{10.8499} & \multirow{4}{*}{0.001} \\
\hline & EDTA & $7445.2^{\mathrm{a}}$ & 576.2 & 257.68 & & \\
\hline & FFC & $5527.7^{\mathrm{b}}$ & 544.24 & 243.39 & & \\
\hline & LFC & $8111.5^{\mathrm{a}}$ & 1185.9 & 530.34 & & \\
\hline
\end{tabular}

Means within the same column with different superscripts differ significantly $(\mathrm{P}<0.05)$

${ }^{1}$ Mean of duplicate determination of five cheesemaking trials.

3NA $=$ Lowfat Cheddar disodium citrate

EDTA $=$ Lowfat Cheddar disodium EDTA

$\mathrm{FFC}=$ Full fat Cheddar control

LFC $=$ Lowfat Cheddar control

\section{Cohesiveness}

Wilks' Lambda Test (Table 23) and the profiles (Figure 10) show that the mean TPA cohesiveness profiles over time are not significantly different $(\mathrm{P}=0.0642)$. While there is no evidence that the relative changes in TPA cohesiveness over the ripening are 
different (i.e., the cohesiveness temporal profiles appear parallel) $(\mathrm{P}=0.4)$, they do not exhibit significant differences of mean overall TPA cohesiveness $(\mathrm{P}=0.0673)$.

Since the MANOVA results did not show any statistically significant differences, subsequent univariate ANOVAs are not needed or recommended. However, for consistency the results are displayed below (Table 24).

Table 22. TPA Cohesiveness. Wilks' Lambda Test.

\begin{tabular}{ccccc}
\hline \hline Cohesiveness & F & Df1 & df2 & P \\
\hline \hline Equality & 1.67 & 35 & 36.1 & 0.0642 \\
Parallel & 1.125 & 12 & 24 & 0.4 \\
Overall level & 3.1 & 3 & 12 & 0.0673 \\
\hline
\end{tabular}

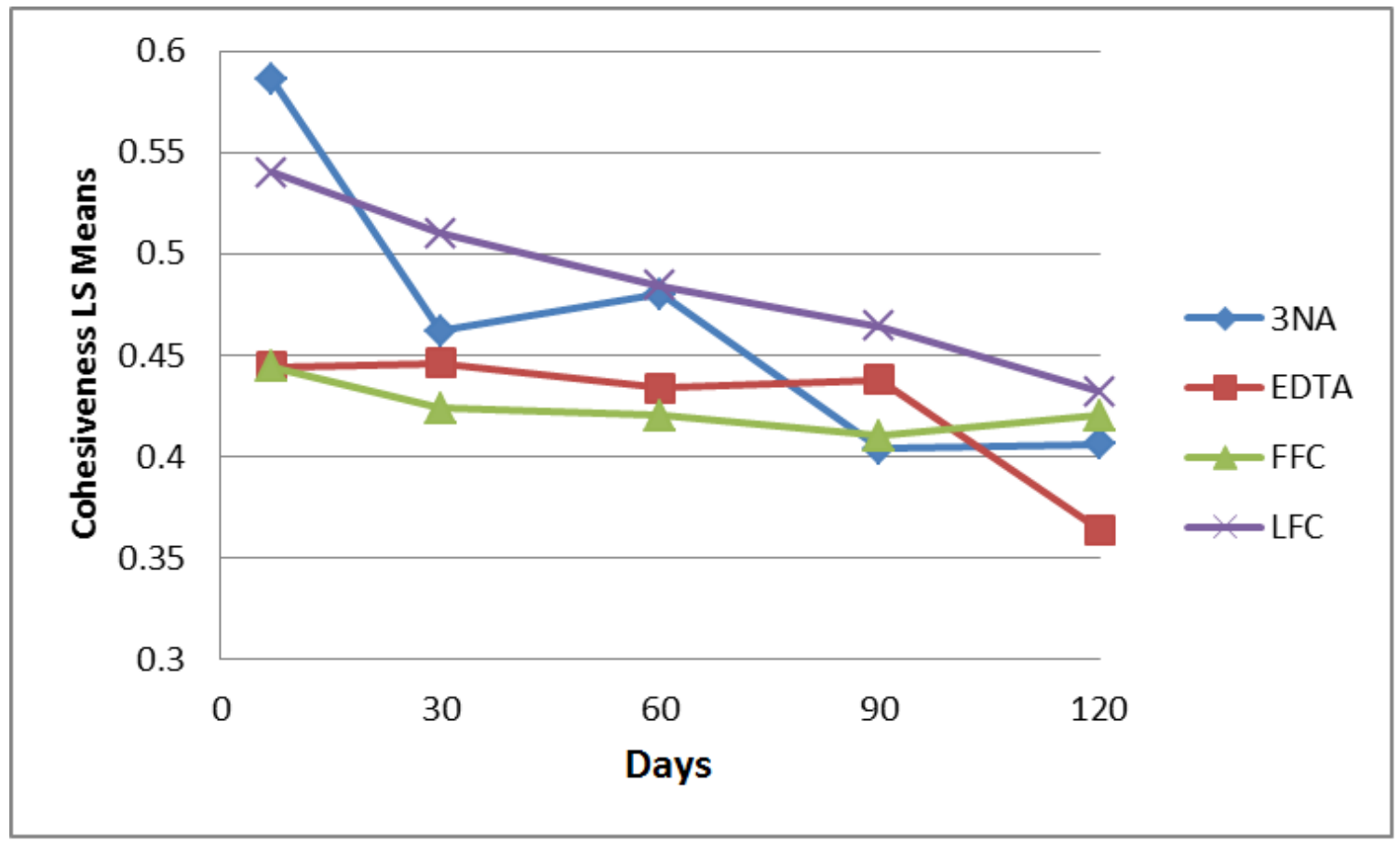

Figure 10. TPA Cohesiveness. Least square means of LF cheeses and FFC during 120 days ripening. 
Table 23. TPA Cohesiveness. Tukey LSD Means1 for all treatments during ripening.

\begin{tabular}{|ccccccc|}
\hline \hline Parameter by day & Treatment & Mean & Std Dev & Std error & F(3,12) & P \\
\hline \hline \multirow{3}{*}{7 Cohesiveness (g) } & 3NA & $0.586^{\mathrm{a}}$ & 0.1539 & 0.0688 & & \\
& EDTA & $0.444^{\mathrm{a}}$ & 0.0467 & 0.0209 & 2.76 & 0.0881 \\
& FFC & $0.444^{\mathrm{a}}$ & 0.0573 & 0.0256 & & \\
& LFC & $0.54^{\mathrm{a}}$ & 0.1428 & 0.0639 & & \\
\hline \multirow{3}{*}{30 Cohesiveness (g) } & 3NA & $0.462^{\mathrm{a}}$ & 0.0835 & 0.0373 & & \\
& EDTA & $0.446^{\mathrm{a}}$ & 0.0619 & 0.0277 & 1.14 & 0.3718 \\
& FFC & $0.424^{\mathrm{a}}$ & 0.0773 & 0.0346 & & \\
& LFC & $0.51^{\mathrm{a}}$ & 0.0946 & 0.0423 & & \\
\hline \multirow{3}{*}{60 Cohesiveness (g) } & 3NA & $0.48^{\mathrm{a}}$ & 0.1098 & 0.0491 & & \\
& EDTA & $0.434^{\mathrm{a}}$ & 0.0684 & 0.0306 & 2.691 & 0.0932 \\
& FFC & $0.42^{\mathrm{a}}$ & 0.0367 & 0.0164 & & \\
& LFC & $0.484^{\mathrm{a}}$ & 0.0783 & 0.035 & & \\
\hline \multirow{3}{*}{ 90 Cohesiveness $(\mathrm{g})$} & 3NA & $0.404^{\mathrm{a}}$ & 0.055 & 0.0246 & & \\
& EDTA & $0.438^{\mathrm{a}}$ & 0.0826 & 0.0369 & 0.8261 & 0.5045 \\
& FFC & $0.41^{\mathrm{a}}$ & 0.0524 & 0.0235 & & \\
& LFC & $0.464^{\mathrm{a}}$ & 0.1074 & 0.048 & & \\
\hline \multirow{3}{*}{120 Cohesiveness (g) } & 3NA & $0.406^{\mathrm{a}}$ & 0.0456 & 0.0204 & & \\
& EDTA & $0.364^{\mathrm{a}}$ & 0.0619 & 0.0277 & 0.6251 & 0.6124 \\
& FFC & $0.42^{\mathrm{a}}$ & 0.08 & 0.0358 & & \\
& LFC & $0.432^{\mathrm{a}}$ & 0.1305 & 0.0583 & & \\
\hline
\end{tabular}

Means within the same column with different superscripts differ significantly $(\mathrm{P}<0.05)$

${ }^{1}$ Mean of duplicate determination of five cheesemaking trials.

$$
\begin{gathered}
\text { 3NA }=\text { Lowfat Cheddar disodium citrate } \\
\text { EDTA }=\text { Lowfat Cheddar disodium EDTA } \\
\text { FFC }=\text { Full fat Cheddar control } \\
\text { LFC }=\text { Lowfat Cheddar control }
\end{gathered}
$$

\section{Springiness}

Since the MANOVA results did not show any statistically significant differences, subsequent univariate ANOVAs are not needed or recommended. However, for consistency the results are displayed below. While the ANOVA for 120 day Springiness Table 25 shows significant evidence for a difference in mean springiness across the cheeses, these results should be interpreted with caution, as the initial MANOVA did not 
provide any evidence for difference across all times. This apparent difference could easily be a "false positive" or Type I error.

Table 24. TPA Springiness. Wilks’ Lambda Test.

\begin{tabular}{ccccc}
\hline \hline Springiness & $\mathrm{F}$ & $\mathrm{df} 1$ & $\mathrm{df} 2$ & $\mathrm{P}$ \\
\hline \hline Equality & 1.06 & 15 & 22.5 & 0.44 \\
Parallel & 1.15 & 12 & 24 & 0.36 \\
Overall level & 1.74 & 3 & 12 & 0.22 \\
\hline
\end{tabular}

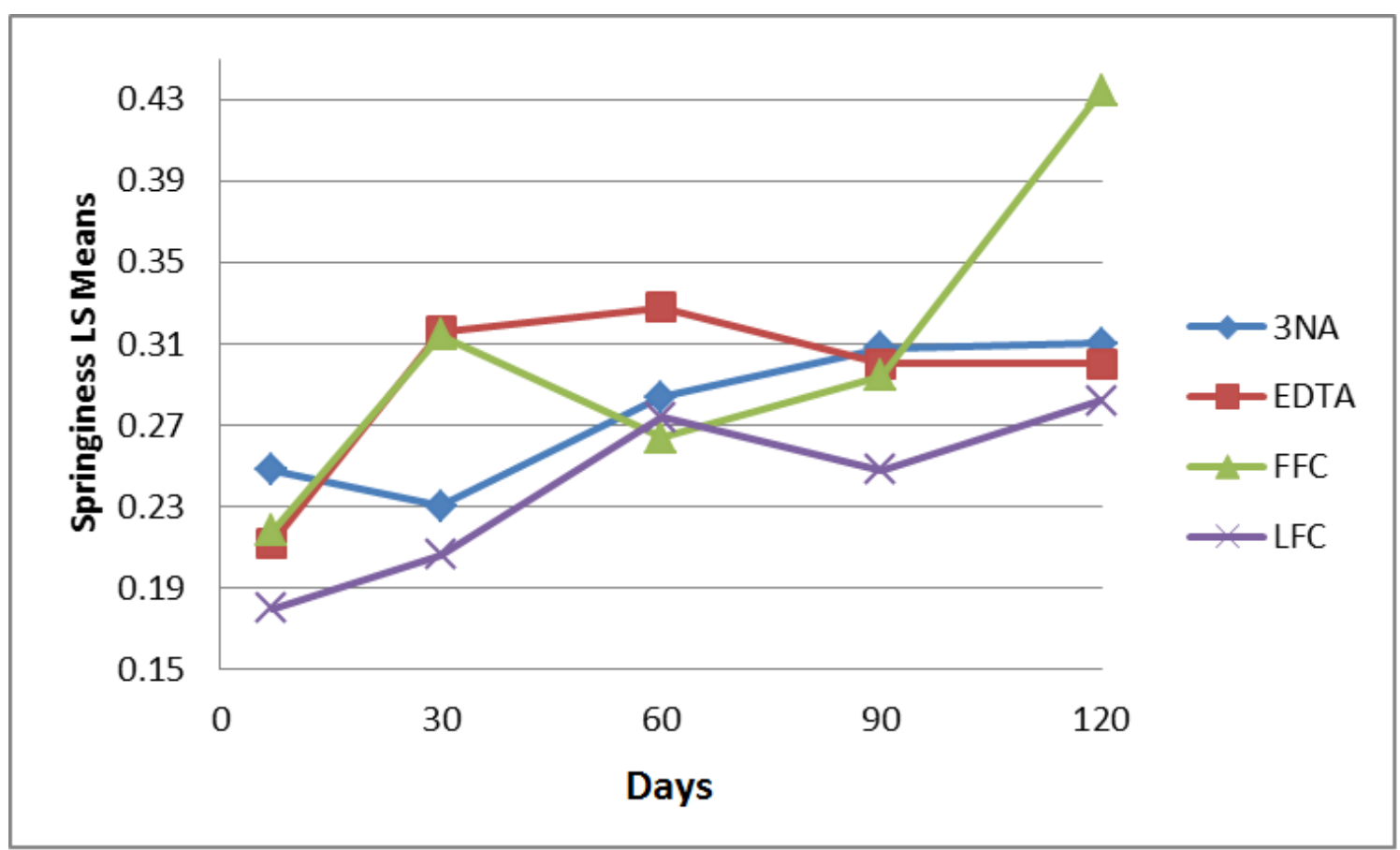

Figure 11. TPA Springiness. Least square means of LF cheeses and FFC during 120 days ripening.

There was no significant difference in TPA springiness $(\mathrm{P}>0.05)$ irrespective of the type of cheese over ripening time until 90 days (Table 25). After $120 \mathrm{~d}$ ripened the TPA springiness of the control FFC was significantly different than control LF cheese. No specific pattern was observed in (Fig 11). 
Table 25. TPA Springiness. Tukey LSD Means ${ }^{1}$ for all treatments during ripening.

\begin{tabular}{|c|c|c|c|c|c|c|}
\hline Parameter by day & Treatment & Mean & Std Dev & Std error & $F(3,12)$ & $\mathbf{P}$ \\
\hline \multirow{4}{*}{7 Springiness (g) } & $3 \mathrm{NA}$ & $0.248^{\mathrm{a}}$ & 0.1137 & 0.0508 & \multirow{4}{*}{0.8945} & \multirow{4}{*}{0.4721} \\
\hline & EDTA & $0.212^{\mathrm{a}}$ & 0.0259 & 0.0116 & & \\
\hline & FFC & $0.218^{\mathrm{a}}$ & 0.0576 & 0.0258 & & \\
\hline & LFC & $0.18^{\mathrm{a}}$ & 0.02 & 0.0089 & & \\
\hline \multirow{4}{*}{30 Springiness (g) } & $3 \mathrm{NA}$ & $0.23^{\mathrm{a}}$ & 0.1079 & 0.0483 & \multirow{4}{*}{2.3098} & \multirow{4}{*}{0.1282} \\
\hline & EDTA & $0.316^{\mathrm{a}}$ & 0.1016 & 0.0455 & & \\
\hline & FFC & $0.314^{\mathrm{a}}$ & 0.0991 & 0.0443 & & \\
\hline & LFC & $0.206^{\mathrm{a}}$ & 0.0568 & 0.0254 & & \\
\hline \multirow{4}{*}{60 Springiness (g) } & $3 \mathrm{NA}$ & $0.284^{\mathrm{a}}$ & 0.1036 & 0.0463 & \multirow{4}{*}{0.637} & \multirow{4}{*}{0.6054} \\
\hline & EDTA & $0.328^{\mathrm{a}}$ & 0.1701 & 0.0761 & & \\
\hline & $\mathrm{FFC}$ & $0.264^{\mathrm{a}}$ & 0.0635 & 0.0284 & & \\
\hline & LFC & $0.274^{\mathrm{a}}$ & 0.1069 & 0.0478 & & \\
\hline \multirow{4}{*}{90 Springiness (g) } & $3 \mathrm{NA}$ & $0.308^{a}$ & 0.0779 & 0.0348 & \multirow{4}{*}{0.6153} & \multirow{4}{*}{0.6182} \\
\hline & EDTA & $0.3^{\mathrm{a}}$ & 0.1102 & 0.0493 & & \\
\hline & FFC & $0.294^{\mathrm{a}}$ & 0.0706 & 0.0316 & & \\
\hline & LFC & $0.248^{\mathrm{a}}$ & 0.0589 & 0.0263 & & \\
\hline \multirow{4}{*}{120 Springiness (g) } & $3 \mathrm{NA}$ & $0.31^{\mathrm{ab}}$ & 0.1168 & 0.0522 & \multirow{4}{*}{4.064} & \multirow{4}{*}{0.0331} \\
\hline & EDTA & $0.3^{\mathrm{ab}}$ & 0.0381 & 0.017 & & \\
\hline & FFC & $0.434^{\mathrm{a}}$ & 0.0856 & 0.0383 & & \\
\hline & LFC & $0.282^{b}$ & 0.0581 & 0.026 & & \\
\hline
\end{tabular}

Means within the same column with different superscripts differ significantly $(\mathrm{P}<0.05)$

${ }^{1}$ Mean of duplicate determination of five cheesemaking trials.

3NA = Lowfat Cheddar disodium citrate

EDTA $=$ Lowfat Cheddar disodium EDTA

FFC $=$ Full fat Cheddar control

LFC $=$ Lowfat Cheddar control 


\section{Gumminess}

Table 26. TPA Gumminess. Wilks' Lambda Test.

\begin{tabular}{ccccc}
\hline \hline Gumminess & $\mathrm{F}$ & df1 & df2 & $\mathrm{P}$ \\
\hline \hline Equality & 3.43 & 15 & 22.5 & 0.0042 \\
Parallel & 2.85 & 12 & 24 & 0.14 \\
Overall level & 11.13 & 3 & 12 & 0.0009 \\
\hline
\end{tabular}

Wilks' Lambda Test (Table 26) and the profiles (Figure 12) show that the mean TPA gumminess profiles over time are significantly different $(\mathrm{P}=0.0042)$. While there is no evidence that the relative changes in TPA gumminess over the ripening are different (i.e., the hardness temporal profiles appear parallel $)(\mathrm{P}=0.14)$, they do exhibit significant differences of mean overall TPA hardness $(\mathrm{P}=0.0009)$. Figure 12 shows the changes on hardness of the four treatments during ripening. We can clearly see that overall FFC was the gummiest variant. EDTA and $3 \mathrm{Na}$ follow a very similar pattern during ripening and LFC remained harder compared to any other treatment. 


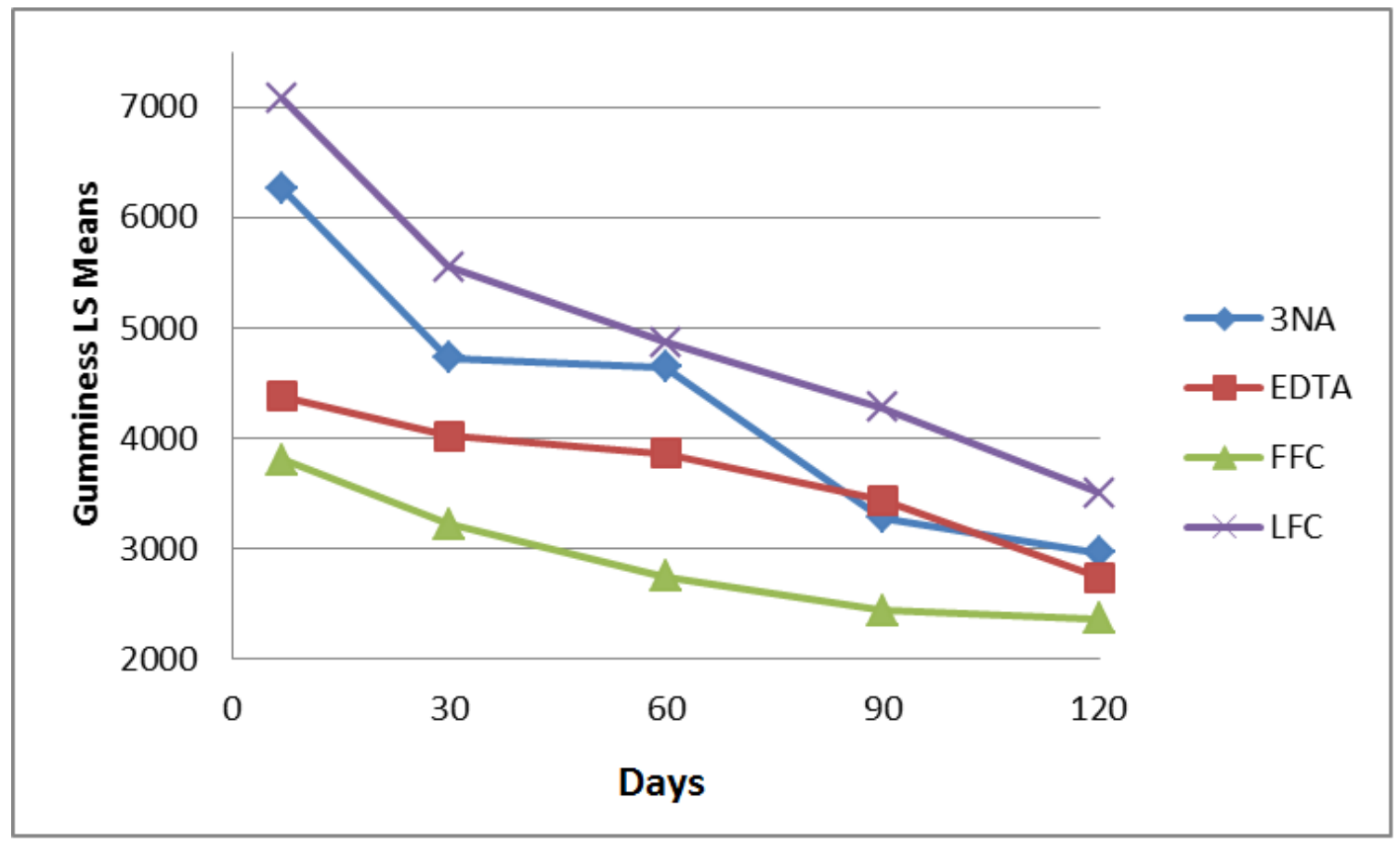

Figure 12. TPA Gumminess. Least square means of LFC and FFC during ripening. 
Table 27. TPA Gumminess. Tukey LSD Means ${ }^{1}$ for all treatments during ripening.

\begin{tabular}{|ccccccc|}
\hline \hline Parameter by day & Treatment & Mean & Std Dev & Std error & F(3,12) & P \\
\hline \hline \multirow{4}{*}{7 Gumminess (g) } & 3NA & $6254.8^{\mathrm{ab}}$ & 1441 & 644.45 & & \\
& EDTA & $4376.1^{\mathrm{bc}}$ & 902.12 & 403.44 & 8.884 & 0.0022 \\
& FFC & $3804.5^{\mathrm{c}}$ & 421.13 & 188.33 & & \\
& LFC & $7075^{\mathrm{a}}$ & 2629.5 & 1176 & & \\
\hline \multirow{3}{*}{30 Gumminess (g) } & 3NA & $4726.9^{\mathrm{ab}}$ & 1540.2 & 688.81 & & \\
& EDTA & $4018.2^{\mathrm{ab}}$ & 1560.4 & 697.84 & 6.7708 & 0.0063 \\
& FFC & $3217^{\mathrm{b}}$ & 531.86 & 237.86 & & \\
& LFC & $5549.4^{\mathrm{a}}$ & 1393.6 & 623.22 & & \\
\hline \multirow{3}{*}{60 Gumminess (g) } & 3NA & $4648.1^{\mathrm{a}}$ & 1014.3 & 453.6 & & \\
& EDTA & $3859^{\mathrm{a}}$ & 1158.5 & 518.09 & 14.6422 & 0.0003 \\
& FFC & $2744.7^{\mathrm{b}}$ & 293.73 & 131.36 & & \\
& LFC & $4869.6^{\mathrm{a}}$ & 1191.5 & 532.87 & & \\
\hline \multirow{3}{*}{90 Gumminess (g) } & 3NA & $3279.2^{\mathrm{a}}$ & 572.11 & 255.86 & & \\
& EDTA & $3436.4^{\mathrm{a}}$ & 781.57 & 349.53 & 4.5797 & 0.0233 \\
& FFC & $2435.3^{\mathrm{a}}$ & 519.58 & 232.36 & & \\
& LFC & $4278.3^{\mathrm{a}}$ & 1400.1 & 626.14 & & \\
\hline \multirow{2}{*}{120 Gumminess (g) } & 3NA & $2963.1^{\mathrm{a}}$ & 477.26 & 213.44 & & \\
& EDTA & $2738.7^{\mathrm{a}}$ & 471.08 & 210.67 & 1.5792 & 0.2458 \\
& FFC & $2366.8^{\mathrm{a}}$ & 660.15 & 295.23 & & \\
& LFC & $3506.6^{\mathrm{a}}$ & 1250.8 & 559.39 & & \\
\hline
\end{tabular}

Means within the same column with different superscripts differ significantly $(\mathrm{P}<0.05)$

${ }^{1}$ Mean of duplicate determination of five cheesemaking trials.

3NA = Lowfat Cheddar disodium citrate

EDTA $=$ Lowfat Cheddar disodium EDTA

$\mathrm{FFC}=$ Full fat Cheddar control

$\mathrm{LFC}=$ Lowfat Cheddar control

TPA Gumminess in FFC was significantly lower $(\mathrm{P}<0.05)$ than those of LFC and $3 \mathrm{Na}$ during the first 60 days of ripening. After 90 and 120 days ripen the mean TPA treatments were not significantly different $(\mathrm{P}>0.05)$. Increase in TPA Gumminess in LF Cheddar cheeses can be attributed to the firm and elastic protein (Table 27). 


\section{Chewiness}

Wilks' Lambda Test (Table 28) and the profiles (Figure 13) show that the mean TPA chewiness profiles over time are not significantly different $(\mathrm{P}=0.636)$. While there is no evidence that the relative changes in TPA chewiness over the ripening are different (i.e., the chewiness temporal profiles appear parallel $)(\mathrm{P}=0.31)$, they do exhibit significant differences of mean overall TPA chewiness $(\mathrm{P}=0.0055)$.

Table 28. TPA Chewiness. Wilks' Lambda Test.

\begin{tabular}{ccccc}
\hline \hline Chewiness & F & df1 & df2 & P \\
\hline \hline Equality & 2.02 & 15 & 22 & 0.636 \\
Parallel & 1.25 & 12 & 24 & 0.3098 \\
Overall level & 7.05 & 3 & 12 & 0.0055 \\
\hline
\end{tabular}

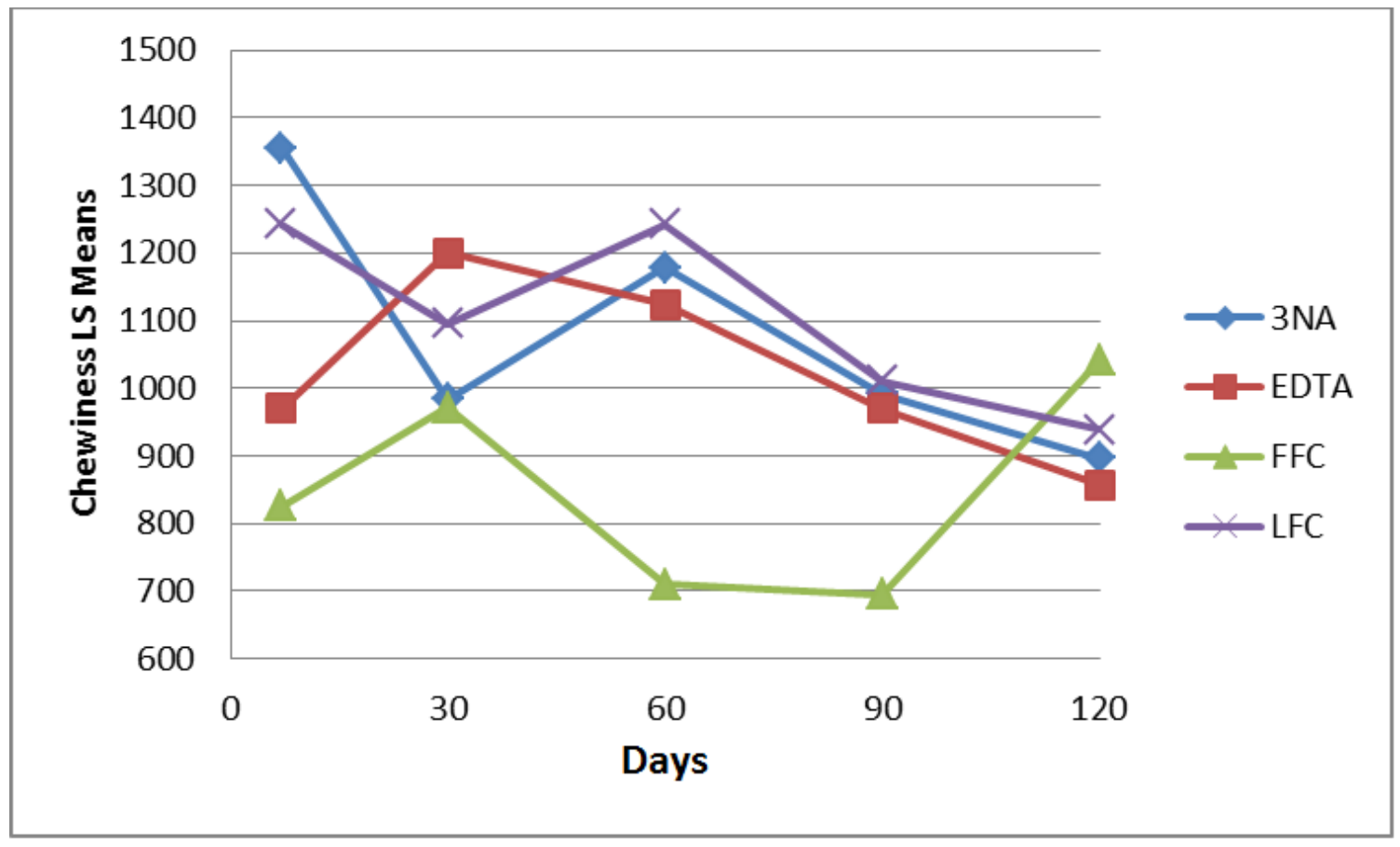

Figure 13. TPA Chewiness. Least square means of LFC and FFC during ripening. 
There was no significant difference in TPA chewiness $(\mathrm{P}>0.05)$ between all cheeses over ripening time as shown in Table 29.

Table 29. TPA Chewiness. Tukey LSD Means ${ }^{1}$ for all treatments during ripening.

\begin{tabular}{|ccccccc|}
\hline \hline Parameter by day & Treatment & Mean & Std Dev & Std error & F (3,12) & P \\
\hline \hline \multirow{3}{*}{7 Chewiness (g) } & 3NA & $1356^{\mathrm{a}}$ & 372.93 & 166.78 & & \\
& EDTA & $969.35^{\mathrm{a}}$ & 113.96 & 50.964 & 3.158 & 0.0643 \\
& FFC & $825.38^{\mathrm{a}}$ & 180.58 & 80.759 & & \\
& LFC & $1242.4^{\mathrm{a}}$ & 368.14 & 164.64 & & \\
\hline \multirow{3}{*}{30 Chewiness (g) } & 3NA & $983.55^{\mathrm{a}}$ & 232.07 & 103.78 & & \\
& EDTA & $1200.3^{\mathrm{a}}$ & 387.75 & 173.41 & 0.7425 & 0.547 \\
& FFC & $971.03^{\mathrm{a}}$ & 213.91 & 95.664 & & \\
& LFC & $1095.6 \mathrm{a}$ & 152.83 & 68.349 & & \\
\hline \multirow{5}{*}{60 Chewiness (g) } & 3NA & $1178.3^{\mathrm{a}}$ & 179.55 & 80.299 & & \\
& EDTA & $1124^{\mathrm{a}}$ & 335.82 & 150.18 & 10.3542 & 0.0012 \\
& FFC & $710.59^{\mathrm{a}}$ & 114.31 & 51.121 & & \\
& LFC & $1242.2^{\mathrm{a}}$ & 300.17 & 134.24 & & \\
\hline \multirow{3}{*}{ 90 Chewiness (g) } & 3NA & $991.49^{\mathrm{a}}$ & 145.03 & 64.859 & & \\
& EDTA & $970.19^{\mathrm{a}}$ & 213.53 & 95.495 & 3.1925 & 0.0626 \\
& FFC & $694.63^{\mathrm{a}}$ & 103.98 & 46.499 & & \\
& LFC & $1011.4^{\mathrm{a}}$ & 220.02 & 98.397 & & \\
\hline \multirow{3}{*}{120 Chewiness (g) } & 3NA & $896.4^{\mathrm{a}}$ & 354.56 & 158.57 & & \\
& EDTA & $857.57^{\mathrm{a}}$ & 197.38 & 88.271 & 0.4928 & 0.6939 \\
& FFC & $1040.7^{\mathrm{a}}$ & 360.58 & 161.26 & & \\
& LFC & $939.24^{\mathrm{a}}$ & 193.8 & 86.669 & & \\
\hline
\end{tabular}

Means within the same column with different superscripts differ significantly $(\mathrm{P}<0.05)$

${ }^{1}$ Mean of duplicate determination of five cheesemaking trials.

3NA = Lowfat Cheddar disodium citrate

EDTA $=$ Lowfat Cheddar disodium EDTA

$\mathrm{FFC}=$ Full fat Cheddar control

LFC $=$ Lowfat Cheddar control 


\section{Cheese Proteolysis}

\section{Primary Proteolysis}

The firmness and elasticity of cheese is more related to casein breakdown than to fat (Ardö, 1997). The flavor of LF Cheddar cheeses, especially the hard varieties, is usually atypical of their full fat counterparts (Childs and Drake, 2009). In LF Cheddar cheese the lack of and an imbalance of flavor has been associated with lowered levels of fatty acids such as butanoic and hexanoic acids and methyl ketones (Mistry, 2001). In this thesis project, amino acid determination was not performed. Primary and secondary proteolysis was examined during the ripening of the cheeses as proteolysis of $\alpha_{\mathrm{s} 1}$-casein to $\alpha_{\mathrm{s} 1}$-I casein is thought to lead to initial softening of cheese.

Urea-PAGE (Fig 14, 15, and 16) shows how $\alpha_{\mathrm{s} 1}$-casein is hydrolyzed by chymosin during ripening of the LF cheddar cheeses and FFC. Although $\beta$-casein is very resistant to rennet hydrolysis, in cheese, $\beta$-casein in solution is hydrolyzed slowly by plasmin,

producing $\gamma^{1}, \gamma^{2}, \gamma^{3}$-caseins. Chymosin, to a lesser extent, and plasmin are mainly responsible for primary proteolysis (Fox and McSweeney, 1998).

Fig 14, 15 and 16 during 120 d ripen shows a decreasing concentration in concentration of $\beta-\mathrm{CN}$. Although densitometry analysis was not taking account in this project, figures showed a slow decrement of this casein over time. Proper breakdown of the casein matrix, $\beta$-casein in particular, has been shown to make the cheese softer (Andersen et al., 2010).

On the SDS-PAGE qualitatively differences were observed in the proteolysis of $\alpha_{\mathrm{s} 1^{-}}$ casein which is visible after 30 days of ripening and becomes more obvious at 60, 90 and 
120 days. The $\alpha_{\mathrm{s} 1}$-casein in the EDTA sample, especially, seems to undergo more

proteolysis compared to the other treatments. Individual images in the polycrylamide gels show a rate of degradation of $\alpha_{\mathrm{s} 1}$-casein, in LF Cheddar variants, faster than $\beta$-casein.

Although there is no difference in proteolysis rate by statistical analysis, we can clearly see a decrease in the casein band through all the treatments, therefore we can accredit these findings to methodology limitations.

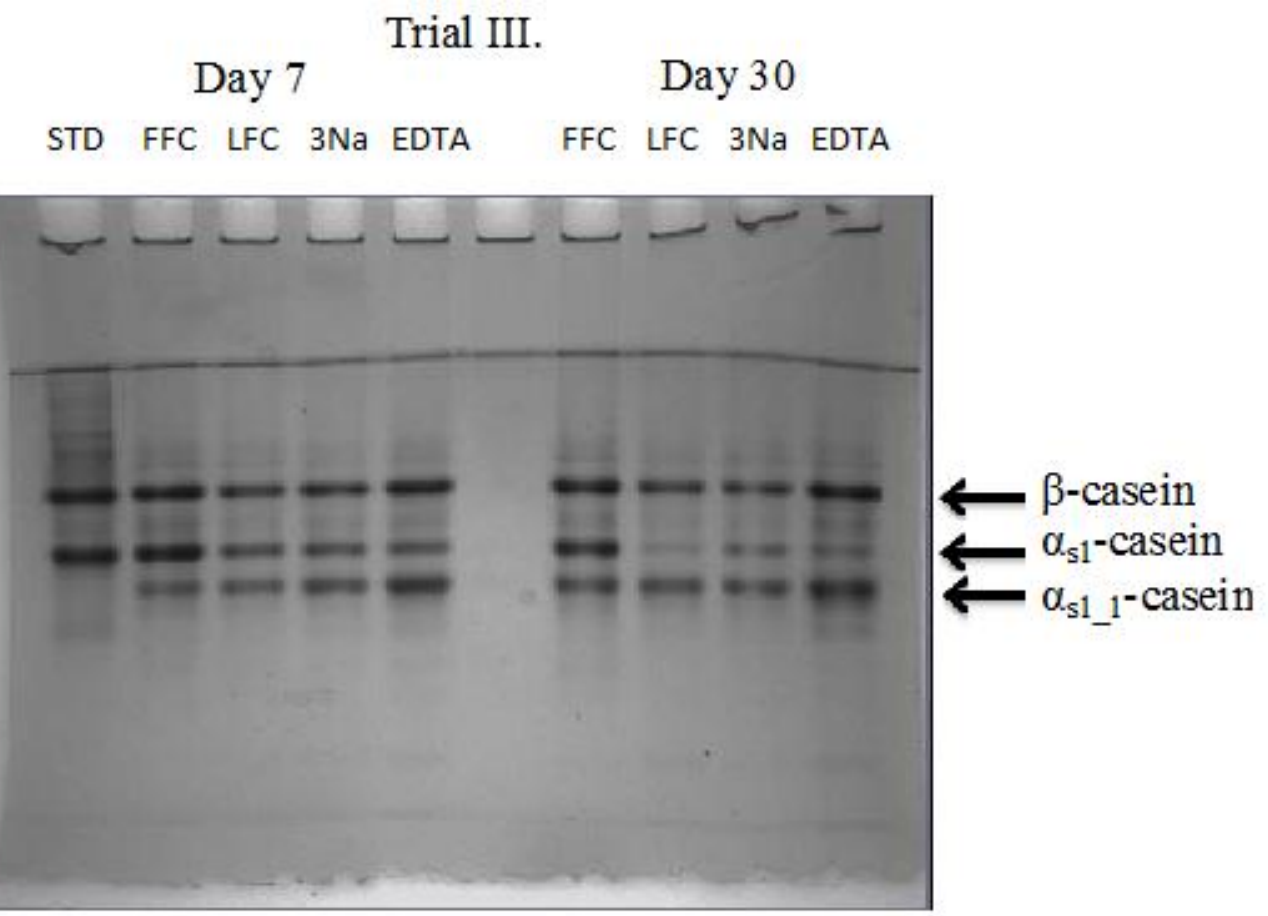

Figure 14. Polyacrylamide gel electrophoresis of LFC and FFC after 7 and 30 days of ripening. (Trial 3). Standard (STD), full fat Cheddar cheese control (FFC), lowfat Cheddar cheese control (LFC), disodium citrate lowfat Cheddar cheese (3Na) and lowfat Cheddar cheese disodium EDTA. 


\section{Trial III.}

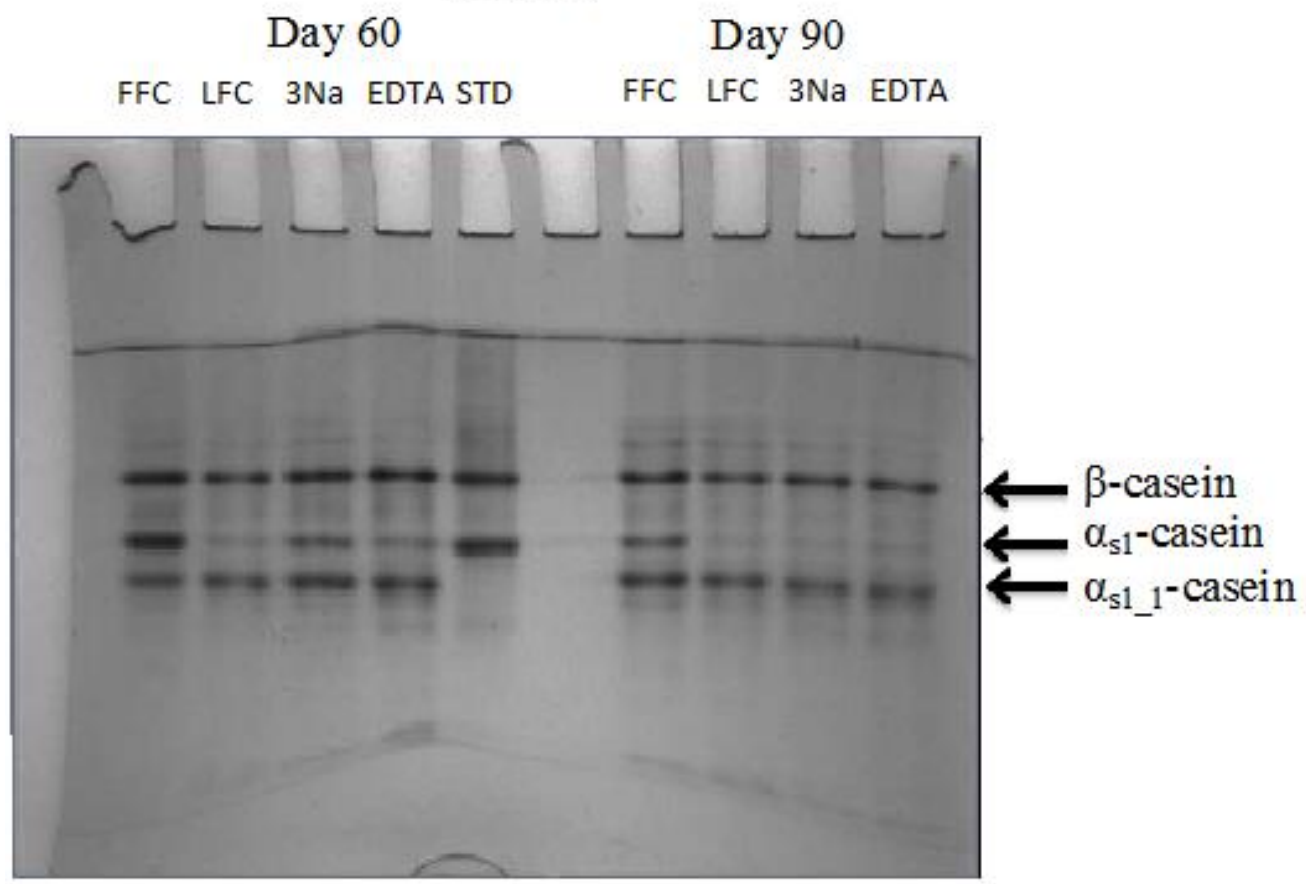

Figure 15. Polyacrylamide gel electrophoresis of LFC and FFC cheeses after 60 and 90 days of ripening.

(Trial 3). Full fat Cheddar cheese control (FFC), lowfat Cheddar cheese control (LFC), disodium citrate lowfat Cheddar cheese (3Na) and lowfat Cheddar cheese disodium EDTA, standard (STD). 


\section{Trial III.}

\section{Day 120}

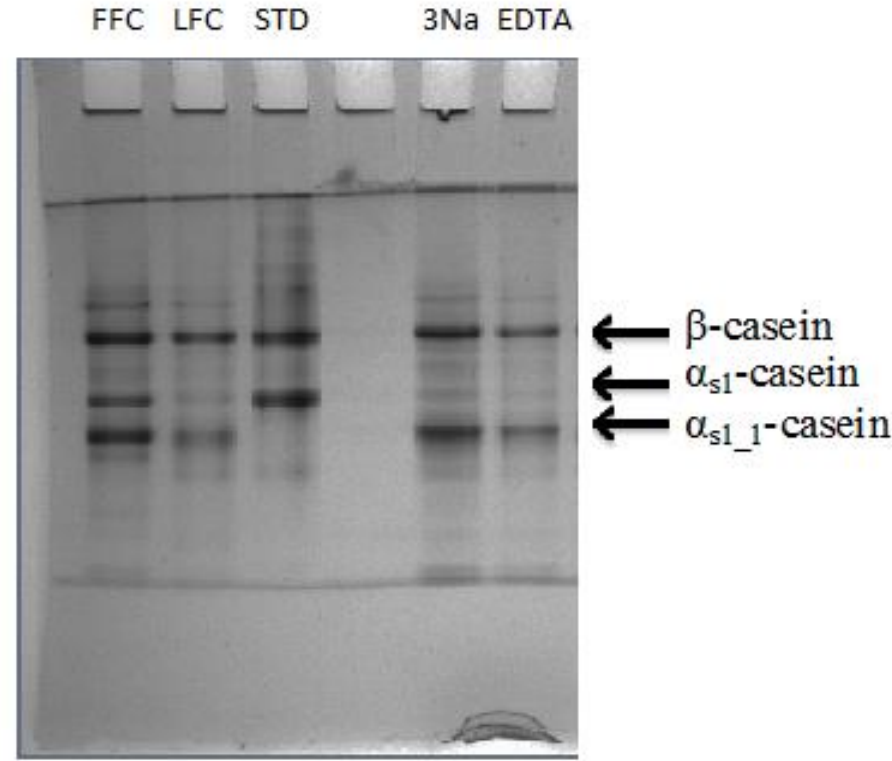

Figure 16. Polyacrylamide gel electrophoresis of LFC and FFC after 120 days of ripening. (Trial 3). Full fat cheddar cheese control (FFC), lowfat Cheddar cheese control (LFC), standard (STD), disodium citrate lowfat Cheddar cheese (3Na) and lowfat Cheddar cheese disodium EDTA.

\section{Secondary Proteolysis. Water Soluble Nitrogen (WSN)}

Secondary proteolysis of the cheeses was quantitatively examined by determination of water soluble nitrogen (WSN).

Table 30. Water Soluble Nitrogen (WSN) content. Wilks' Lambda Test.

\begin{tabular}{ccccc}
\hline \hline WSN & F & df1 & df2 & P \\
\hline \hline Equality & 3.15 & 35 & 36 & 0.0004 \\
Parallel & 1.17 & 12 & 24 & 0.36 \\
Overall level & 16.5 & 3 & 12 & \\
\hline
\end{tabular}

Wilks' Lambda Test (Table 30) and the profiles (Figure 17) show that the mean WSN profiles over time are significantly different $(\mathrm{P}=0.0004)$. While there is no evidence that the relative changes in WSN over the ripening are different (i.e., the WSN temporal 
profiles appear parallel $)(\mathrm{P}=0.36)$, they do exhibit significant differences of mean overall WSN $(\mathrm{P}<0.0001)$. Fig 17 shows \% WSN in cheeses increase overtime for all the variants.

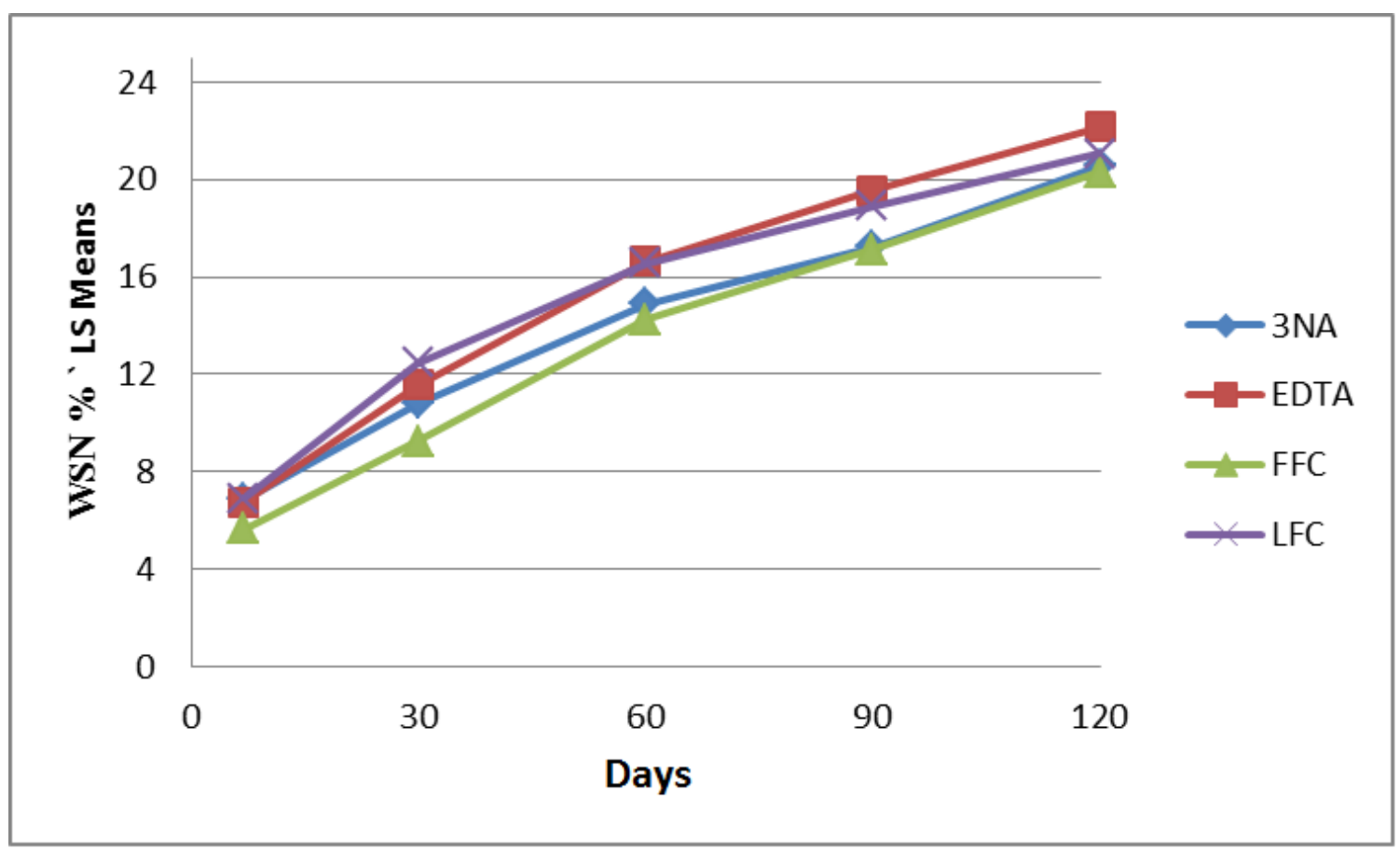

Figure 17. Water Soluble Nitrogen (WSN) content. Least square means of LFC and FFC during ripening.

Significant differences $(P=0.0125)$ were detected at day 7 (Table 31) between the FFC and all the LF cheddar variants being FFC the sample with lesser value. By day 30, no significant difference $(\mathrm{P}>0.05)$ was detected between FFC and 3Na. LF cheeses after day 60 no significant differences between cheese were detected with the exception of day 90 where EDTA and FFC show a significant difference $(\mathrm{P}<0.05)$. Results correlate with the literature, secondary proteolysis is due to the action of chymosin and starter 
proteinases (Farkye, 1995). Therefore, this method may be a better indicator of residual rennet or whether proteases have been used (Rank et al., 1985).

Table 31. Water Soluble Nitrogen (WSN) content. Tukey LSD Means ${ }^{1}$ for all treatments during ripening.

\begin{tabular}{|c|c|c|c|c|c|c|}
\hline Parameter by day & Treatment & Mean & Std Dev & Std error & $F(3,12)$ & $\mathbf{P}$ \\
\hline \multirow{4}{*}{$7 \% \mathrm{WSN}$} & $3 \mathrm{NA}$ & $6.858^{\mathrm{a}}$ & 0.4716 & 0.2109 & \multirow{4}{*}{5.577} & \multirow{4}{*}{0.0125} \\
\hline & EDTA & $6.766^{\mathrm{a}}$ & 0.5108 & 0.2284 & & \\
\hline & FFC & $5.654^{\mathrm{b}}$ & 0.679 & 0.3036 & & \\
\hline & LFC & $6.91^{\mathrm{a}}$ & 0.5236 & 0.2342 & & \\
\hline \multirow{4}{*}{$30 \% \mathrm{WSN}$} & $3 \mathrm{NA}$ & $10.824^{\mathrm{ab}}$ & 2.2051 & 0.9861 & \multirow{4}{*}{6.3} & \multirow{4}{*}{0.0082} \\
\hline & EDTA & $11.568^{\mathrm{a}}$ & 1.1843 & 0.5296 & & \\
\hline & FFC & $9.264^{b}$ & 1.2873 & 0.5757 & & \\
\hline & LFC & $12.472^{\mathrm{a}}$ & 0.5771 & 0.2581 & & \\
\hline \multirow{4}{*}{$60 \% \mathrm{WSN}$} & $3 \mathrm{NA}$ & $14.878^{\mathrm{a}}$ & 2.8747 & 1.2856 & \multirow{4}{*}{2.006} & \multirow{4}{*}{0.1669} \\
\hline & EDTA & $16.624^{\mathrm{a}}$ & 4.7387 & 2.1192 & & \\
\hline & FFC & $14.256^{\mathrm{a}}$ & 2.8012 & 1.2527 & & \\
\hline & LFC & $16.544^{\mathrm{a}}$ & 3.4921 & 1.5617 & & \\
\hline \multirow{4}{*}{$90 \% \mathrm{WSN}$} & $3 \mathrm{NA}$ & $17.226^{\mathrm{ab}}$ & 1.7588 & 0.7865 & \multirow{4}{*}{4.7512} & \multirow{4}{*}{0.0208} \\
\hline & EDTA & $19.55^{\mathrm{a}}$ & 3.2607 & 1.4582 & & \\
\hline & FFC & $17.132^{\mathrm{b}}$ & 0.9166 & 0.4099 & & \\
\hline & LFC & $18.902^{\mathrm{ab}}$ & 2.7136 & 1.2136 & & \\
\hline \multirow{4}{*}{$120 \% \mathrm{WSN}$} & $3 \mathrm{NA}$ & $20.574^{\mathrm{a}}$ & 2.023 & 0.9047 & \multirow{4}{*}{2.3679} & \multirow{4}{*}{0.122} \\
\hline & EDTA & $22.168^{\mathrm{a}}$ & 0.5622 & 0.2514 & & \\
\hline & FFC & $20.316^{\mathrm{a}}$ & 2.1948 & 0.9815 & & \\
\hline & LFC & $21.044^{\mathrm{a}}$ & 2.0167 & 0.9019 & & \\
\hline
\end{tabular}

Means within the same column with different superscripts differ significantly $(\mathrm{P}<0.05)$

${ }^{1}$ Mean of duplicate determination of five cheesemaking trials.

3NA = Lowfat Cheddar disodium citrate

EDTA $=$ Lowfat Cheddar disodium EDTA

FFC $=$ Full fat Cheddar control

LFC $=$ Lowfat Cheddar control 


\section{CONCLUSIONS}

1) Significant reduction of $\mathrm{Ca}^{2+}$ content in EDTA and $3 \mathrm{Na}$ Cheddar cheeses.

2) Addition of chelating agents, especially EDTA, showed to be the most effective in soften the cheese before 60 days.

3) Reduction of $\mathrm{Ca}^{2+}$ content was quantified. At $0.02 \%$ sodium citrate and $0.2 \%$ disodium EDTA addition, $\mathrm{Ca}^{2+}$ decreased in a rate of 34.7 and $31.3 \%$ respectively compared to FFC. Reduction of $14.7 \%$ on the content of $\mathrm{Ca}^{2+}$ for the $\mathrm{LF}$ cheese control was registered in comparison to FFC. 


\section{DIRECTIONS FOR FUTURE RESEARCH}

Further research of the complexity of the texture of LF Cheddar cheeses is a potential research due to a customer need of having a natural cheese low in fat.

Possible research directions are as follows:

1. Investigate the effects of addition of higher concentrations of chelating agents in the cheese making process.

2. Explore the possibility to combine LF Cheddar cheese technologies, such as ultrafiltration, addition of yeast or application of fat mimetics.

3. Flavor profile of the LF cheeses could be examined using Gas Chromatography Mass.

4. A trained panel to develop a descriptive sensory evaluation will lead to a better understanding of the texture of LF cheeses. 


\section{BIBLIOGRAPHY}

Andersen, L. T., Y. Ardö, and W. L. P. Bredie. 2010. Study of taste-active compounds in the water-soluble extract of mature Cheddar cheese. Int. Dairy J. 20(8):528-536.

AOAC. 1995. Official methods of analysis of AOAC International (16 ${ }^{\text {th }}$ ed., vol. 2). AOAC International, Gaithersburg, MD.

Ardö, Y. 1997. Flavour and texture in low-fat cheese. Pages 207-218 in Microbiology and Biochemistry of Cheese and Fermented Milk. Springer.

Association, I. D. F. 2012. Cheese Sales \& Trends.

Banks, J. M. 2004. The technology of low-fat cheese manufacture. Int. Dairy J. 57(4):199-207.

Baskin, M. L., J. Ard, F. Franklin, and D. B. Allison. 2005. Prevalence of obesity in the United States. Obesity Reviews 6(1):5-7.

Bourne, M. C. 1978. Texture Profile Analysis. Food Technology 32(7):62-\&.

Bryant, A., Z. Ustunol, and J. Steffe. 1995. Texture of cheddar cheese as influenced by fat reduction. J. Dairy Sci. 60(6):1216-\&.

Bryant, R. J., J. Cadogan, and C. M. Weaver. 1999. The new dietary reference intakes for calcium: implications for osteoporosis. Journal of the American College of Nutrition 18(suppl 5):406S-412S.

Burton, C. D. 1990. Hypochlorite distinfectant stabilized with calcium chelant. Google Patents.

Carić, M. and M. Kaláb. 1993. Processed cheese products. Pages 467-505 in Cheese: chemistry, physics and microbiology. Springer. 
Chen, A. H., J. W. Larkin, C. J. Clark, and W. E. Irwin. 1979. Textural Analysis of Cheese. J. Dairy Sci. 62(6):901-907.

Childs, J. L. and M. Drake. 2009. Consumer Perception of Fat Reduction in Cheese. J. Sens. Stud. 24(6):902-921.

Cook, A. J. and J. E. Friday. 2003. Food mixture or ingredient sources for dietary calcium: shifts in food group contributions using four grouping protocols. Journal of the American Dietetic Association 103(11):1513-1519.

Dabour, N., E. Kheadr, N. Benhamou, I. Fliss, and G. LaPointe. 2006. Improvement of texture and structure of reduced-fat cheddar cheese by exopolysaccharide-producing lactococci. J. Dairy Sci. 89(1):95-110.

De Kort, E., M. Minor, T. Snoeren, T. van Hooijdonk, and E. van der Linden. 2011. Effect of calcium chelators on physical changes in casein micelles in concentrated micellar casein solutions. International Dairy Journal 21(12):907-913.

Drake, M. A., T. D. Boylston, and B. G. Swanson. 1996. Fat Mimetics in Low-Fat Cheddar Cheese. J. Food Sci. 61(6):1267-1271.

Drake, M. A., R. E. Miracle, and D. J. McMahon. 2010. Influence of fat on flavour and flavour development in cheddar cheese. Aust. J. Dairy Technol. 65(3):195-199.

Drake, M. A. and B. G. Swanson. 1995. Reduced- and low-fat cheese technology: A review. Trends in Food Science \& Technology 6(11):366-369.

Farkye, N. Y. 1995. Contribution of milk-clotting enzymes and plasmin to cheese ripening. Advances in experimental medicine and biology 367.

Farkye, N. Y. 2004. Symposium Contribution Cheese technology. Int. Dairy J. 57(2/3):91-98. 
Fox, P. F. 1992. Advanced dairy chemistry. 1, Proteins. Elsevier Applied Science, London [etc.].

Fox, P. F. and P. L. McSweeney. 1998. Dairy chemistry and biochemistry. Chapman \& Hall.

Fox, P. F., P. L. McSweeney, T. M. Cogan, and T. P. Guinee. 2000. Fundamentals of cheese science. Springer.

Fox, P. F., P. L. McSweeney, T. M. Cogan, and T. P. Guinee. 2004a. Cheese: Chemistry, Physics and Microbiology: General Aspects. Vol. 1. Academic Press.

Fox, P. F. and P. L. H. McSweeney. 2006. Advanced Dairy Chemistry Volume 2: Lipids. Springer.

Fox, P. F., P. L. McSweeny, T. M. Cogan, and T. P. Guinee. 2004b. Cheese: Chemistry, physics \& microbiology, Volume 2: Major cheese groups.

Goddard, J. M., D. J. McClements, and E. A. Decker. 2012. Innovative technologies in the control of lipid oxidation. Lipid Technology 24(12):275-277.

Hoffmann, W., J. Gartner, K. Luck, N. Johannsen, and A. Maurer. 2012. Effect of emulsifying salts containing potassium on the quality of block-type processed cheese. Int. Dairy J. 25(1):66-72.

Inc, D. M. March, 2009. Low-Fat Cheese Research.8.

Jacobs, M. M. 1993. Diet, Nutrition, and Cancer Research: An Overview. Nutrition Today 28(3):19-23.

Johnson, M. E., R. Kapoor, D. J. McMahon, D. R. McCoy, and R. G. Narasimmon. 2009. Reduction of Sodium and Fat Levels in Natural and Processed Cheeses: Scientific and 
Technological Aspects. Comprehensive Reviews in Food Science and Food Safety 8(3):252-268.

Johnson, M. E. and J. A. Lucey. 2006. Calcium: a key factor in controlling cheese functionality. Aust. J. Dairy Technol. 61(2):147-153.

Kethireddipalli, P., A. R. Hill, and D. G. Dalgleish. 2010. Protein interactions in heattreated milk and effect on rennet coagulation. Int. Dairy J. 20(12):838-843.

Kosikowski, F. V. and V. V. Mistry. 1997. Cheese and fermented milk foods. Volume 1: origins and principles. Cheese and fermented milk foods. Volume 1: origins and principles. No. Ed. 3.

Lawrence, R. C., L. K. Creamer, and J. Gilles. 1987. Symposium - Cheese Ripening Technology - Texture Development During Cheese Ripening. J. Dairy Sci. 70(8):17481760.

Lucey, J. A., C. Dick, H. Singh, and P. A. Munro. 1997. Dissociation of colloidal calcium phosphate-depleted casein particles as influenced by $\mathrm{pH}$ and concentration of calcium and phosphate. Milchwissenschaft-Milk Science International 52(11):603-606.

Lucey, J. A. and P. F. Fox. 1993. Importance of Calcium and Phosphate in Cheese Manufacture: A Review. J. Dairy Sci. 76(6):1714-1724.

McGregor, J. U. and C. H. White. 1990a. Effect of Enzyme Treatment and Ultrafiltration on the Quality of Low-fat Cheddar Cheese. J. Dairy Sci. 73(3):571-578.

McGregor, J. U. and C. H. White. 1990b. Optimizing Ultrafiltration Parameters for the Development od Low-fat cheddar cheese. J. Dairy Sci. 73(2):314-318.

McMahon, D. J. 2010. Issues with lower fat and lower salt cheeses. Aust. J. Dairy Technol. 65(3):200-205. 
Metzger, L. E., D. M. Barbano, M. A. Rudan, and P. S. Kindstedt. 2000. Effect of Milk Preacidification on Low Fat Mozzarella Cheese. I. Composition and Yield. J. Dairy Sci. 83(4):648-658.

Mistry, V. V. 2001. Low fat cheese technology. Int. Dairy J. 11(4-7):413-422.

Mizuno, R. and J. A. Lucey. 2005. Effects of Two Types of Emulsifying Salts on the Functionality of Nonfat Pasta Filata Cheese. J. Dairy Sci. 88(10):3411-3425.

Panel, N. O. E. I. E. 1998. Treatment guidelines.

Pastorino, J., C. L. Hansen, and D. J. McMahon. 2003. Effect of sodium citrate on structure-function relationships of cheddar cheese. J. Dairy Sci. 86(10):3113-3121.

Pons, M. and S. M. Fiszman. 1996. Instrumental texture profile analysis with particular reference to gelled systems. J. Texture Studies 27(6):597-624.

Ramasubramanian, L., R. Webb, B. D'Arcy, and H. C. Deeth. 2013. Characteristics of a calcium-milk coagulum. J. Food Eng. 114(2):147-152.

Rank, T. C., R. Grappin, and N. F. Olson. 1985. Secondary Proteolysis of Cheese During Ripening: A Review. J. Dairy Sci. 68(4):801-805.

Szczesniak, A. S. 2002. Texture is a sensory property. Food Quality and Preference 13(4):215-225.

Wehr, H. M., J. F. Frank, and A. American Public Health. 2004. Standard Methods for the Examination of Dairy Products. American Public Health Association Publications.

Yun, J. J., L. J. Kiely, D. M. Barbano, and P. S. Kindstedt. 1993. Mozzarella CheeseImpact of Cooking Temperature on Chemical Composition, Proteolysis, and Functional Properties. J. Dairy Sci. 76(12):3664-3673. 


\section{APPENDIX A}

Table 32. Dietary Reference Intake Values for Calcium by Life-Stage Group for U.S. and Canada ${ }^{2}$

\begin{tabular}{cc}
\hline \hline Life-Stage Group & (mg/day) \\
\hline 0 to 6 months & 210 \\
6 to 12 months & 270 \\
1 through 3 years & 500 \\
4 through 8 years & 800 \\
9 through 13 years & 1300 \\
14 through 18 years & 1300 \\
19 through 30 years & 1000 \\
31 through 50 years & 1000 \\
51 through 70 years & 1200 \\
$>70$ years & 1200 \\
Pregnancy & \\
$\leq 18$ years & 1300 \\
19 through 50 years & 1000 \\
Lactation & \\
$\leq 18$ years & 1300 \\
19 through 50 years & 1000 \\
\hline
\end{tabular}

${ }^{\text {a } F o o d ~ a n d ~ N u t r i t i o n ~ B o a r d, ~ I n s t i t u t e ~ o f ~ M e d i c i n e, ~ N a t i o n a l ~ A c a d e m y ~ P r e s s, ~ W a s h i n g t o n, ~}$ DC, 1997. 


\section{APPENDIX B}

\section{Cheddar Cheese Composition}

\section{Statistical Data for $p H$}
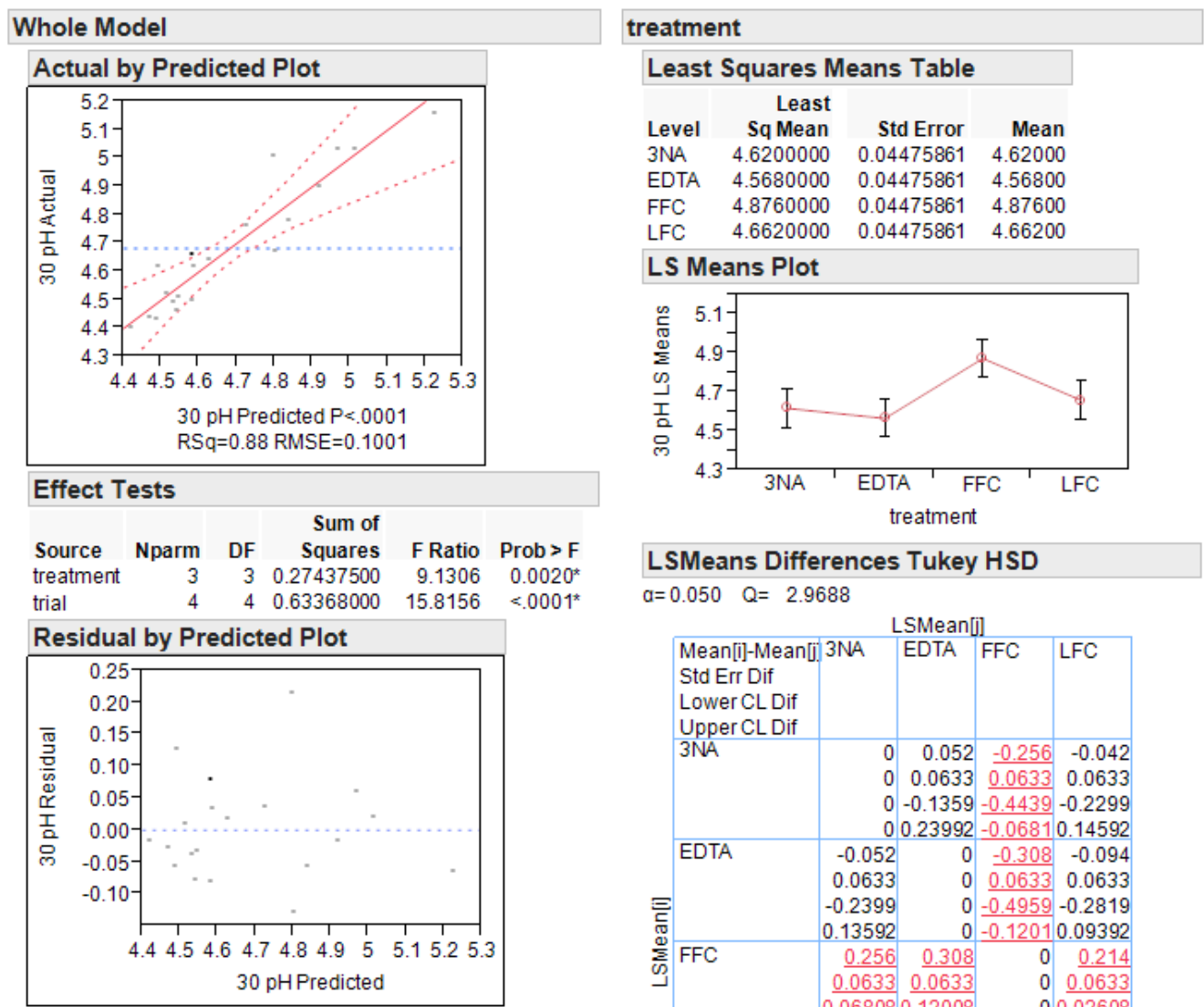

\section{LSMeans Differences Tukey HSD \\ $\alpha=0.050 \quad Q=2.9688$}

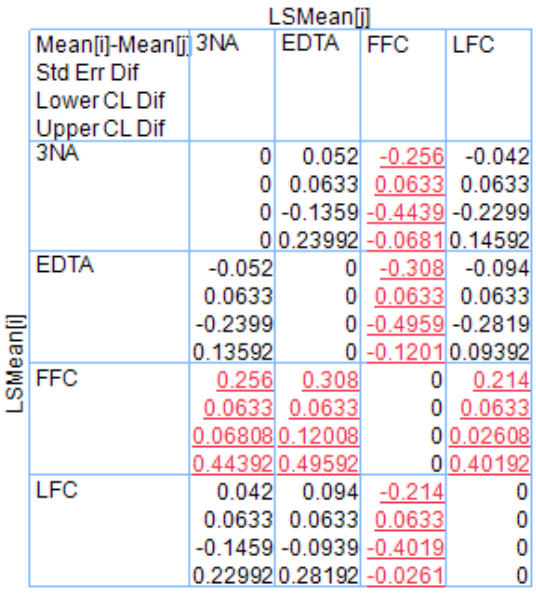

$\begin{array}{lrrr}\text { Level } & & & \begin{array}{r}\text { Least } \\ \text { Sq Mean }\end{array} \\ \text { FFC } & \text { A } & & 4.8760000 \\ \text { LFC } & \text { B } & 4.6620000 \\ \text { 3NA } & \text { B } & 4.6200000 \\ \text { EDTA } & \text { B } & 4.5680000\end{array}$

Levels not connected by same letter are significantly different. 


\section{Statistical Data for Total Solids (TS) content}
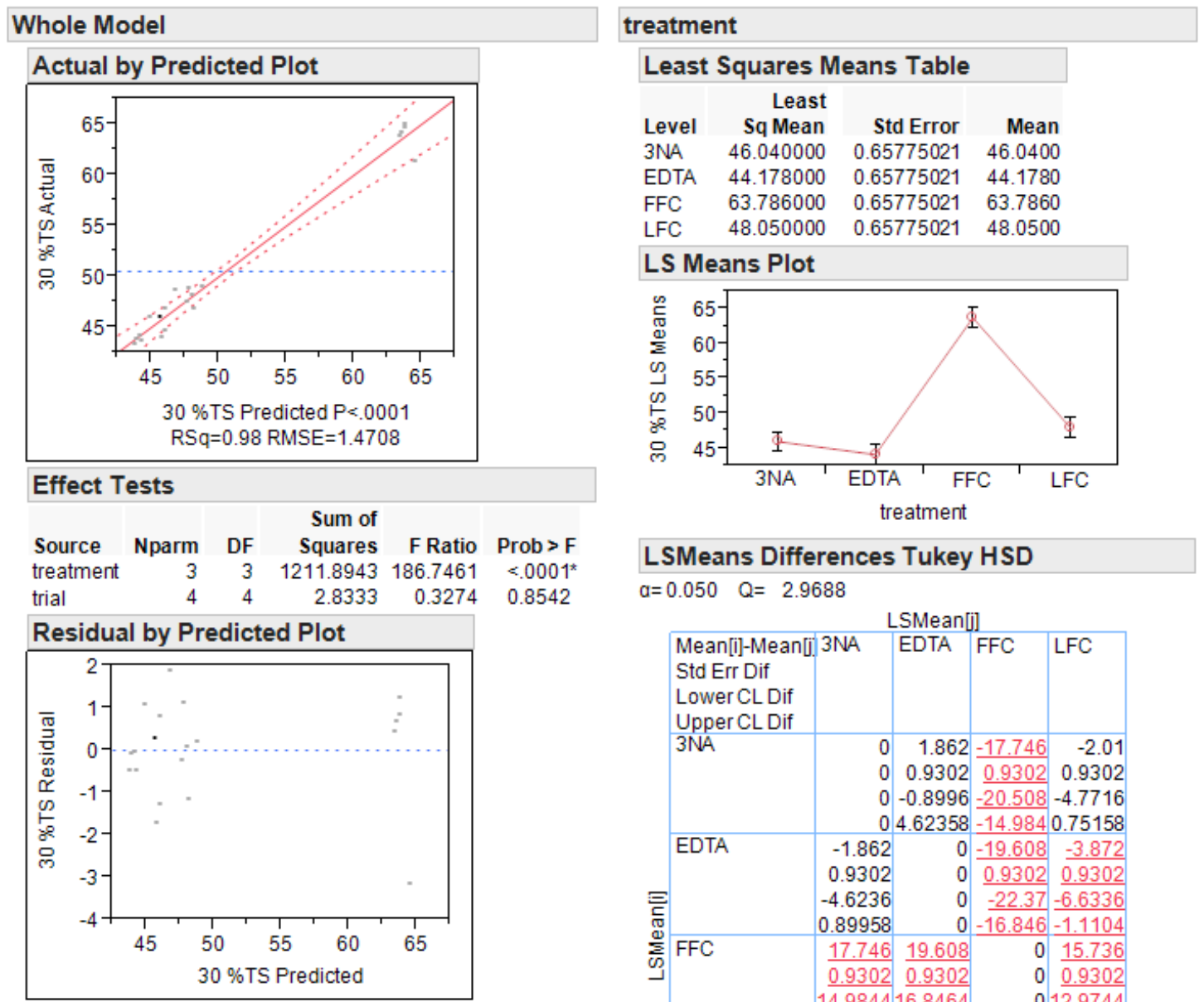

LSMeans Differences Tukey HSD $\mathrm{a}=0.050 \quad \mathrm{Q}=2.9688$

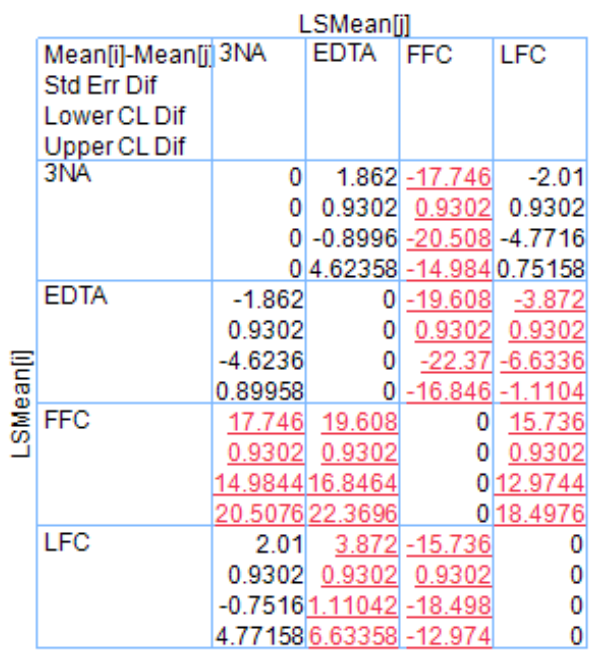

$\begin{array}{lllr}\text { Level } & & & \begin{array}{r}\text { Least } \\ \text { Sq Mean }\end{array} \\ \text { FFC } & \text { A } & & 63.786000 \\ \text { LFC } & \text { B } & 48.050000 \\ \text { 3NA } & \text { B C } & 46.040000 \\ \text { EDTA } & \text { C } & 44.178000\end{array}$

Levels not connected by same letter are significantly different. 


\section{Statistical Data for Moisture content}
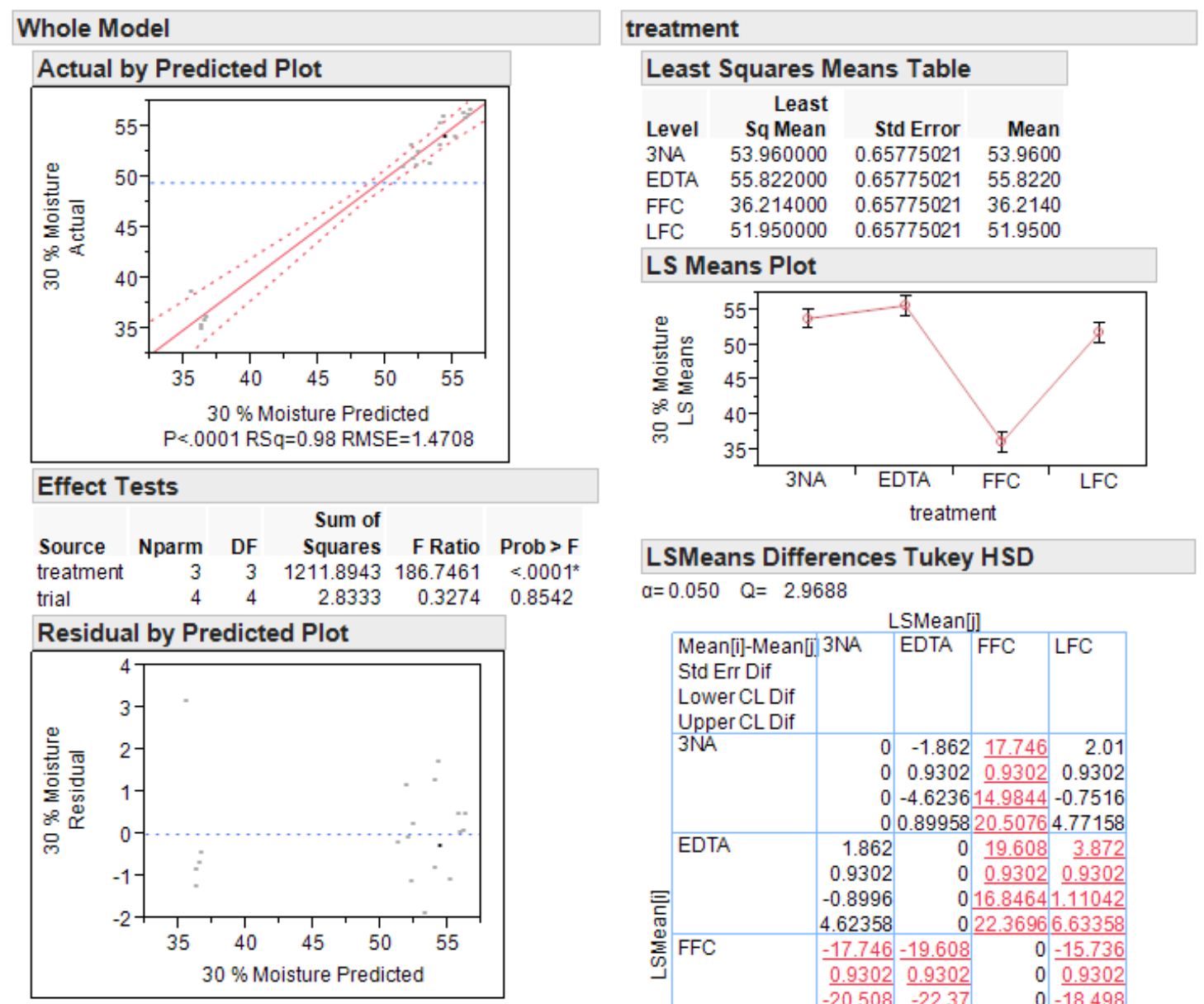

\section{LSMeans Differences Tukey HSD}

$\mathrm{a}=0.050 \quad \mathrm{Q}=2.9688$
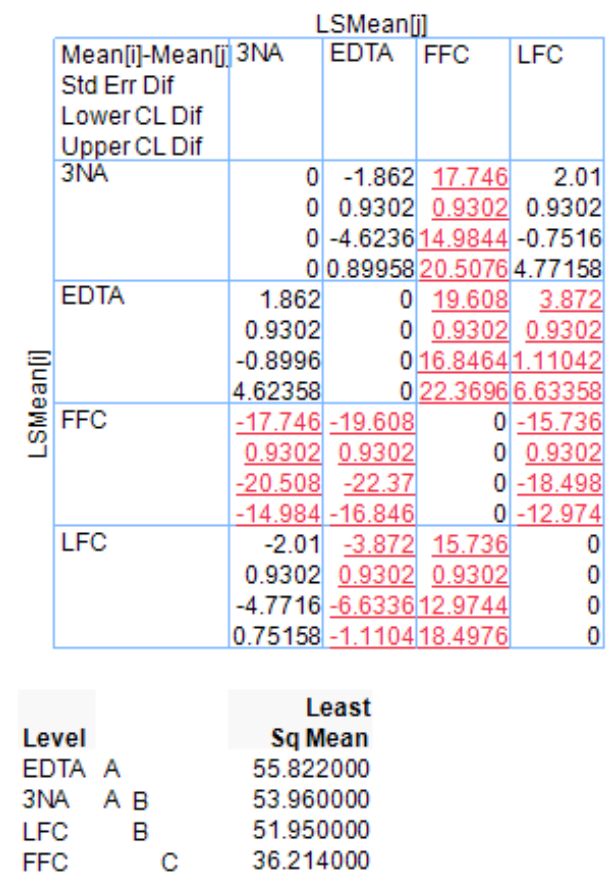

Levels not connected by same letter are significantly different. 


\section{Statistical Data for Salt content}
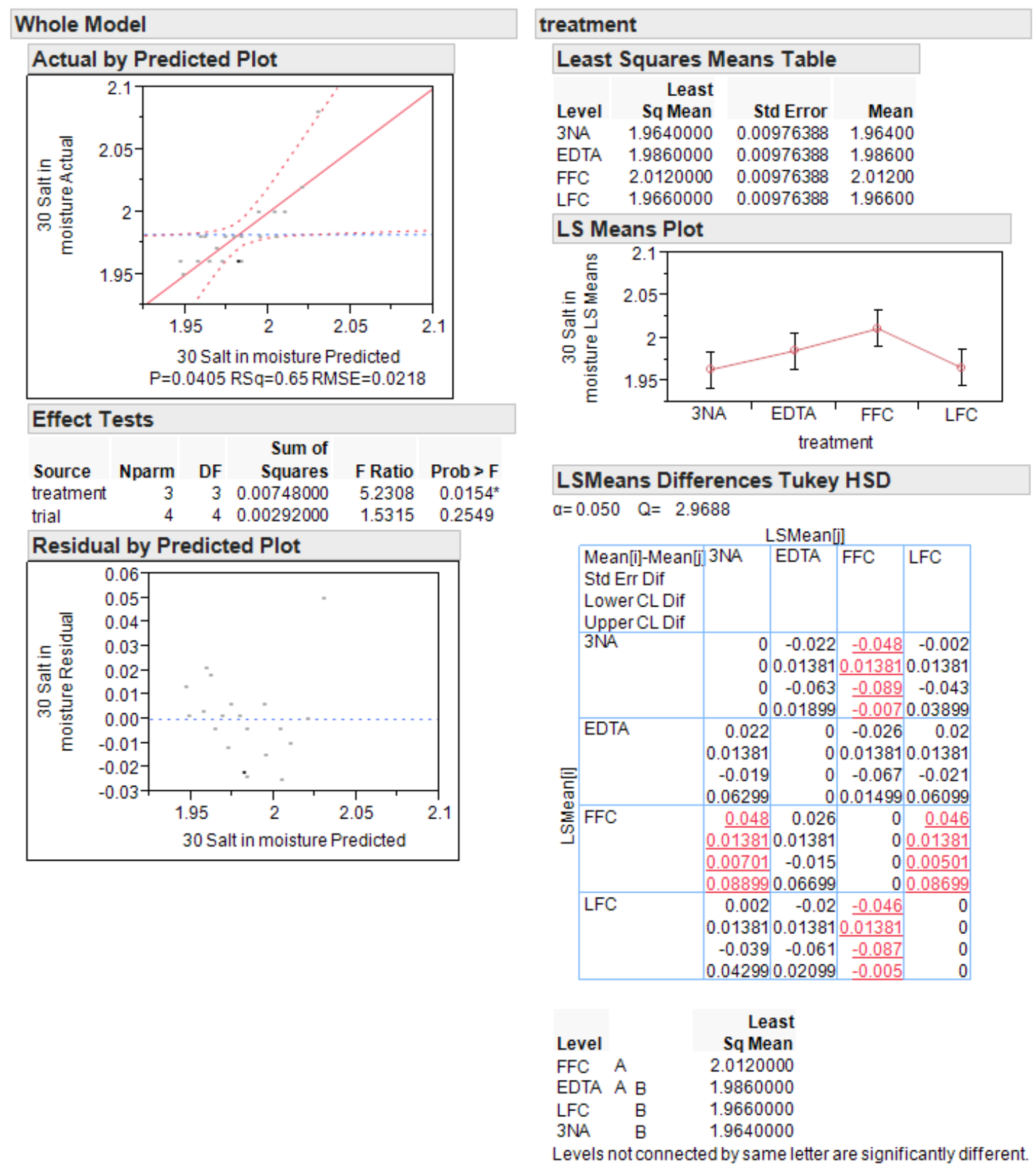


\section{Statistical Data for Fat content}

Whole Model
\begin{tabular}{lrrrrr}
\hline Effect Tests \\
Source & Nparm & DF & $\begin{array}{r}\text { Sum of } \\
\text { Squares }\end{array}$ & F Ratio & Prob $>$ F \\
treatment & 3 & 3 & 2687.6759 & 12580.10 & $<.0001^{*}$ \\
trial & 4 & 4 & 0.2372 & 0.8326 & 0.5298
\end{tabular}

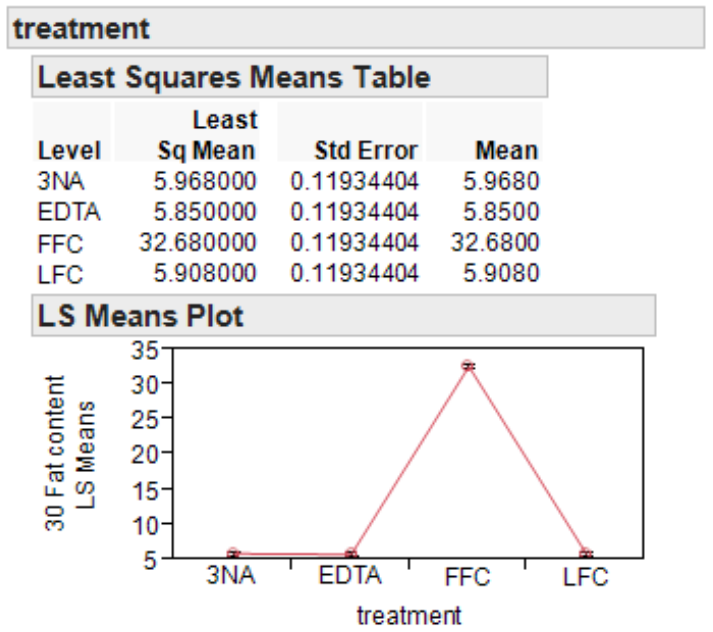

LSMeans Differences Tukey HSD $\mathrm{a}=0.050 \quad \mathrm{Q}=2.9688$

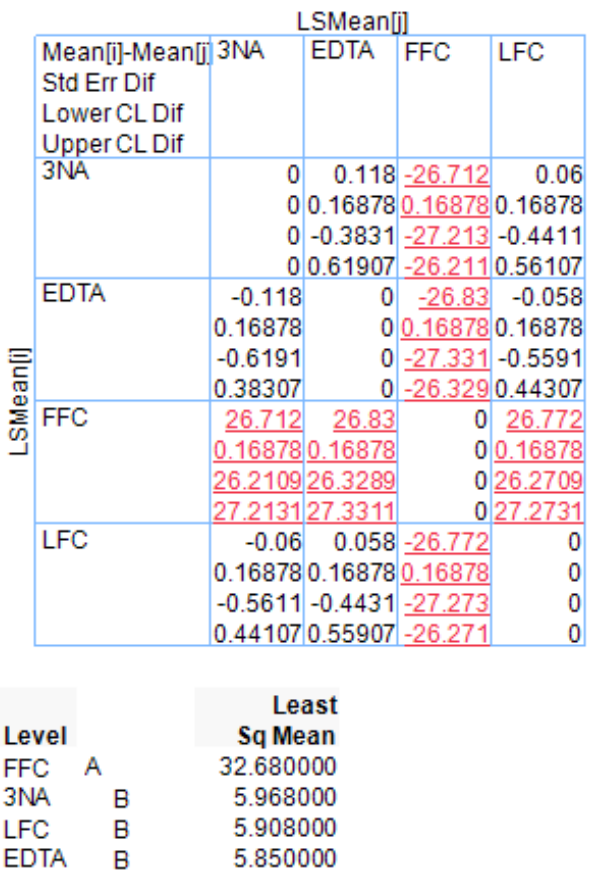

Levels not connected by same letter are significantly different. 
7. Statistical Data for $C^{2+}$. Day7

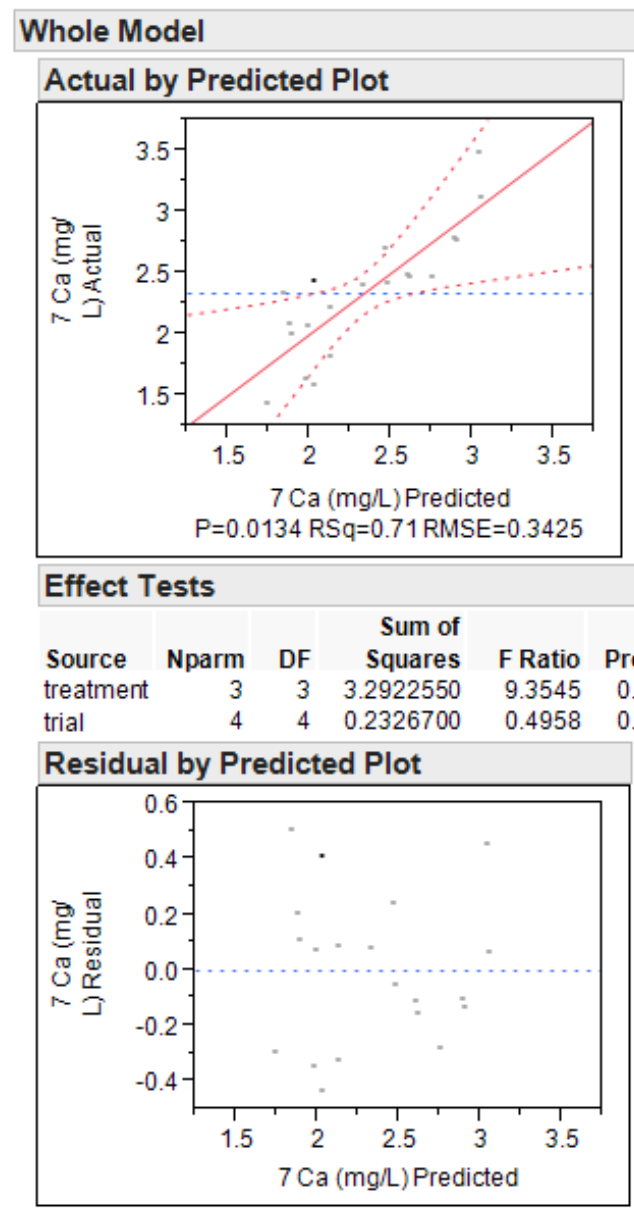

\begin{tabular}{|c|c|c|c|}
\hline \multicolumn{4}{|c|}{ treatment } \\
\hline \multicolumn{4}{|c|}{ Least Squares Means Table } \\
\hline Level & $\begin{array}{r}\text { Least } \\
\text { Sq Mean }\end{array}$ & Std Error & Mean \\
\hline $3 \mathrm{NA}$ & 1.9100000 & 0.15317582 & 1.91000 \\
\hline EDTA & 2.0100000 & 0.15317582 & 2.01000 \\
\hline FFC & 2.9240000 & 0.15317582 & 2.92400 \\
\hline LFC & 2.4940000 & 0.15317582 & 2.49400 \\
\hline
\end{tabular}

LS Means Plot

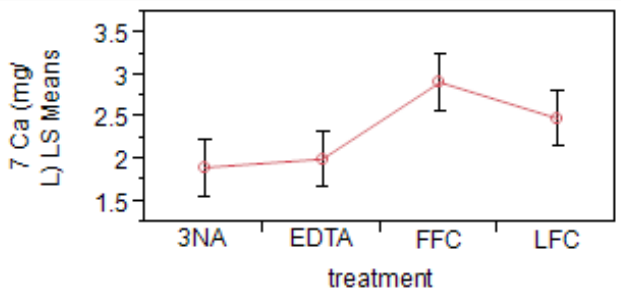

LSMeans Differences Tukey HSD $\mathrm{a}=0.050 \quad \mathrm{Q}=2.9688$

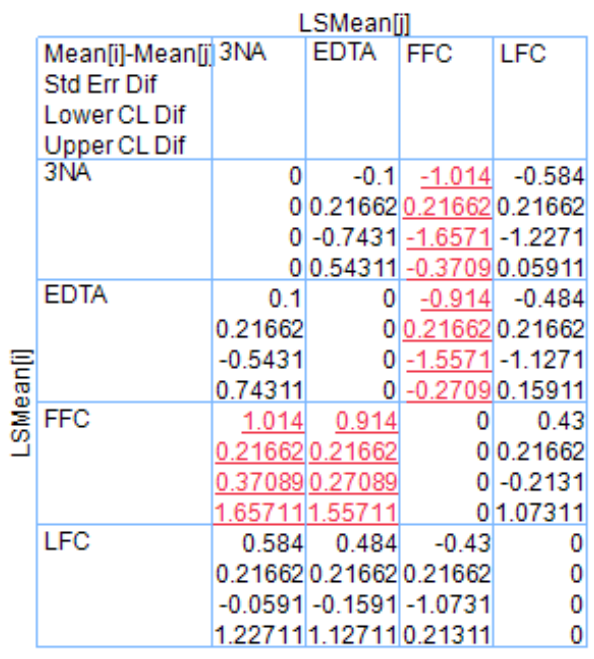

$\begin{array}{lrrr}\text { Level } & & \begin{array}{r}\text { Least } \\ \text { Sq Mean }\end{array} \\ \text { FFC } & \text { A } & 2.9240000 \\ \text { LFC } & \text { A } & \text { B } & 2.4940000 \\ \text { EDTA } & \text { B } & 2.0100000 \\ \text { 3NA } & \text { B } & 1.9100000\end{array}$

Levels not connected by same letter are significantly different. 


\section{Statistical Data for Nitrogen.}
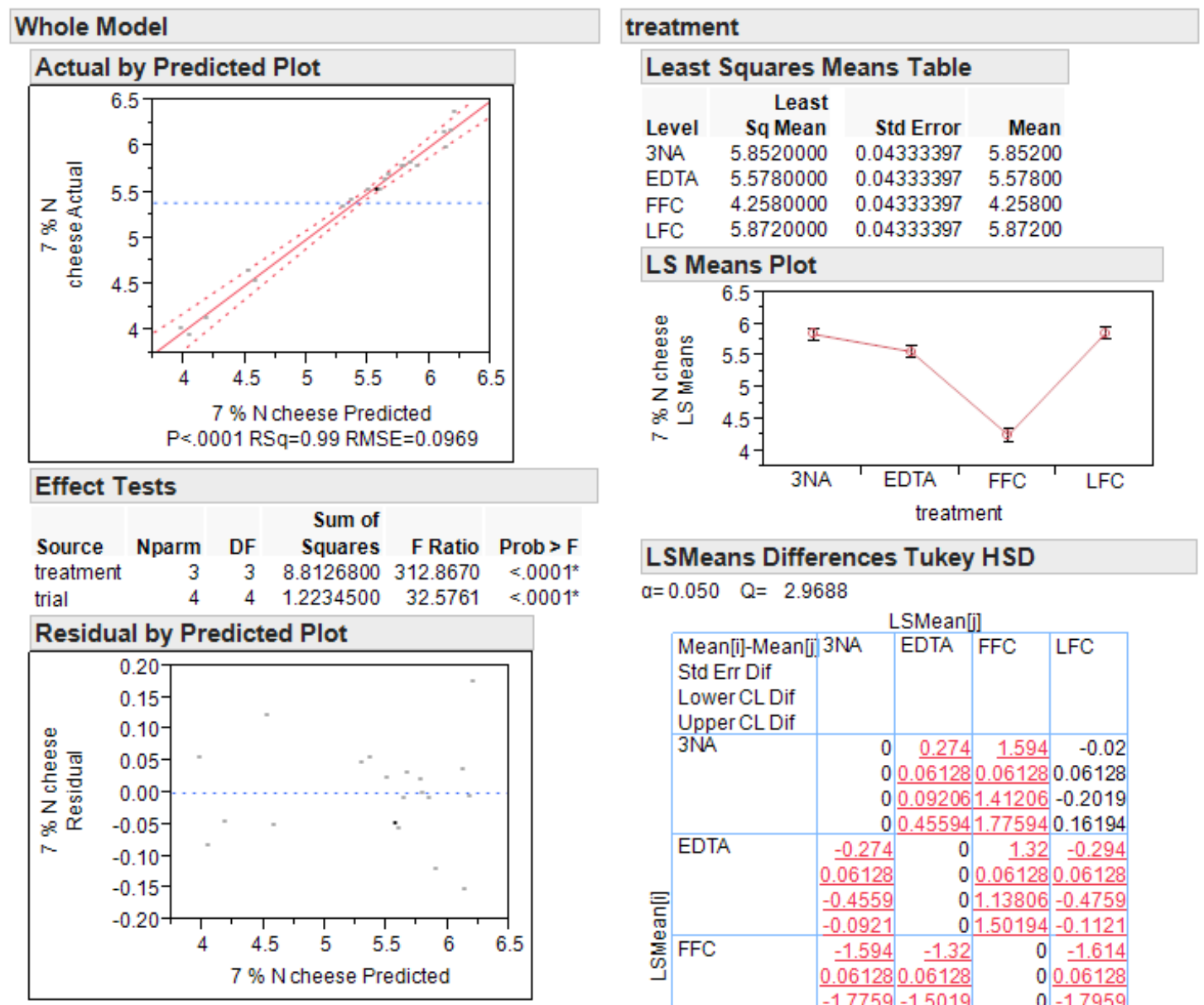

LSMeans Differences Tukey HSD $\mathrm{a}=0.050 \quad \mathrm{Q}=2.9688$
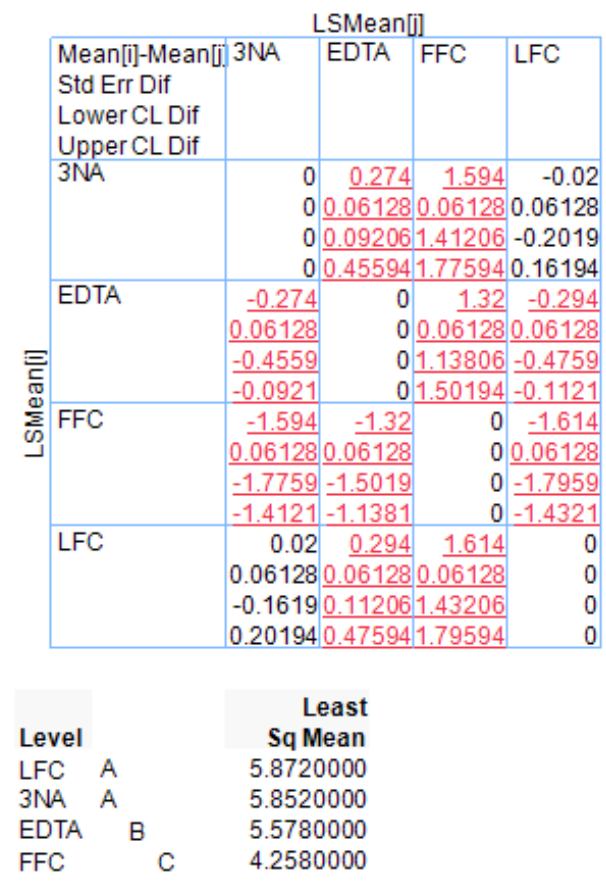

Levels not connected by same letter are significantly different. 
9. Statistical Data for TPA Hardness. Day 7

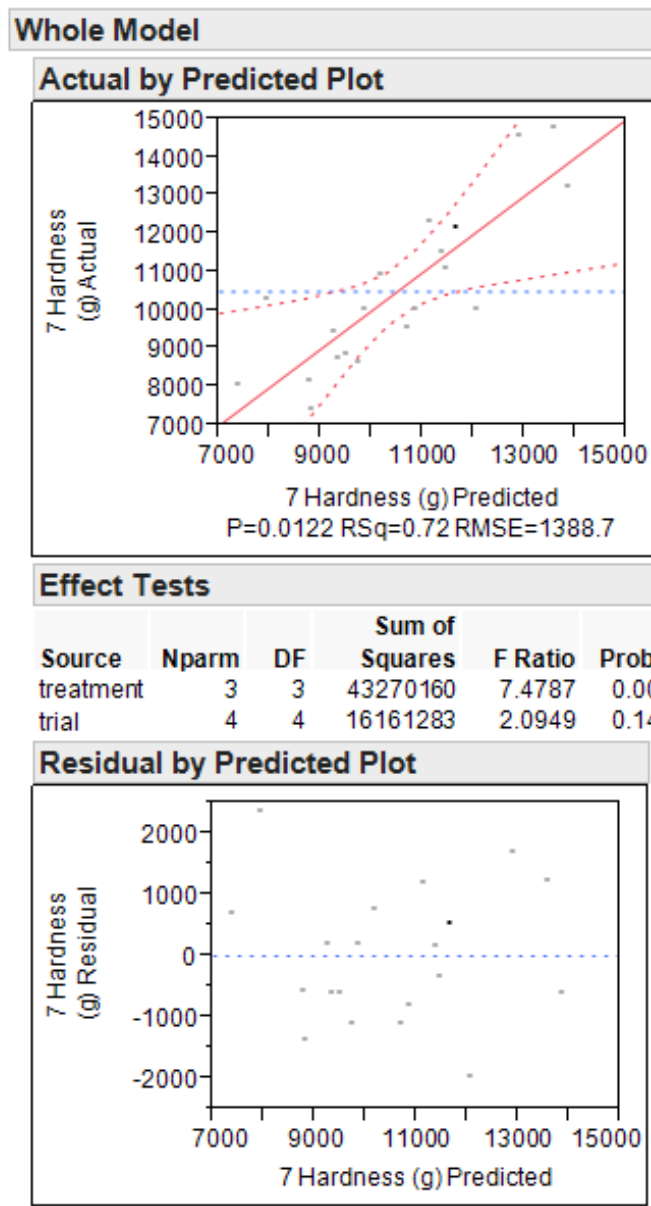

treatment

Least Squares Means Table

$\begin{array}{lrrr} & \text { Least } & & \\ \text { Level } & \text { Sq Mean } & \text { Std Error } & \text { Mean } \\ \text { 3NA } & 10554.072 & 621.06480 & 10554.1 \\ \text { EDTA } & 10046.818 & 621.06480 & 10046.8 \\ \text { FFC } & 8657.706 & 621.06480 & 8657.7 \\ \text { LFC } & 12747.598 & 621.06480 & 12747.6\end{array}$

LS Means Plot

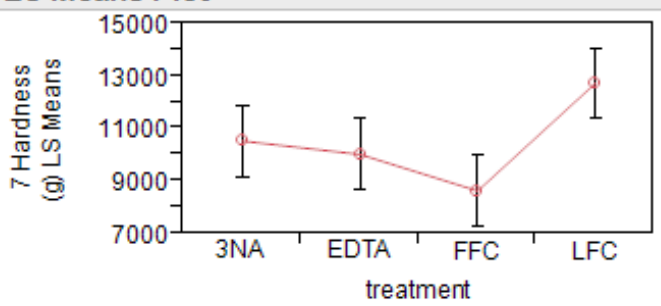

LSMeans Differences Tukey HSD

$\mathrm{a}=0.050 \quad \mathrm{Q}=2.9688$
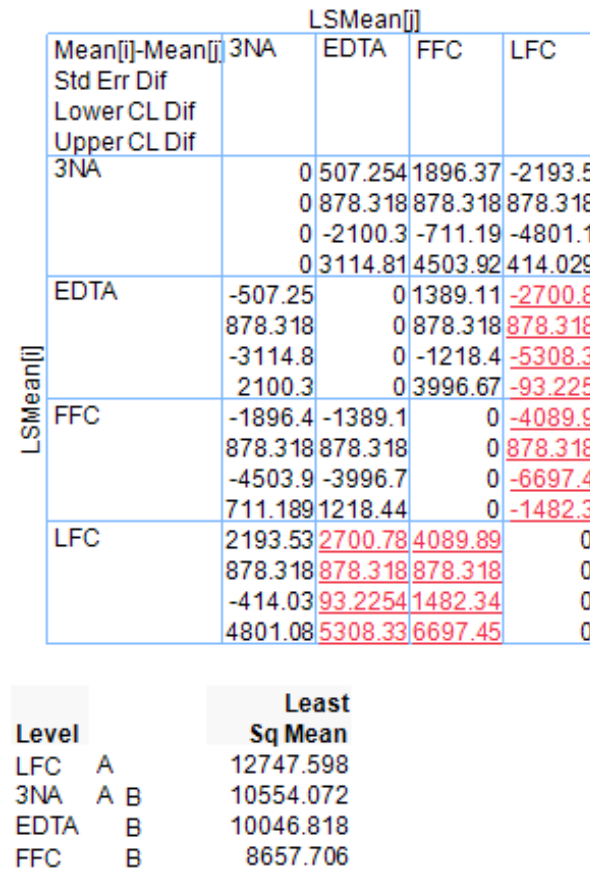

Levels not connected by same letter are significantly different. 
10. Statistical Data for TPA Hardness. Day 30

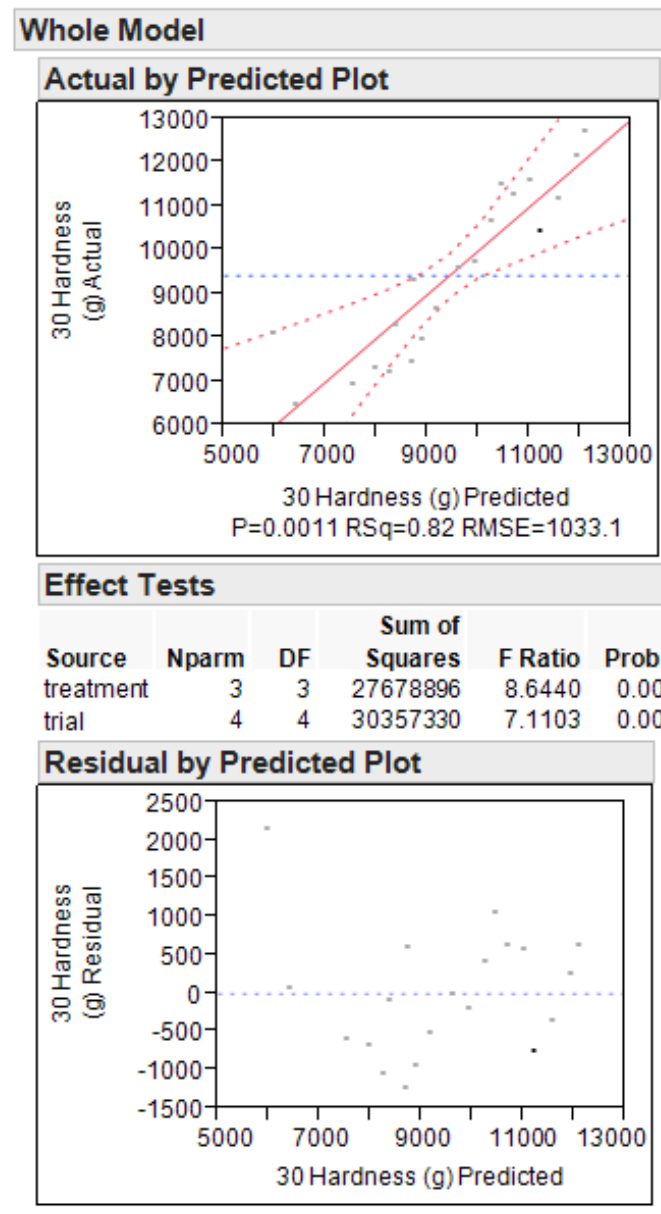

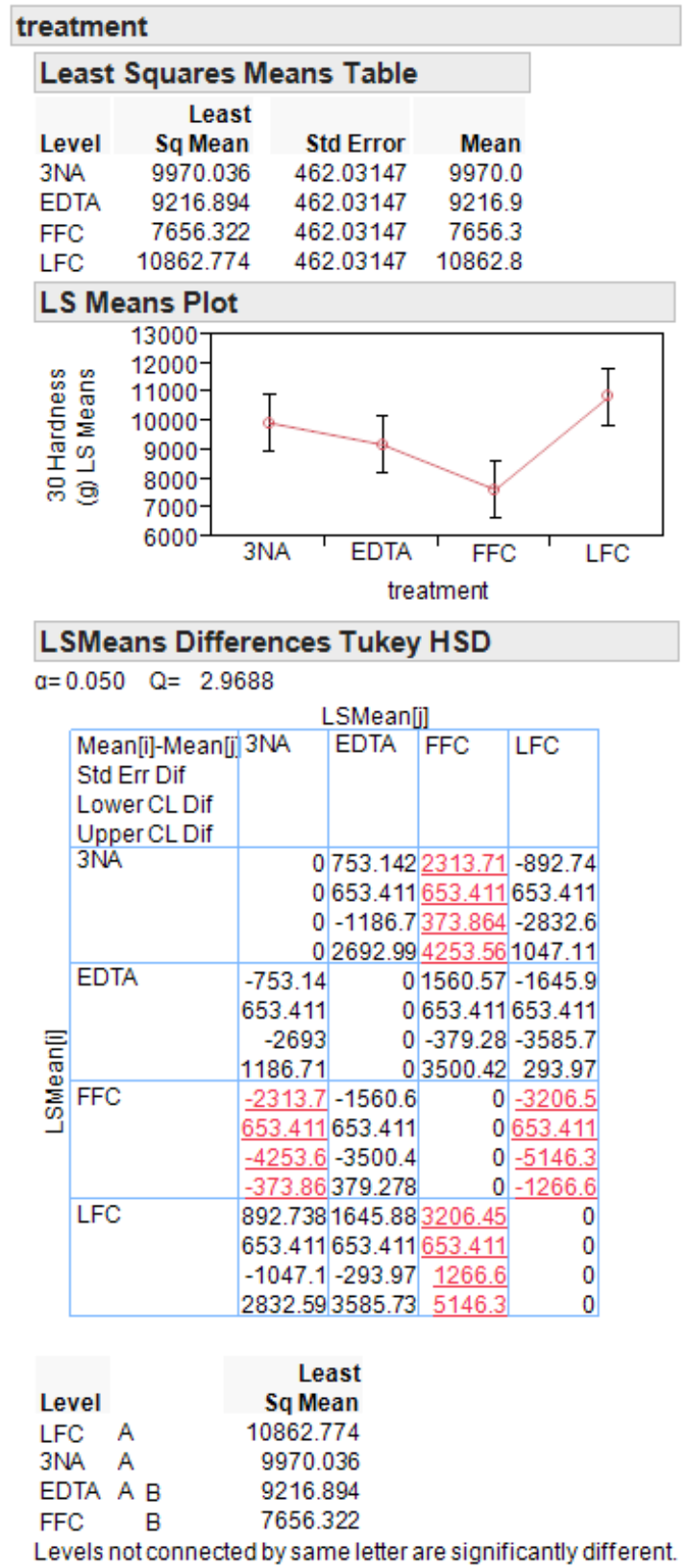




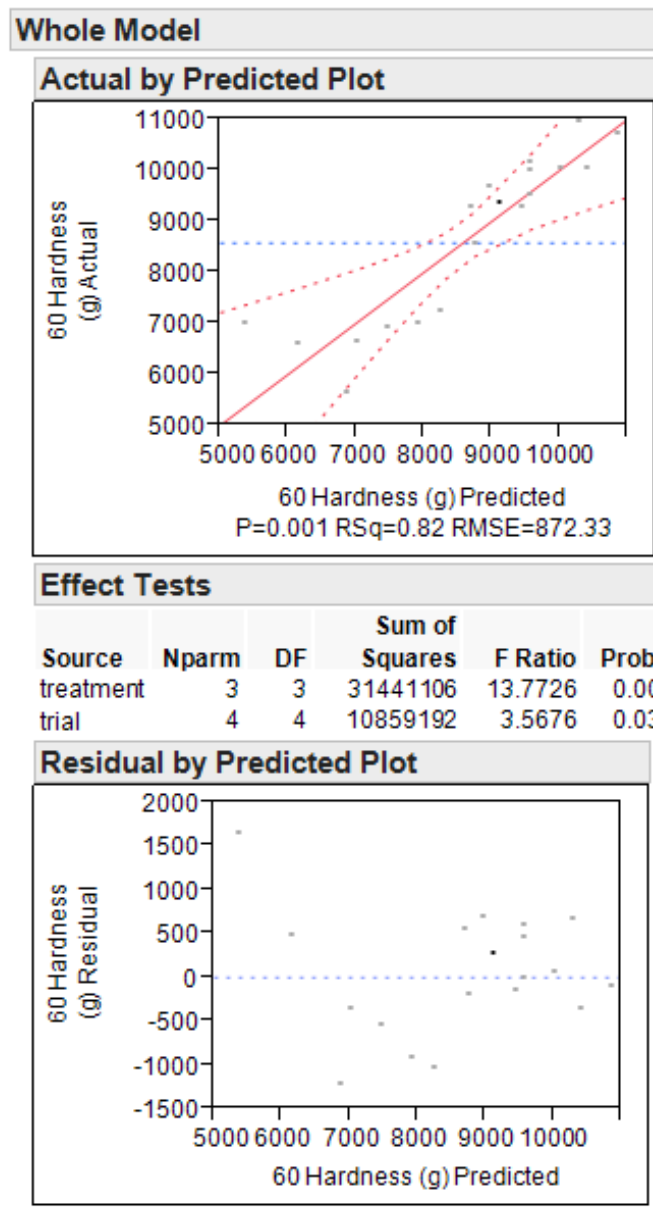

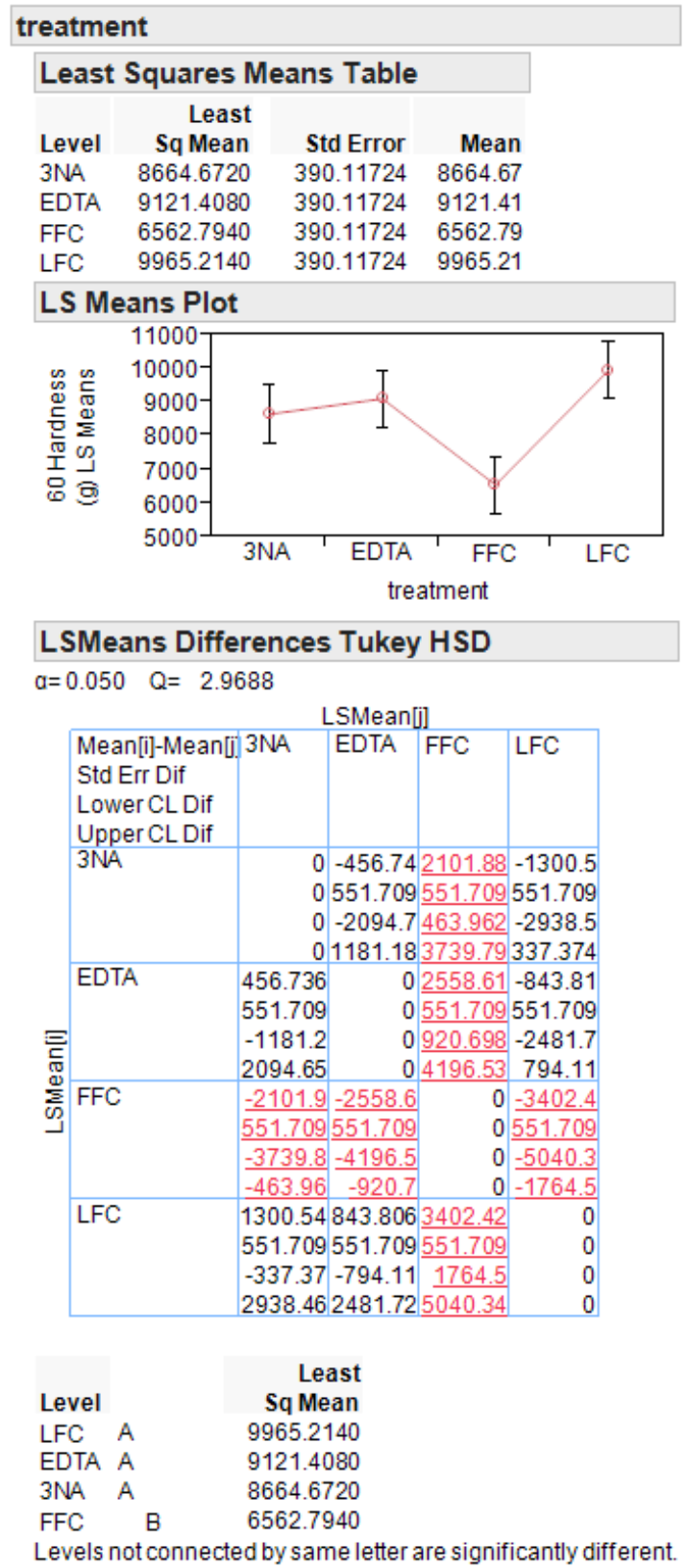


12. Statistical Data for TPA Hardness. Day 90

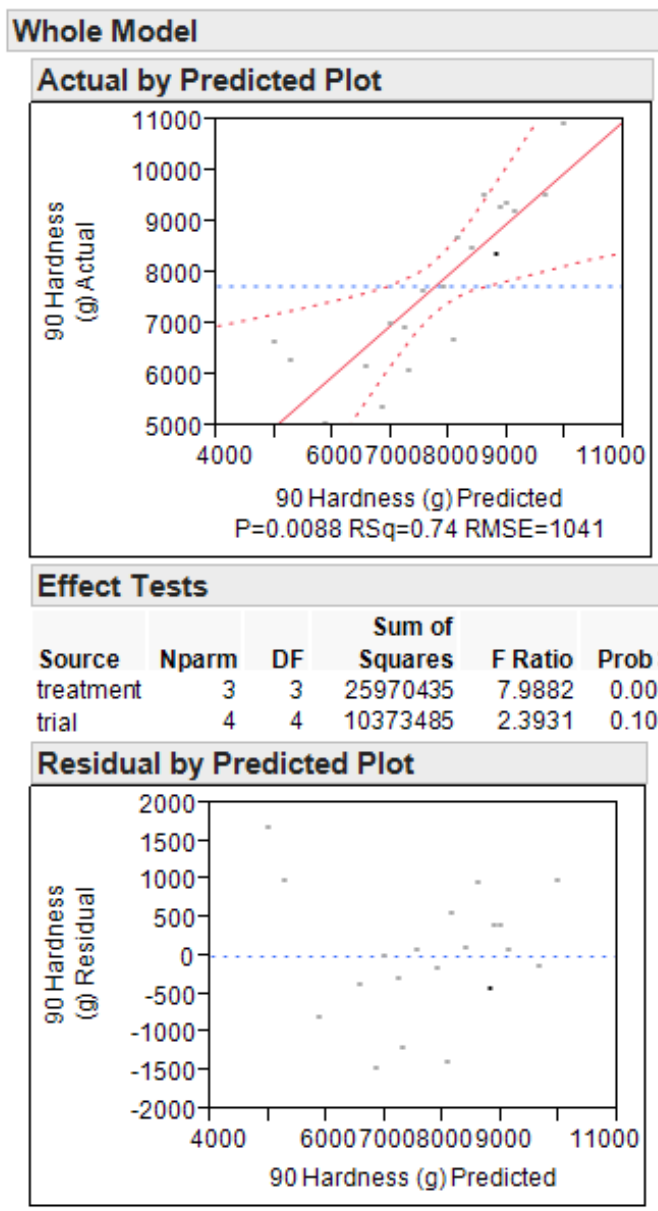

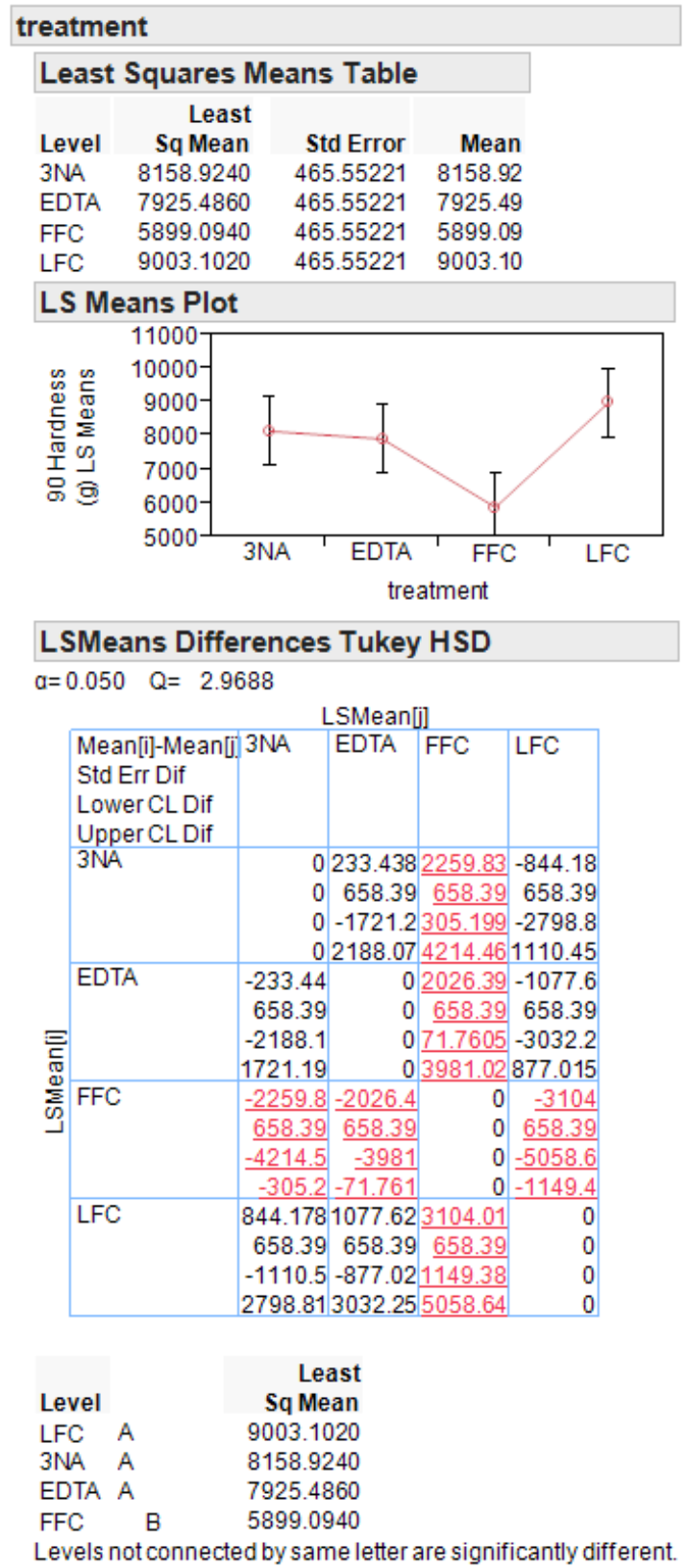


13. Statistical Data for Hardness. Day 120
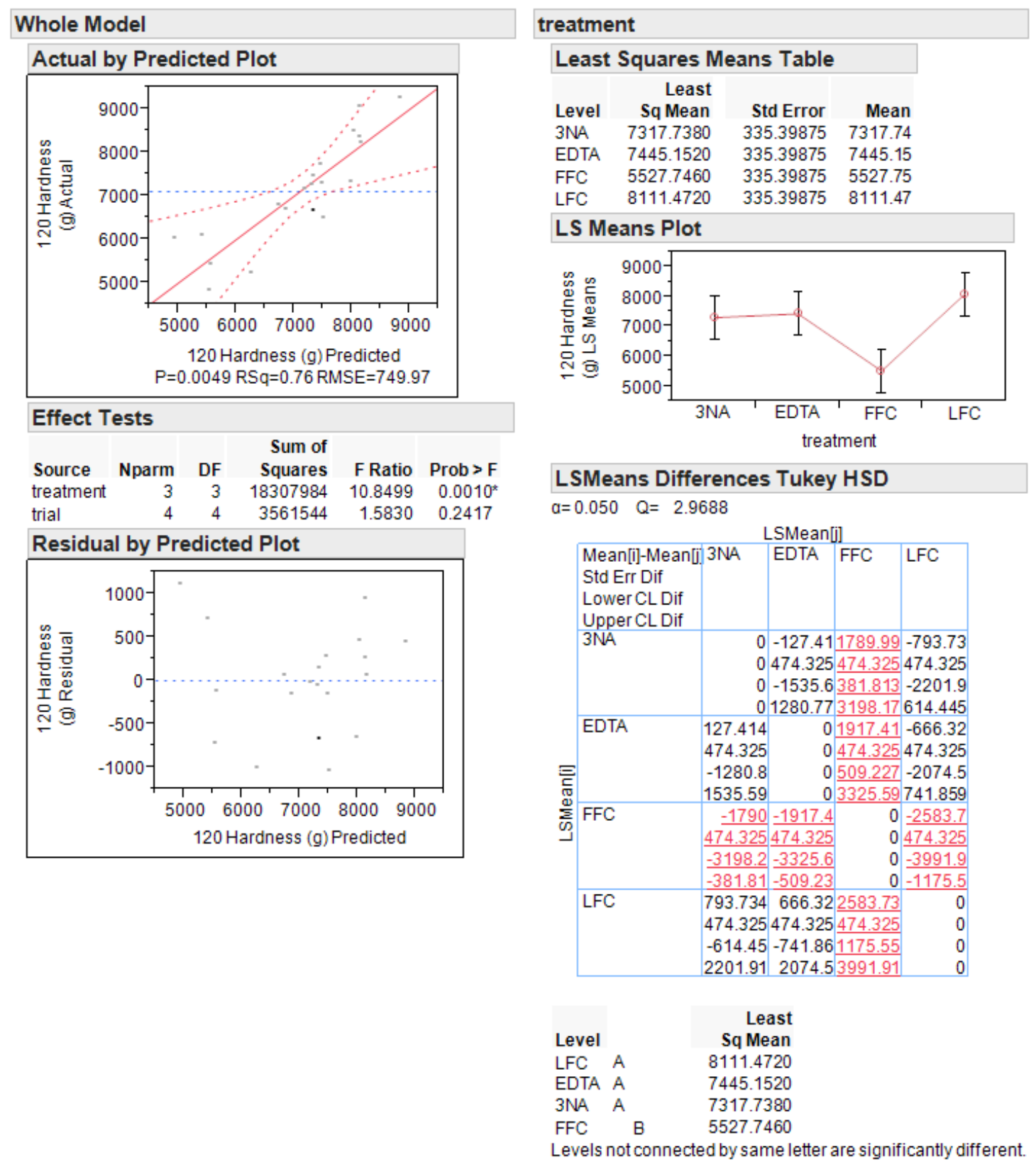


\section{Statistical Data for TPA Cohesiveness. Day 7}
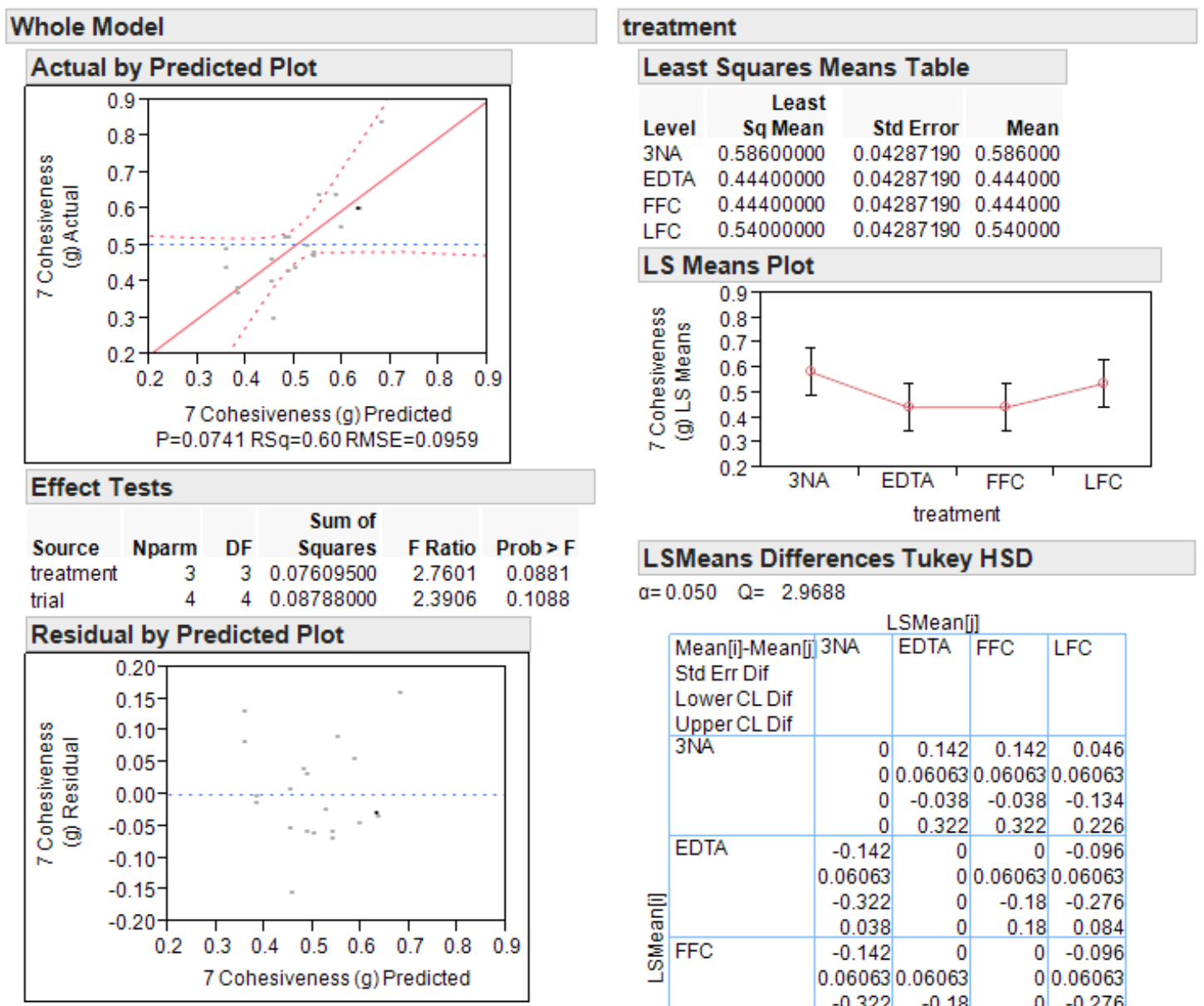

LSMeans Differences Tukey HSD $\mathrm{a}=0.050 \quad \mathrm{Q}=2.9688$

\begin{tabular}{|c|c|c|c|c|}
\hline \multicolumn{5}{|c|}{ LSMean[j] } \\
\hline \multirow{5}{*}{$\begin{array}{l}\text { Mean[i]-Mean[j. } \\
\text { Std Err Dif } \\
\text { Lower CL Dif } \\
\text { Upper CL Dif } \\
\text { 3NA }\end{array}$} & 3NA & EDTA & FFC & LFC \\
\hline & 0 & 0.142 & 0.142 & 0.046 \\
\hline & 0 & 0.06063 & 0.06063 & 0.06063 \\
\hline & 0 & -0.038 & -0.038 & -0.134 \\
\hline & 0 & 0.322 & 0.322 & 0.226 \\
\hline \multirow[t]{4}{*}{ EDTA } & -0.142 & 0 & 0 & -0.096 \\
\hline & 0.06063 & 0 & 0.06063 & 0.06063 \\
\hline & -0.322 & 0 & -0.18 & -0.276 \\
\hline & 0.038 & 0 & 0.18 & 0.084 \\
\hline \multirow[t]{4}{*}{ FFC } & -0.142 & 0 & 0 & -0.096 \\
\hline & 0.06063 & 0.06063 & 0 & 0.06063 \\
\hline & -0.322 & -0.18 & 0 & -0.276 \\
\hline & 0.038 & 0.18 & 0 & 0.084 \\
\hline \multirow[t]{4}{*}{ LFC } & -0.046 & 0.096 & 0.096 & 0 \\
\hline & 0.06063 & 0.06063 & 0.06063 & 0 \\
\hline & -0.226 & -0.084 & -0.084 & 0 \\
\hline & 0.134 & 0.276 & 0.276 & 0 \\
\hline
\end{tabular}

$\begin{array}{lcr}\text { Level } & \text { reast } \\ \text { 3NA } & \text { A } & \begin{array}{r}\text { Lq Mean } \\ \text { Sq }\end{array} \\ \text { LFC } & \text { A } & 0.58600000 \\ \text { EDTA } & \text { A } & 0.54000000 \\ \text { FFC } & \text { A } & 0.44400000 \\ \text { L } & & 0.4400000\end{array}$

Levels not connected by same letter are significantly different. 
15. Statistical Data for TPA Cohesiveness. Day 30
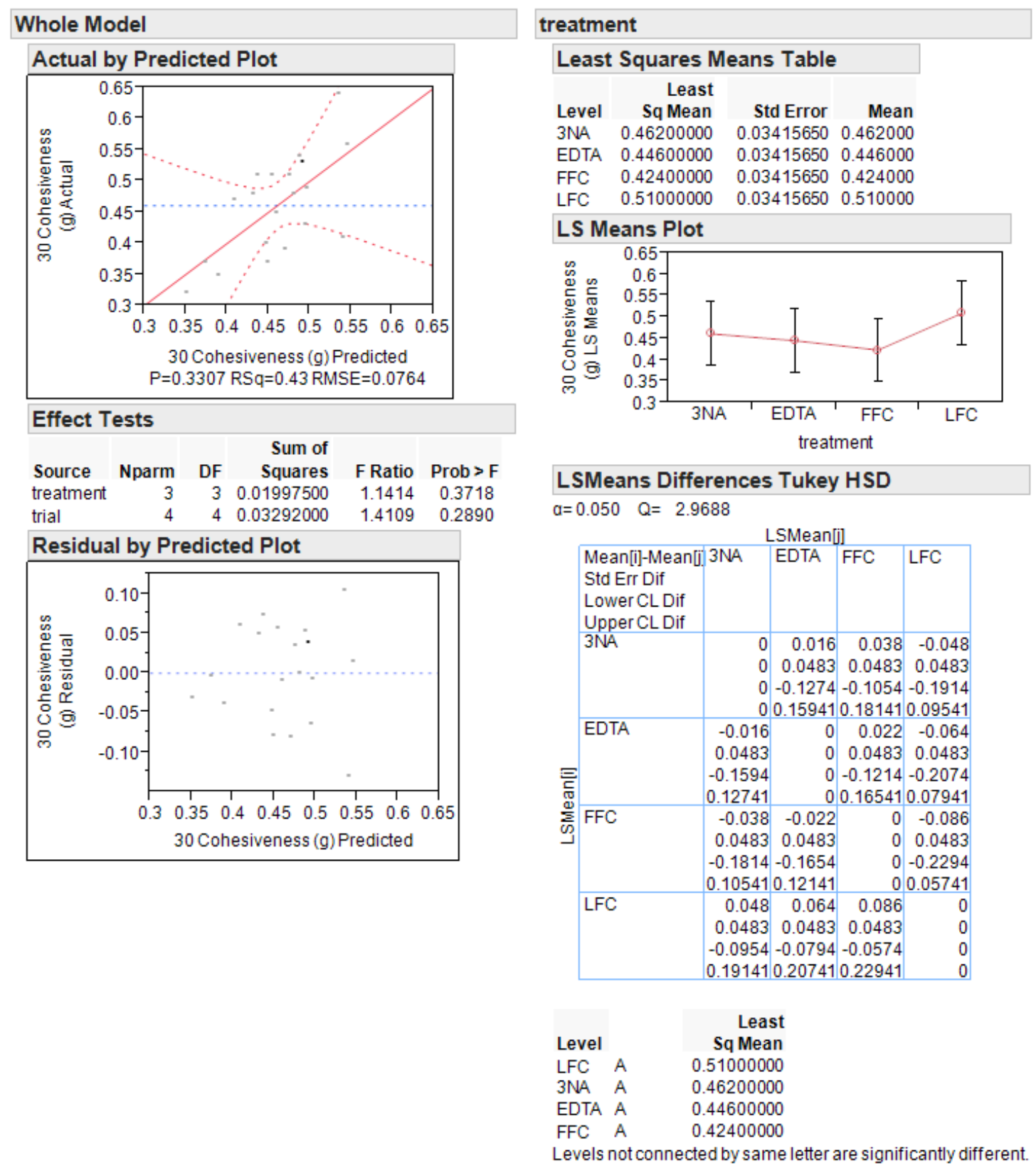
16. Statistical Data for TPA Cohesiveness. Day 60

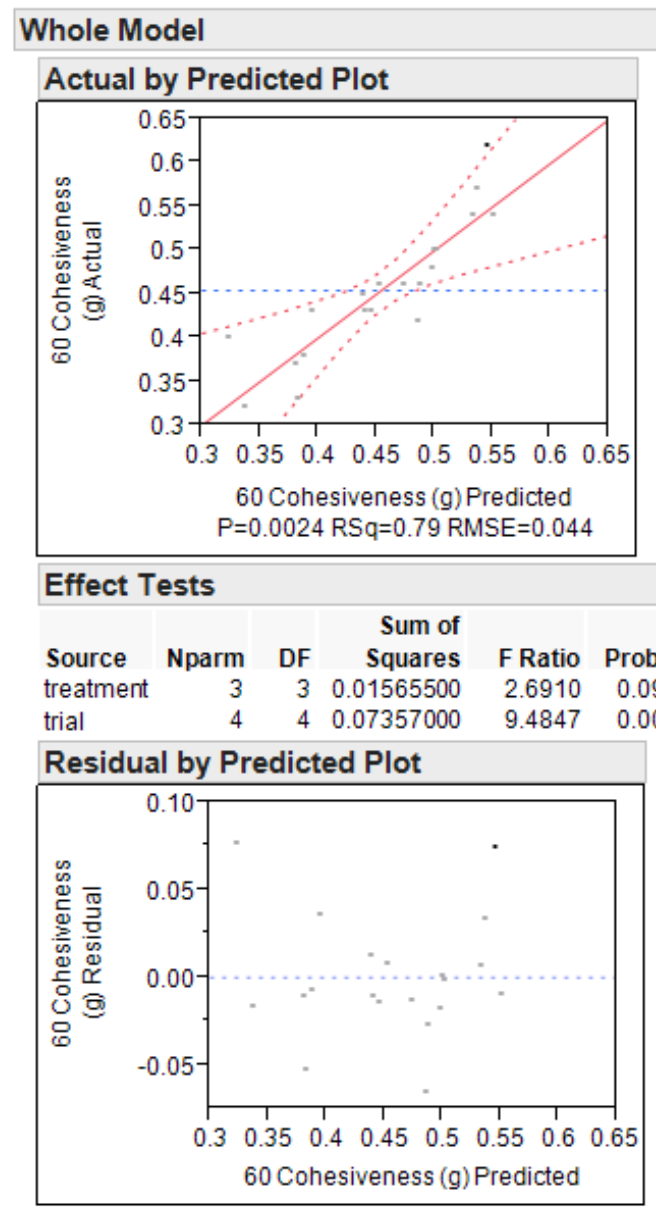

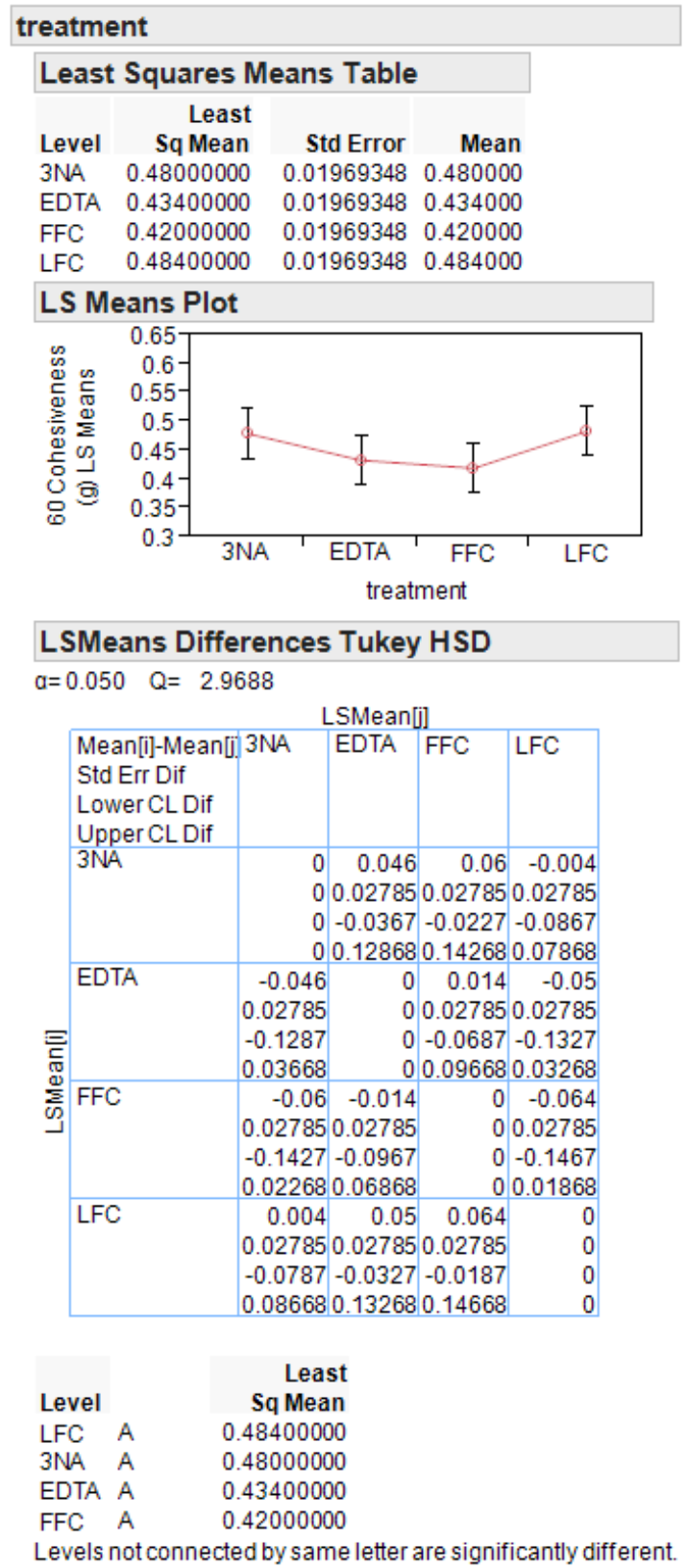



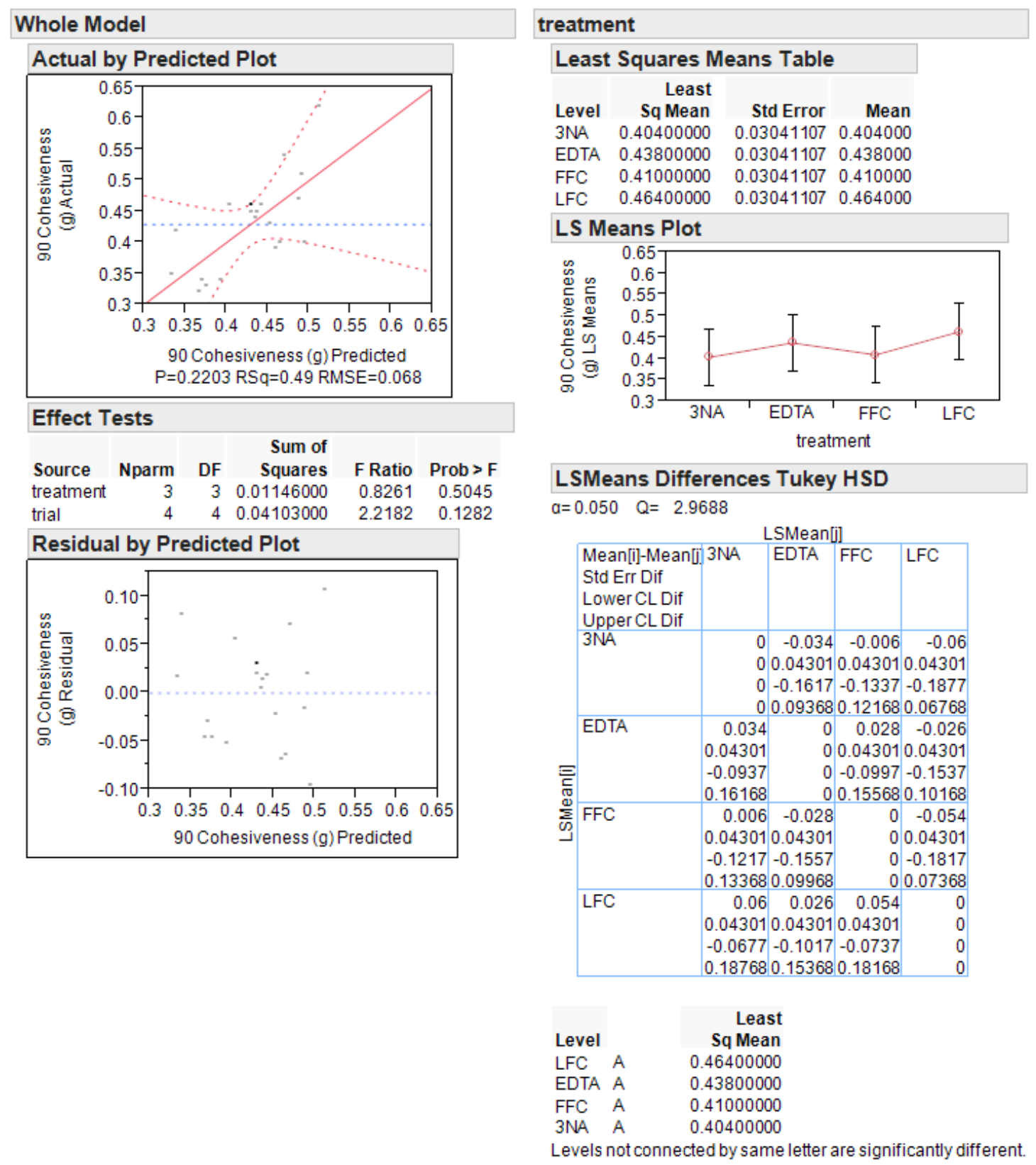


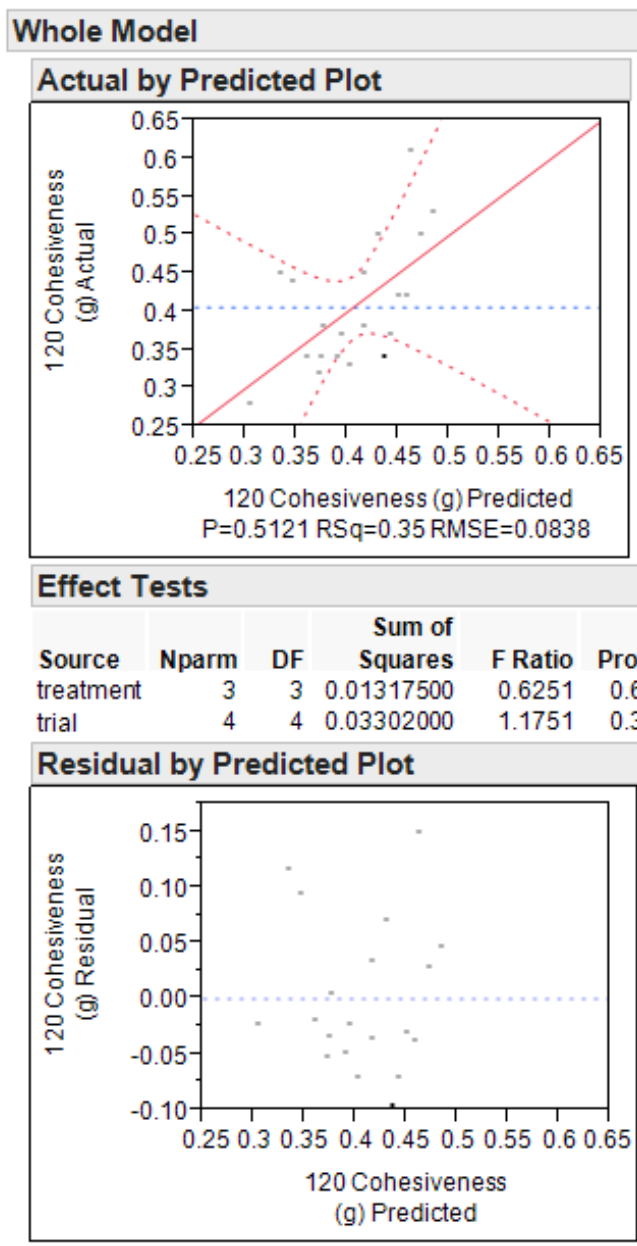

treatment

Least Squares Means Table

$\begin{array}{lrrr}\text { Level } & \begin{array}{r}\text { Least } \\ \text { Sq Mean }\end{array} & \text { Std Error } & \text { Mean } \\ \text { 3NA } & 0.40600000 & 0.03748333 & 0.406000 \\ \text { EDTA } & 0.36400000 & 0.03748333 & 0.364000 \\ \text { FFC } & 0.42000000 & 0.03748333 & 0.420000 \\ \text { LFC } & 0.43200000 & 0.03748333 & 0.432000\end{array}$

LS Means Plot

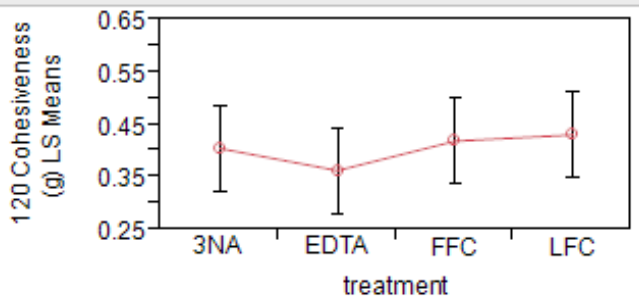

LSMeans Differences Tukey HSD $\mathrm{a}=0.050 \quad \mathrm{Q}=2.9688$

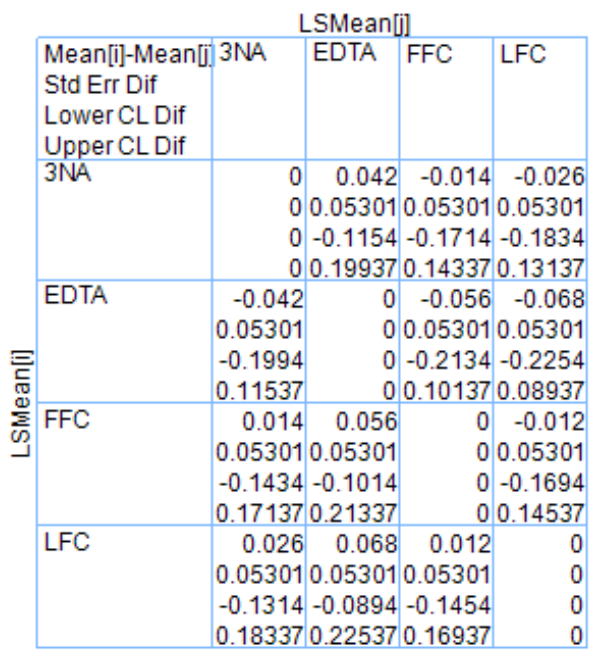

$\begin{array}{lrr}\text { Level } & \begin{array}{r}\text { Least } \\ \text { Sq Mean }\end{array} \\ \text { LFC A } & 0.43200000 \\ \text { FFC } & \text { A } & 0.42000000 \\ \text { 3NA } & \text { A } & 0.40600000 \\ \text { EDTA } & \text { A } & 0.36400000\end{array}$

Levels not connected by same letter are significantly different. 


\section{Statistical Data for TPA Springiness. Day 7}

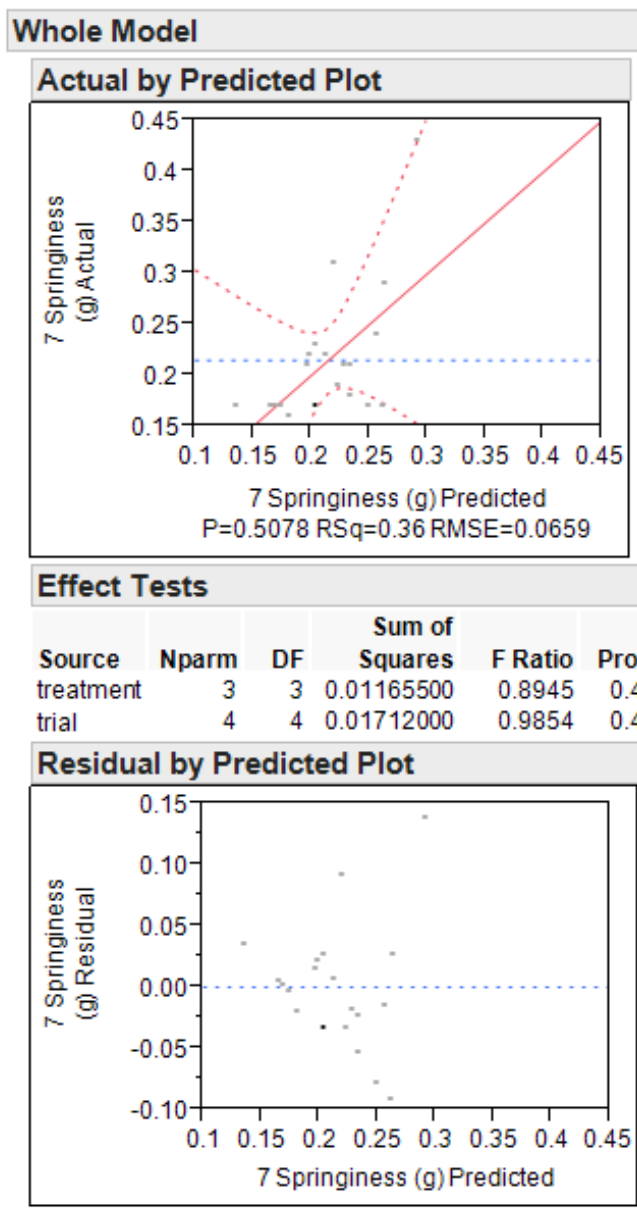

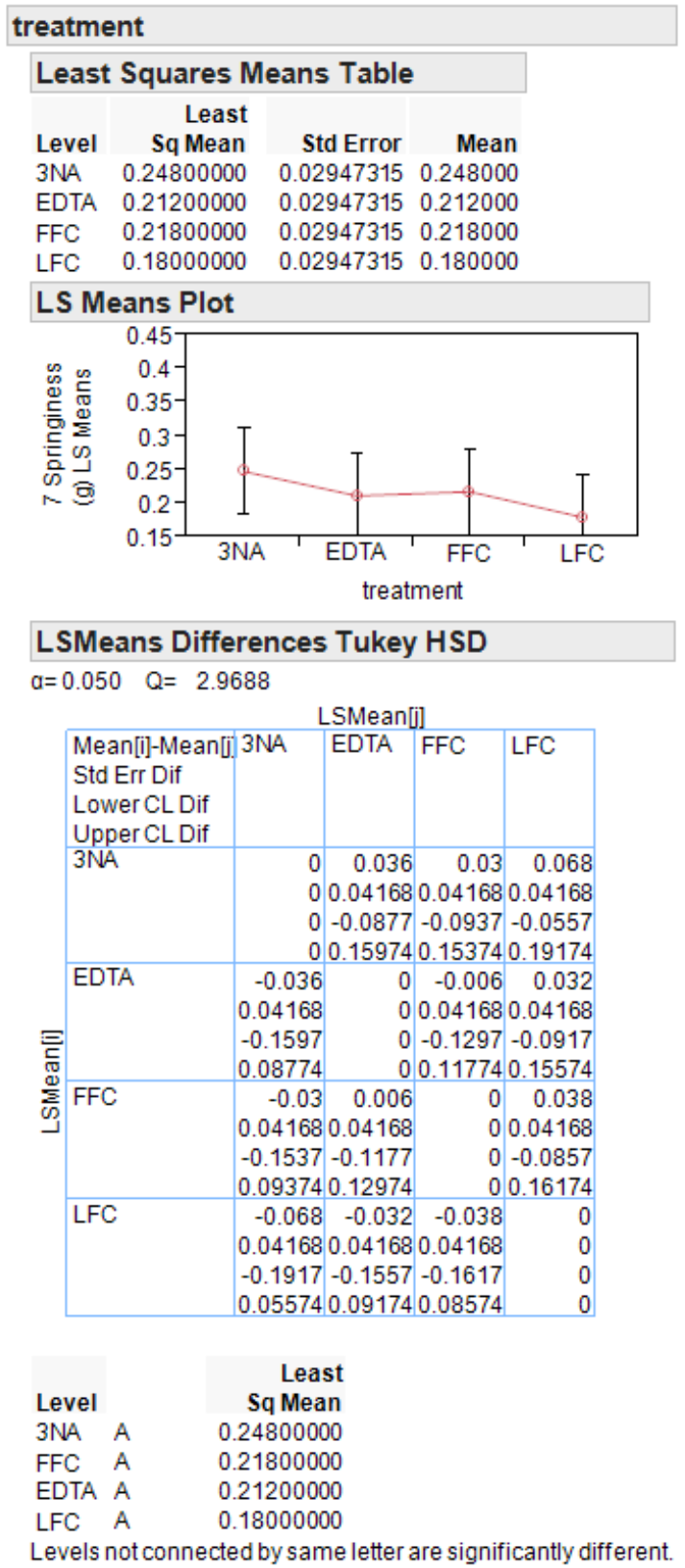


20. Statistical Data for TPA Springiness. Day 30
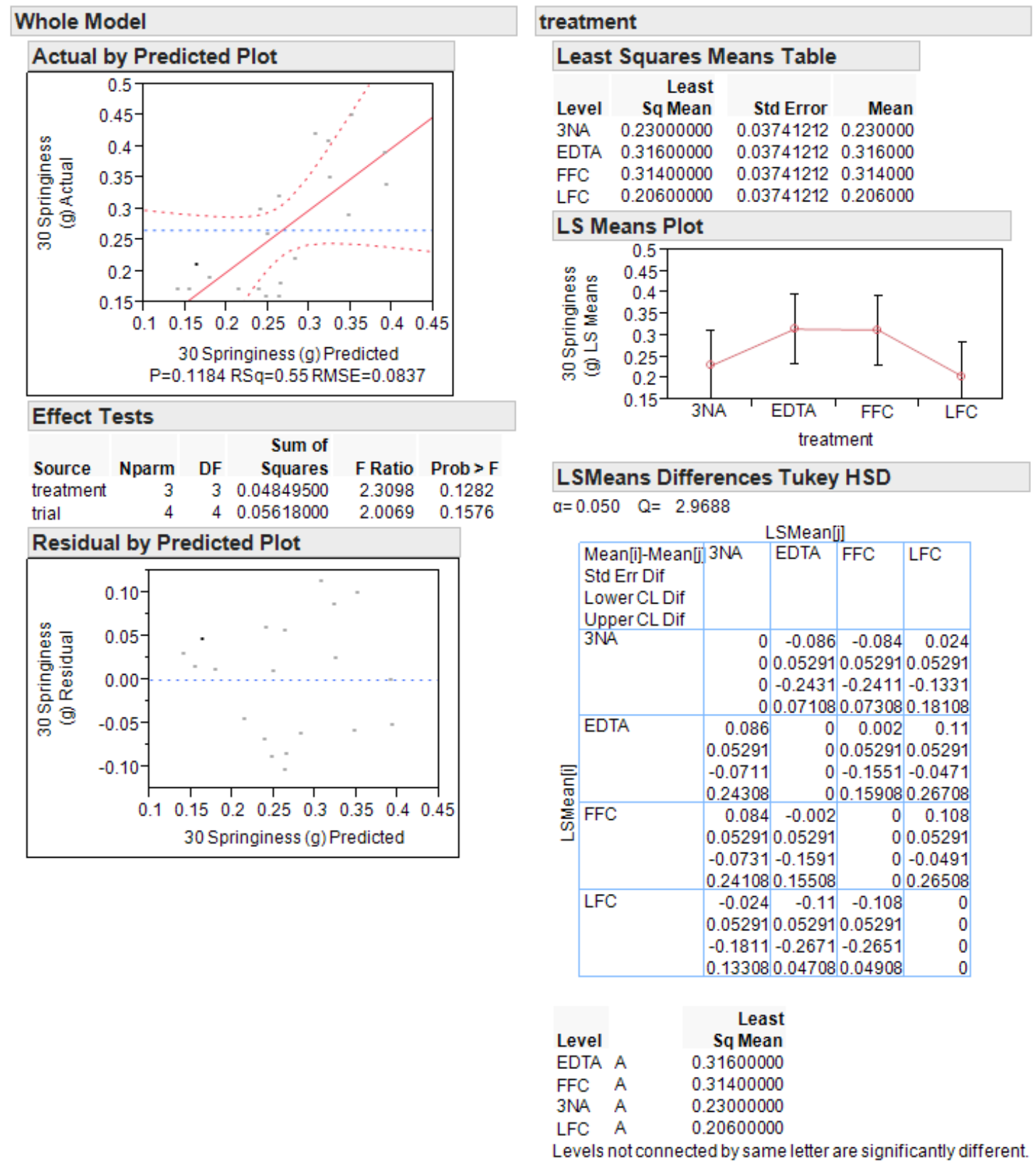
21. Statistical Data for TPA Springiness. Day 60
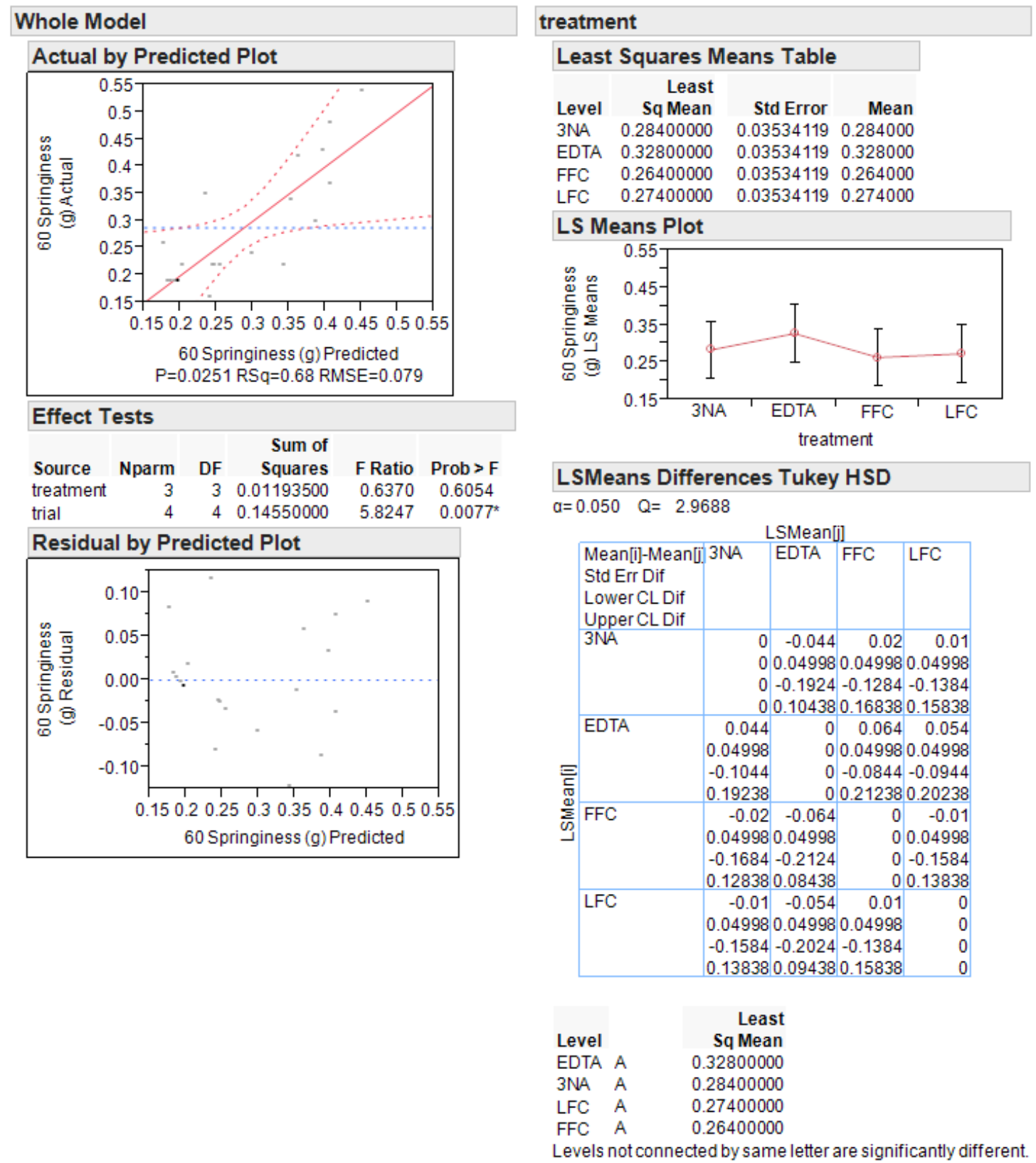
22. Statistical Data for TPA Springiness. Day 90

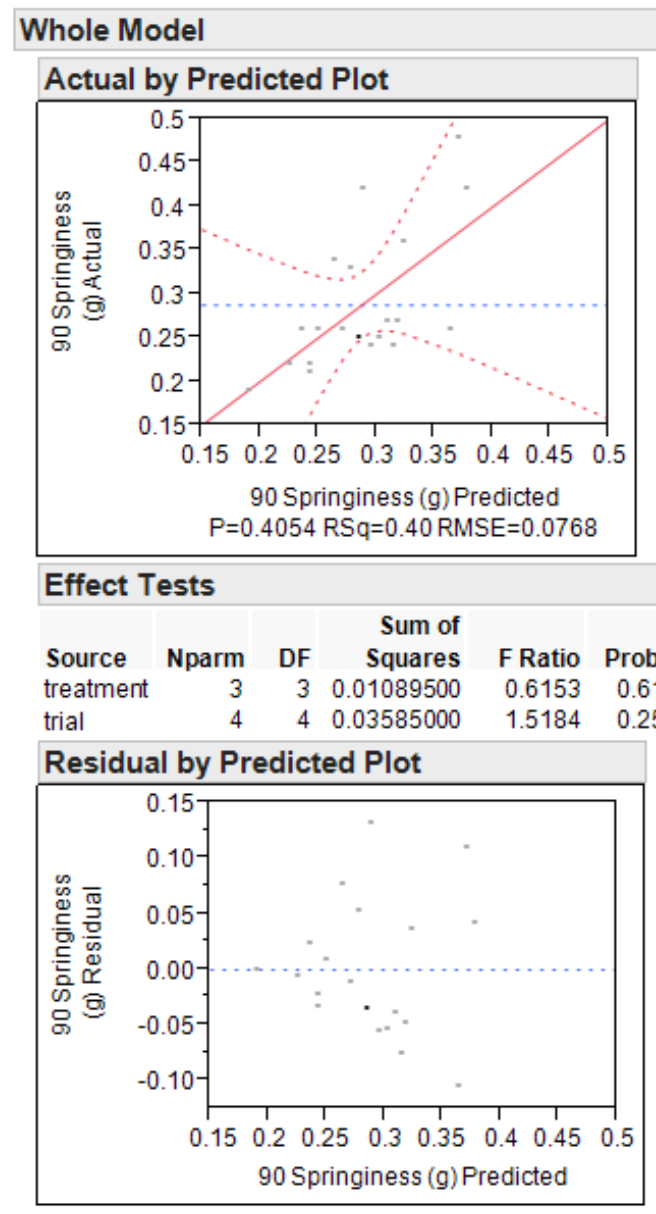

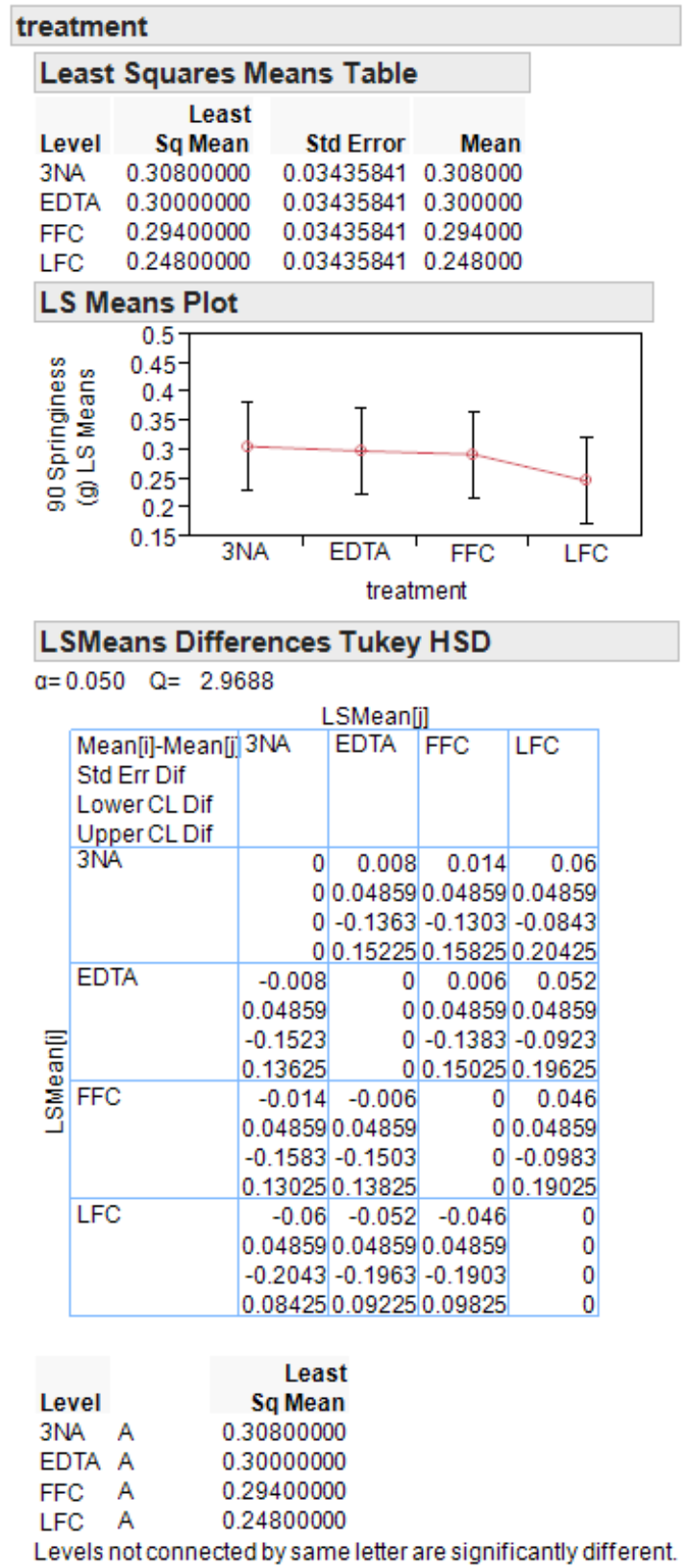



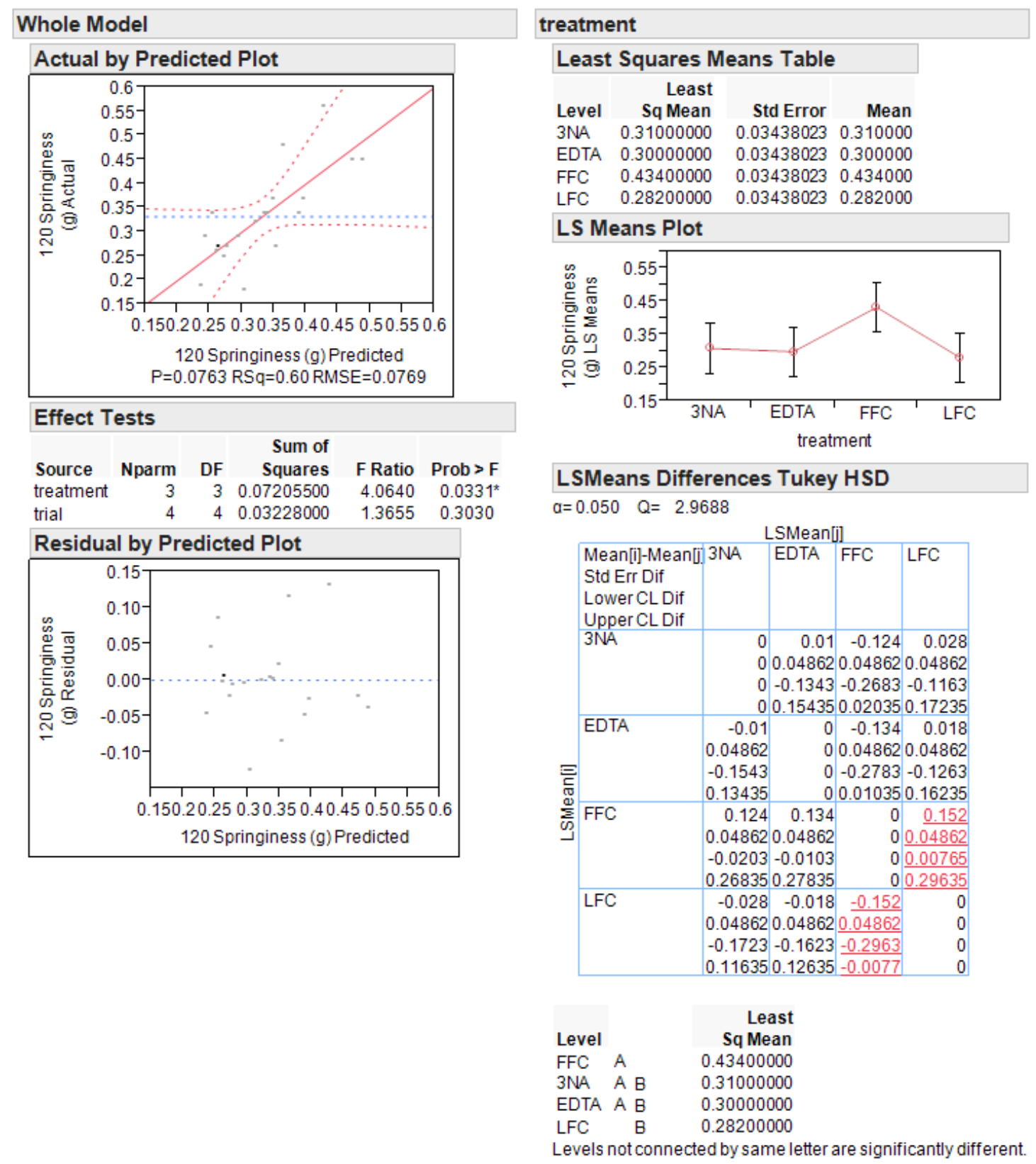
24. Statistical Data for TPA Gumminess. Day 7
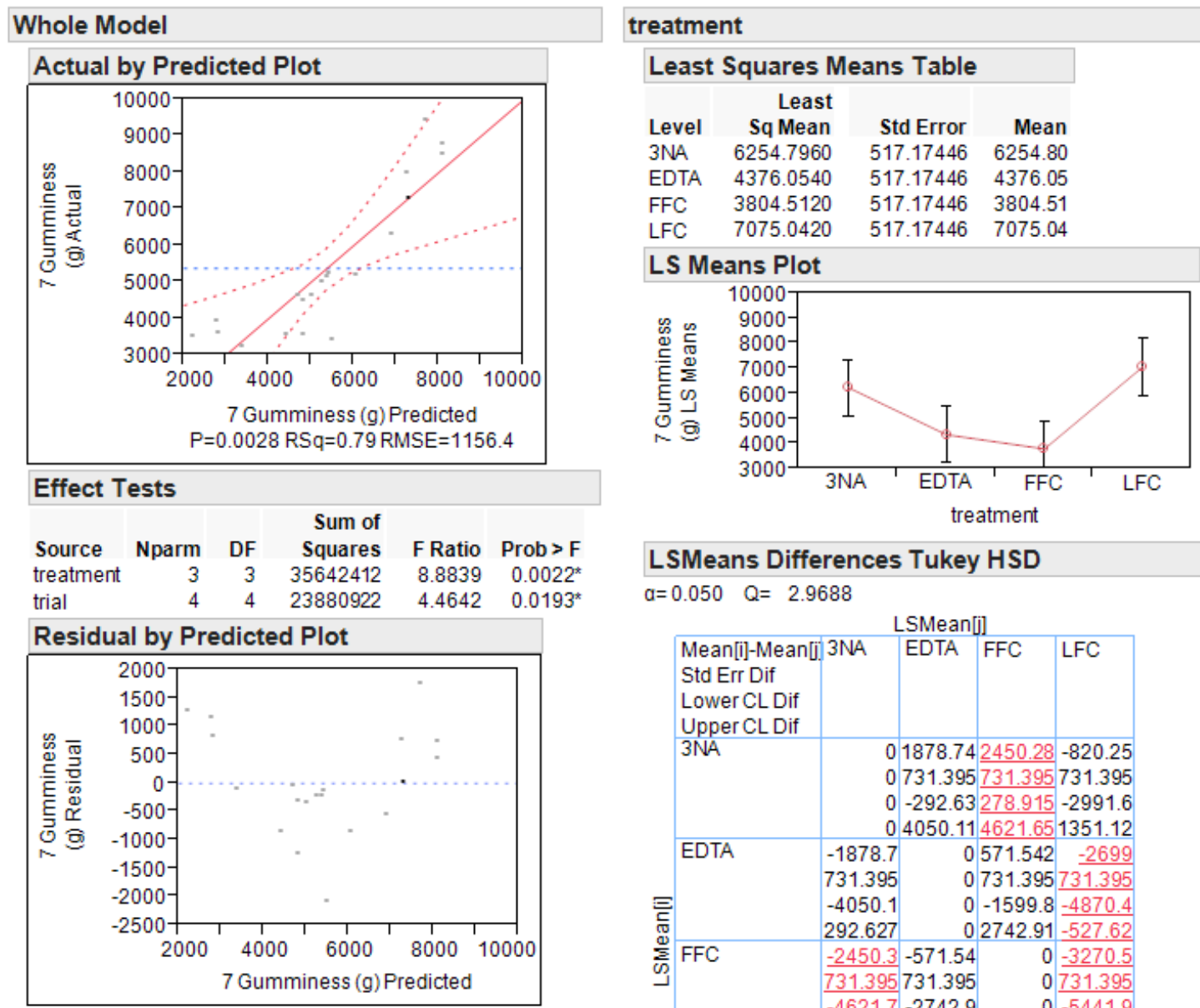

LSMeans Differences Tukey HSD $\mathrm{a}=0.050 \quad \mathrm{Q}=2.9688$
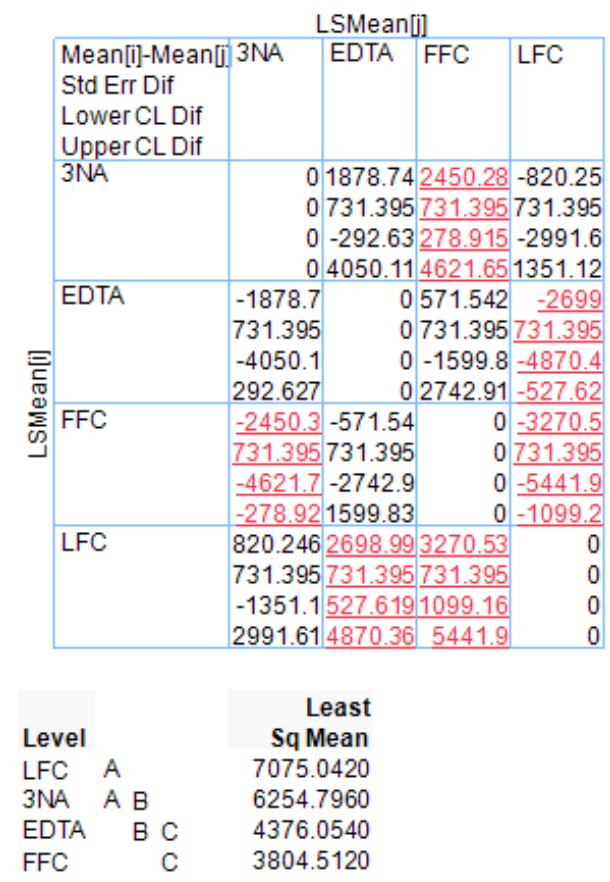

Levels not connected by same letter are significantly different. 
25. Statistical Data for TPA Gumminess. Day 60
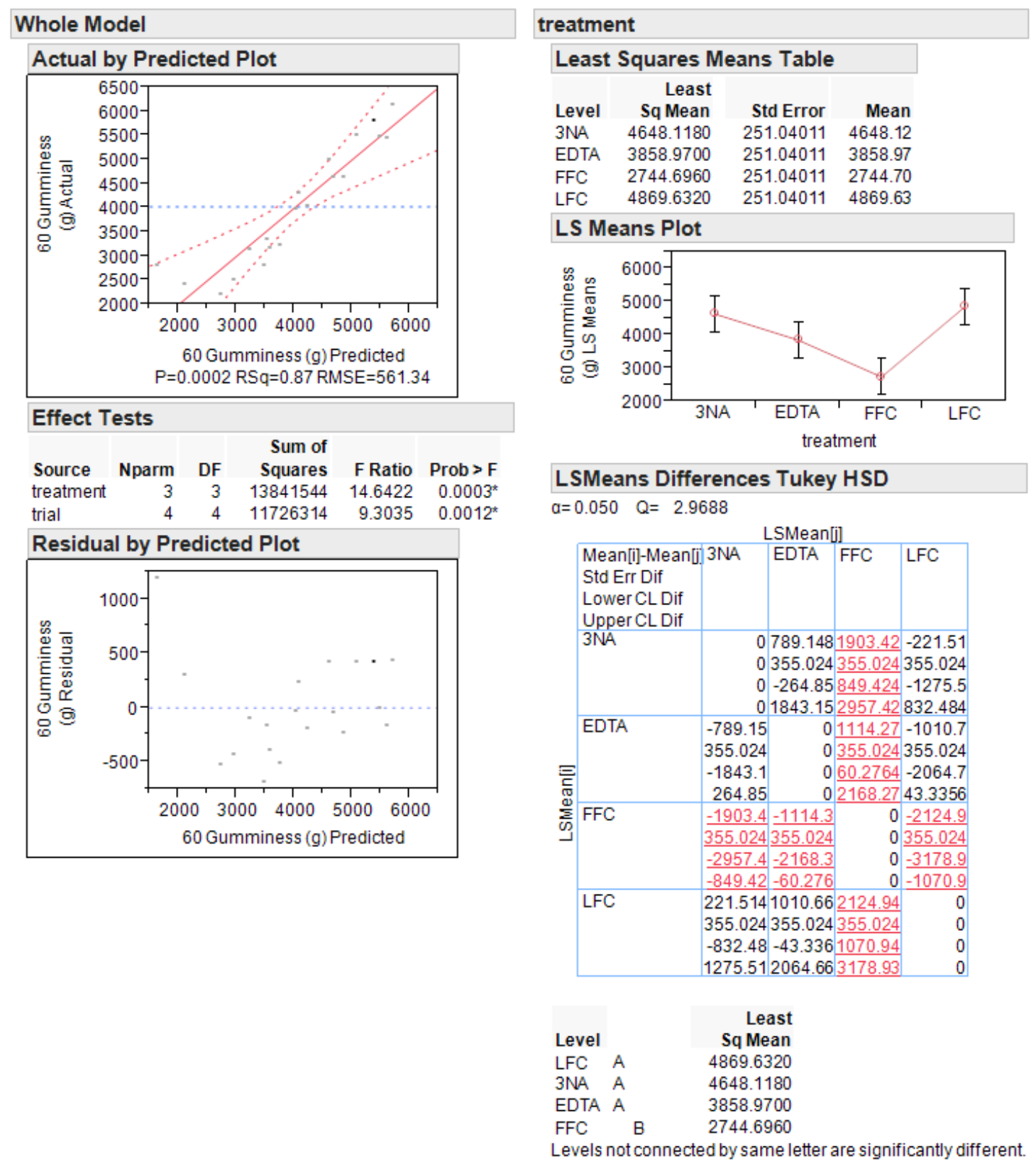
26. Statistical Data for TPA Gumminess. Day 90
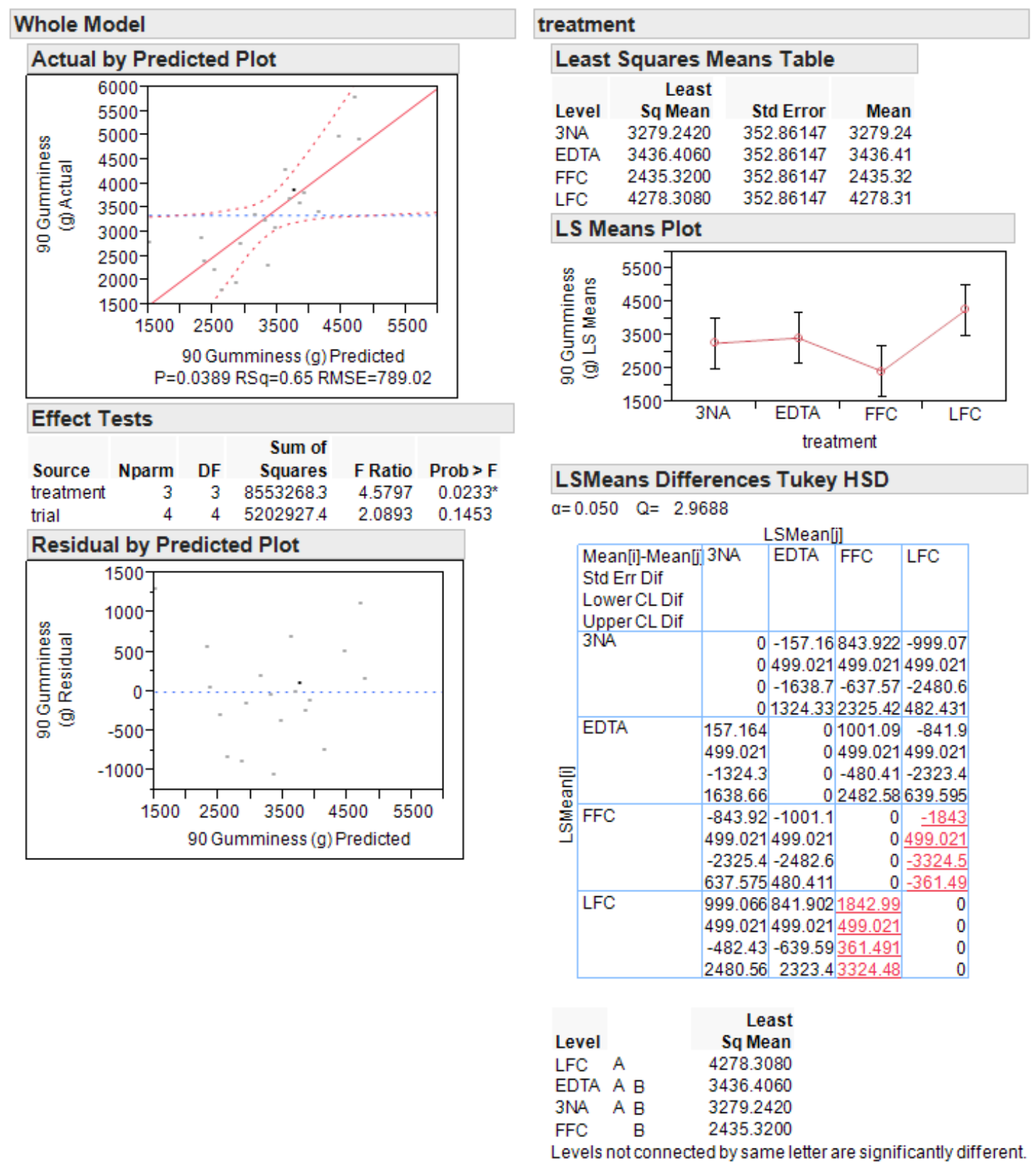
27. Statistical Data for TPA Gumminess. Day 120

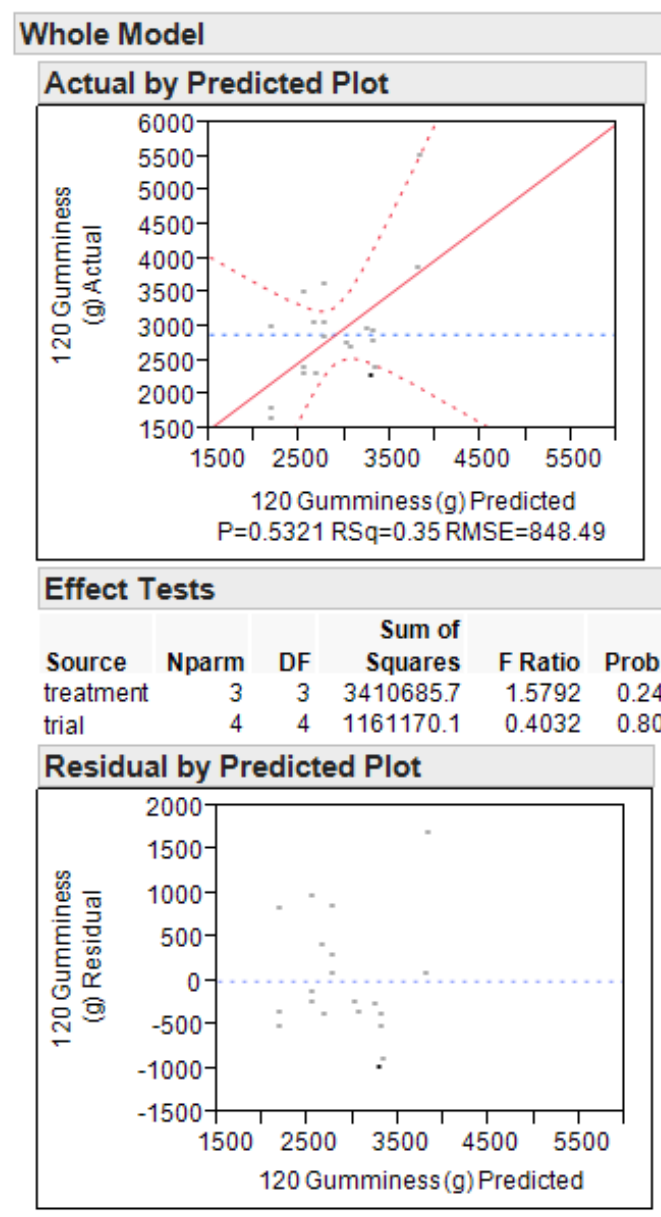




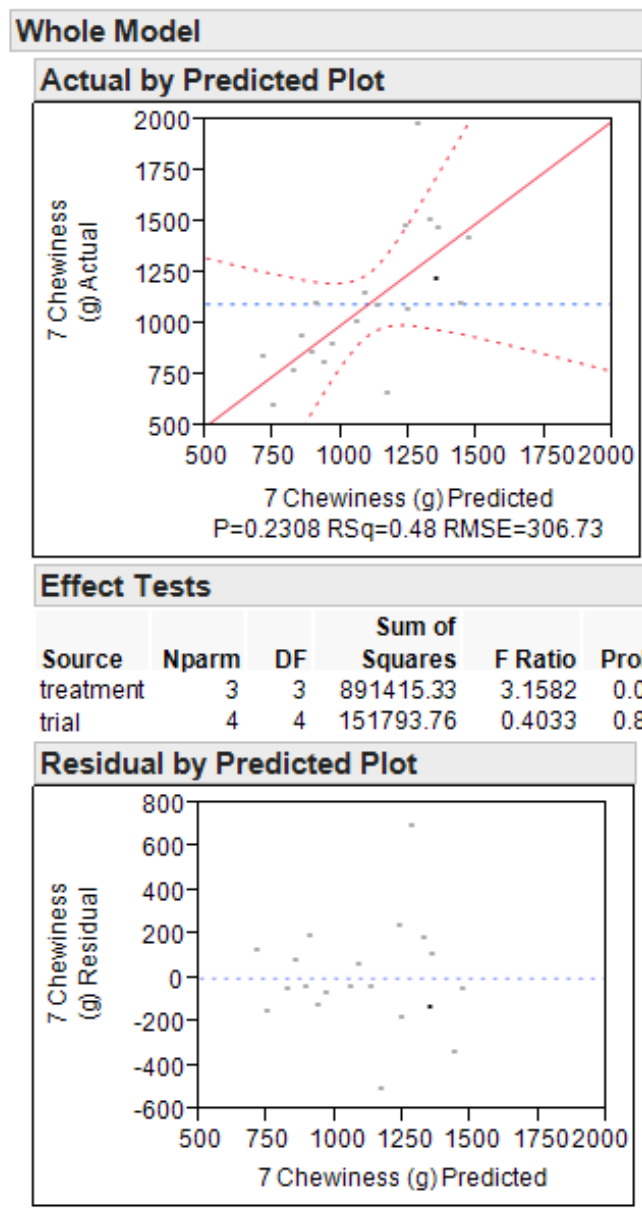

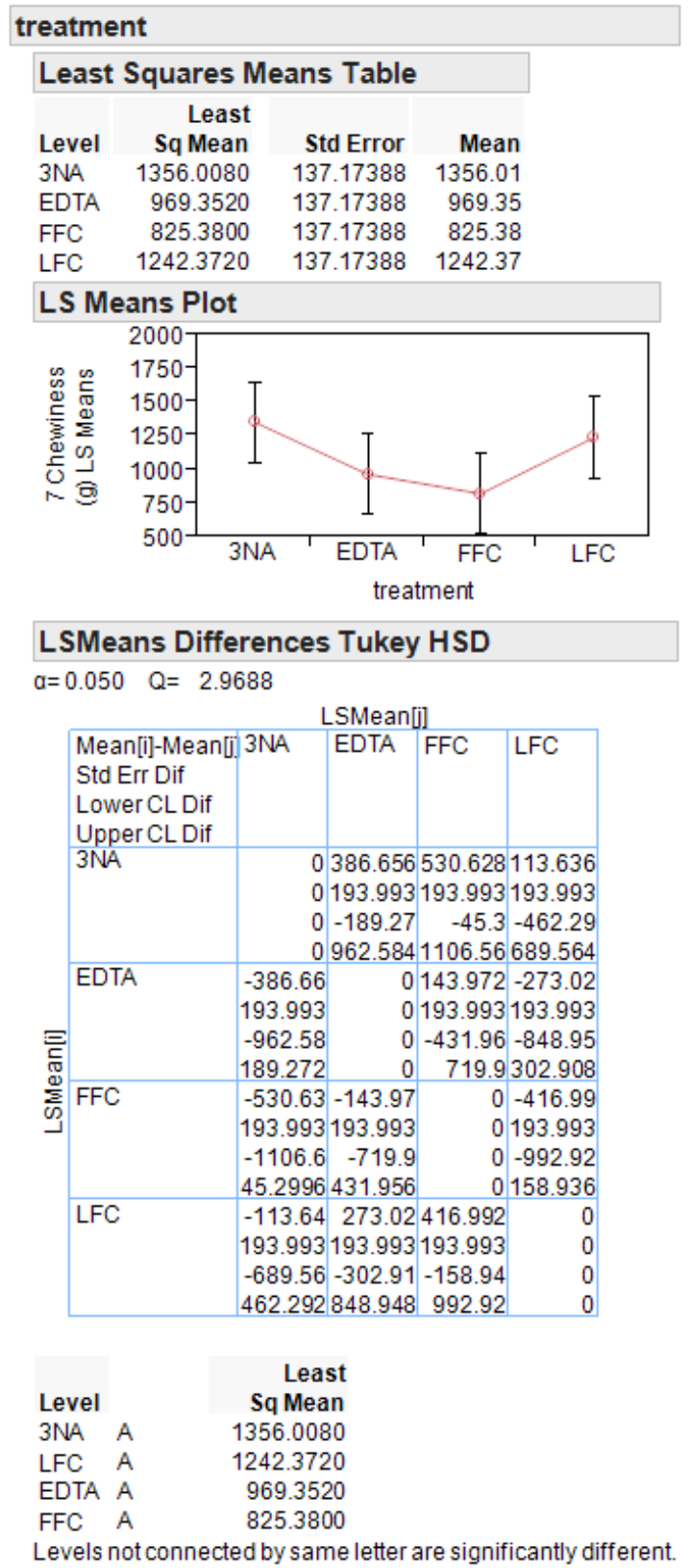


29. Statistical Data for TPA Chewiness. Day 30

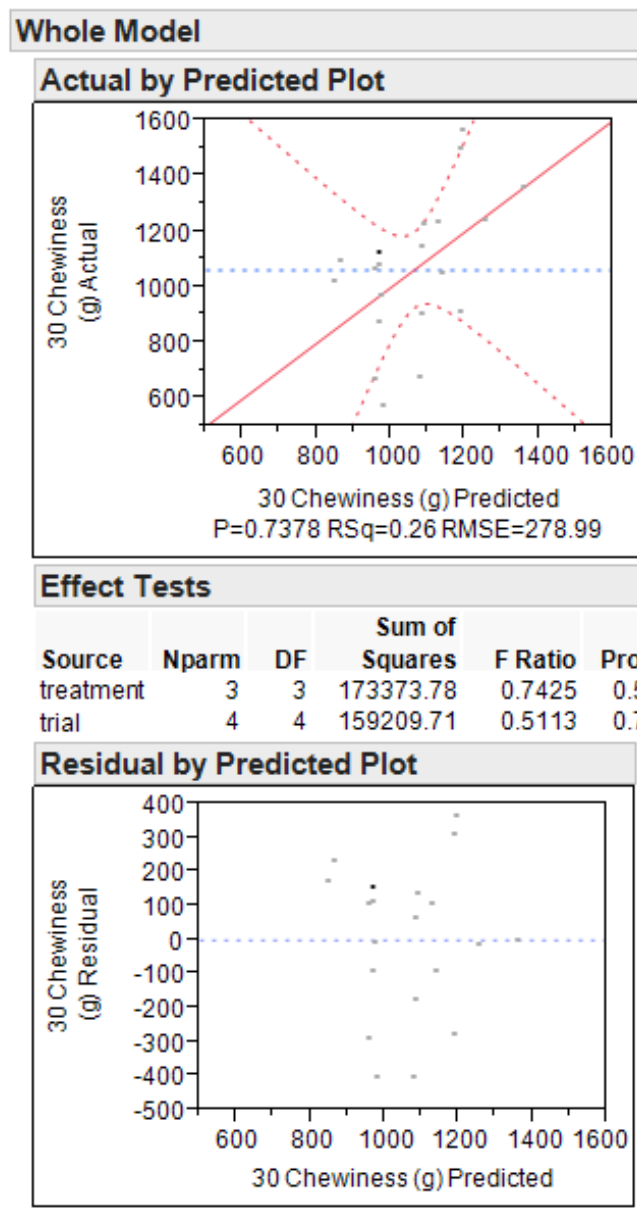

\begin{tabular}{|c|c|c|c|}
\hline \multicolumn{4}{|c|}{ treatment } \\
\hline \multicolumn{4}{|c|}{ Least Squares Means Table } \\
\hline Level & $\begin{array}{r}\text { Least } \\
\text { Sq Mean }\end{array}$ & Std Error & Mean \\
\hline $3 \mathrm{NA}$ & 983.5500 & 124.77033 & 983.55 \\
\hline EDTA & 1200.2680 & 124.77033 & 1200.27 \\
\hline FFC & 971.0280 & 124.77033 & 971.03 \\
\hline LFC & 1095.5840 & 124.77033 & 1095.58 \\
\hline
\end{tabular}

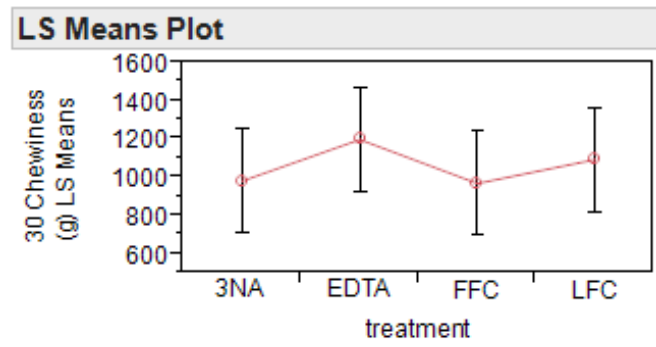

LSMeans Differences Tukey HSD $\mathrm{Q}=0.050 \mathrm{Q}=2.9688$

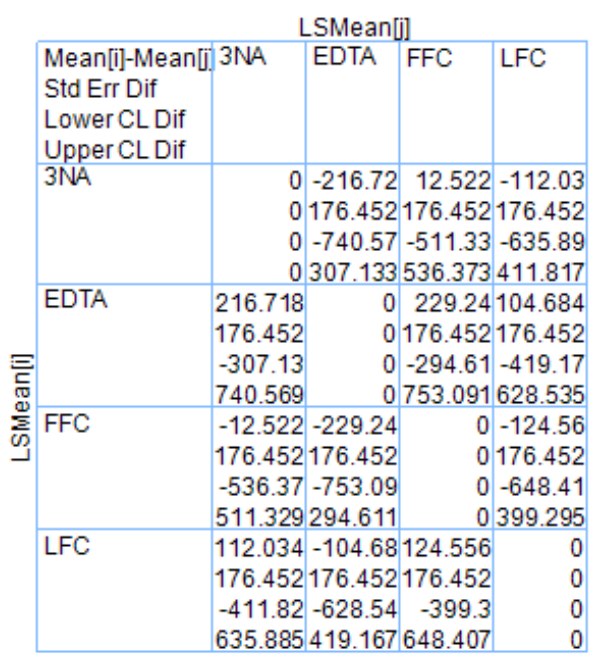

$\begin{array}{lrr}\text { Level } & \begin{array}{r}\text { Least } \\ \text { Sq Mean }\end{array} \\ \text { EDTA } & \text { A } & 1200.2680 \\ \text { LFC } & \text { A } & 1095.5840 \\ \text { 3NA } & \text { A } & 983.5500 \\ \text { FFC } & \text { A } & 971.0280\end{array}$

Levels not connected by same letter are significantly different. 
30. Statistical Data for TPA Chewiness. Day 60
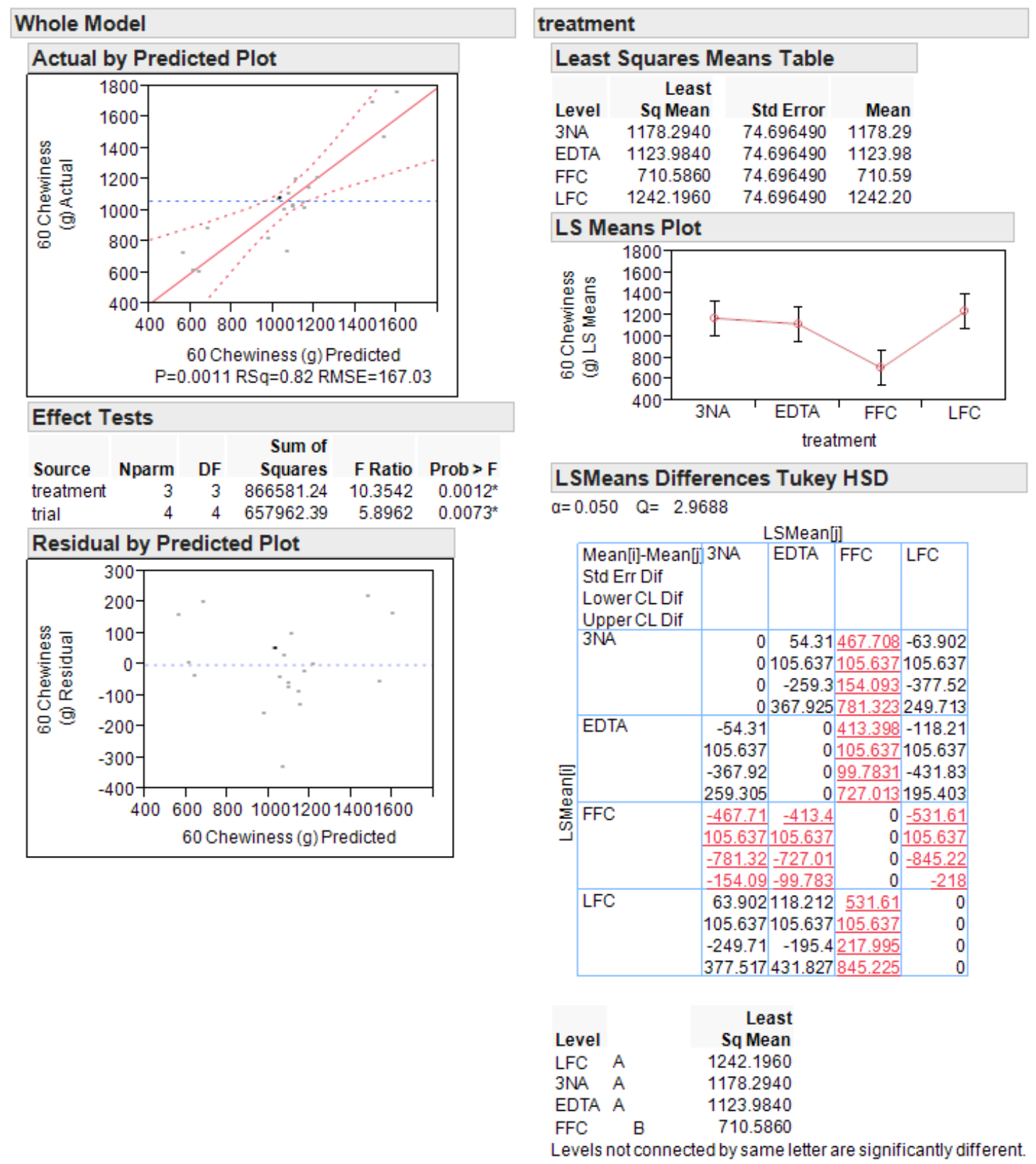
31. Statistical Data for TPA Chewiness. Day 90

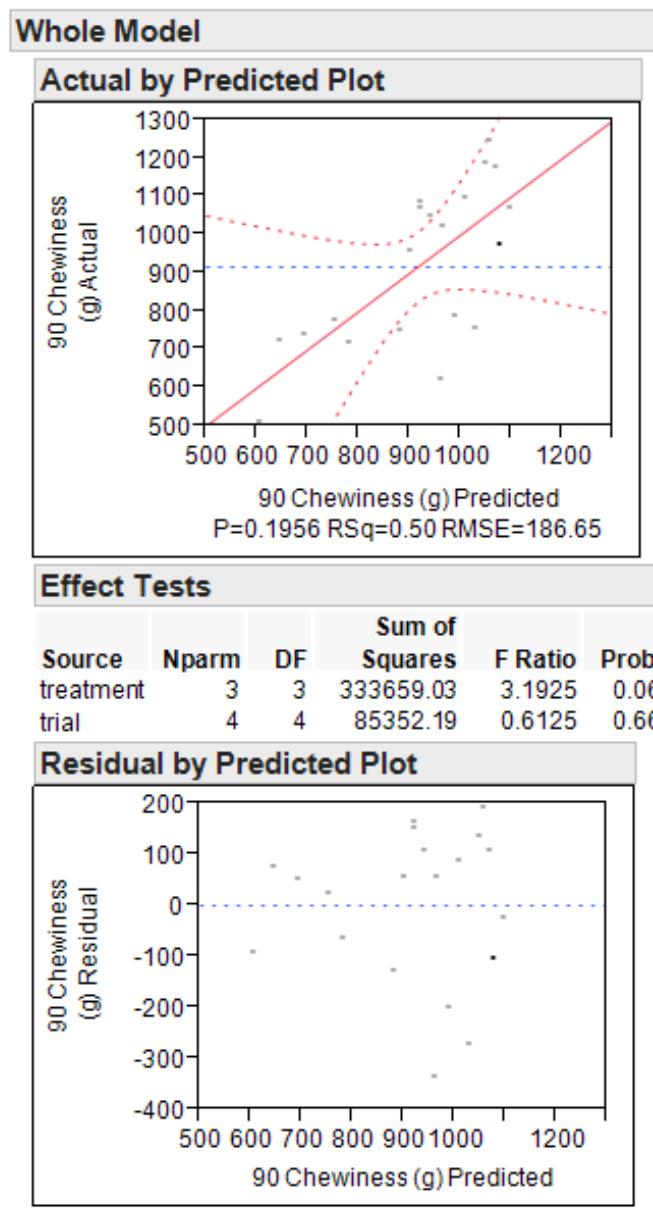

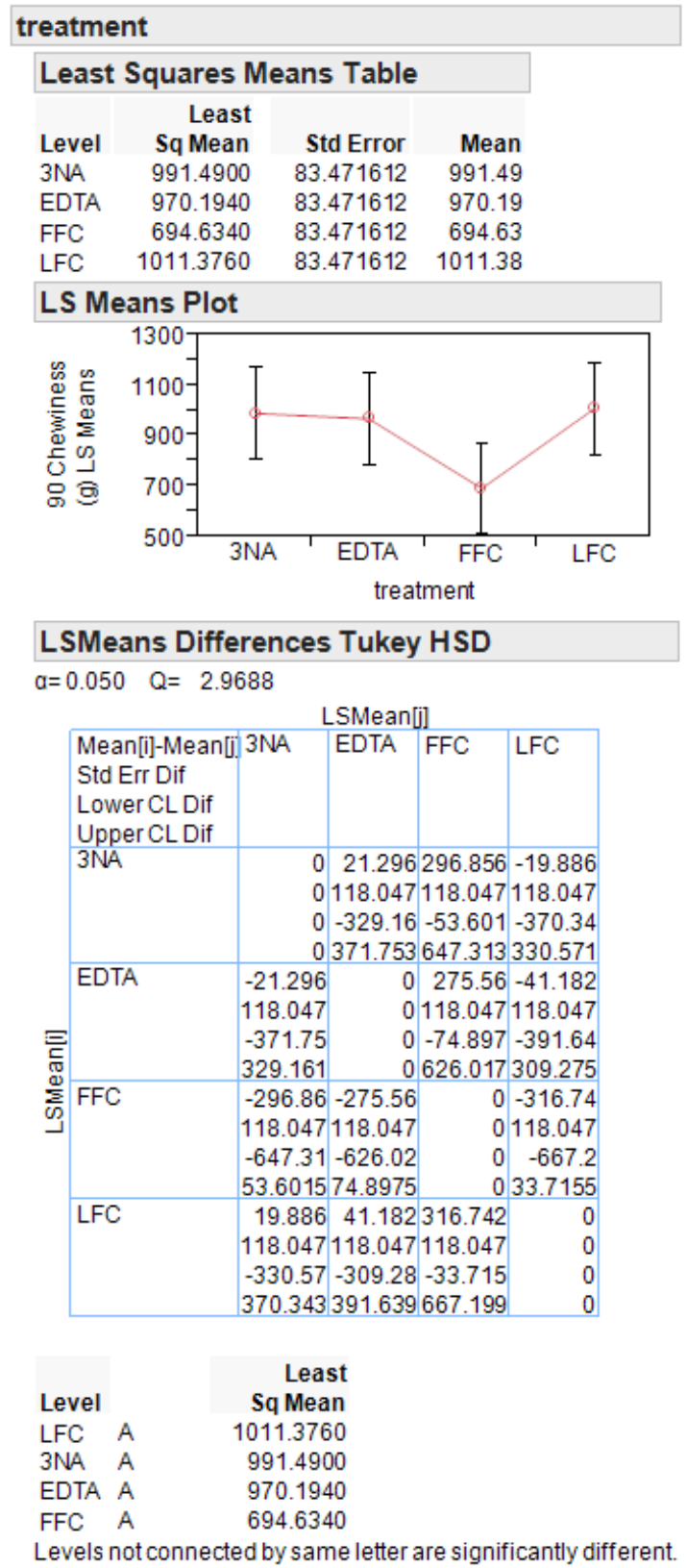


32. Statistical Data for TPA Chewiness. Day 120

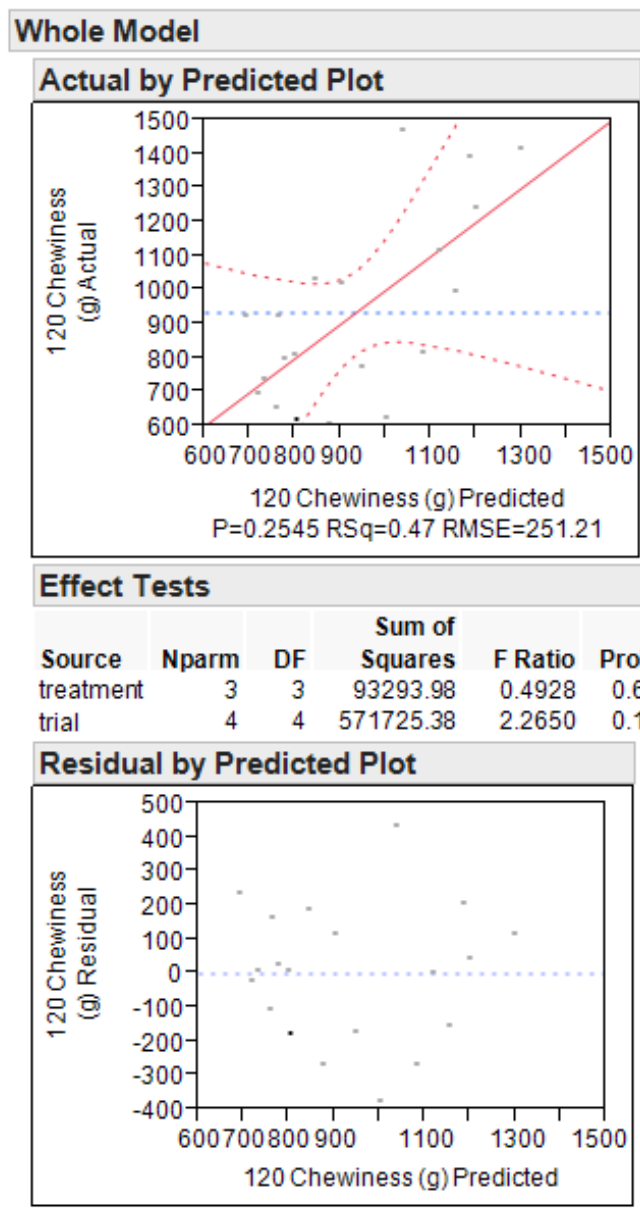

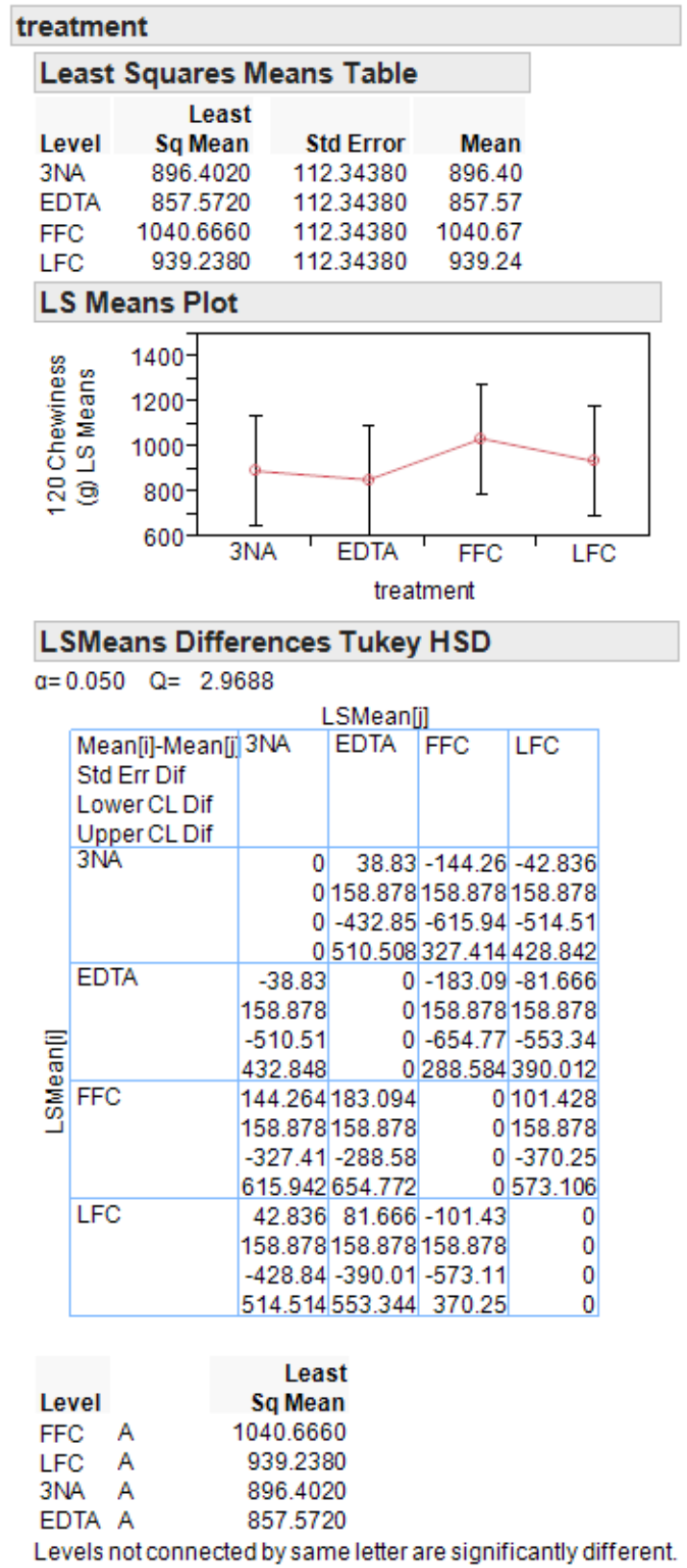




\section{Statistical Data for Water Soluble Nitrogen (WSN) content in Cheese. Day 7}
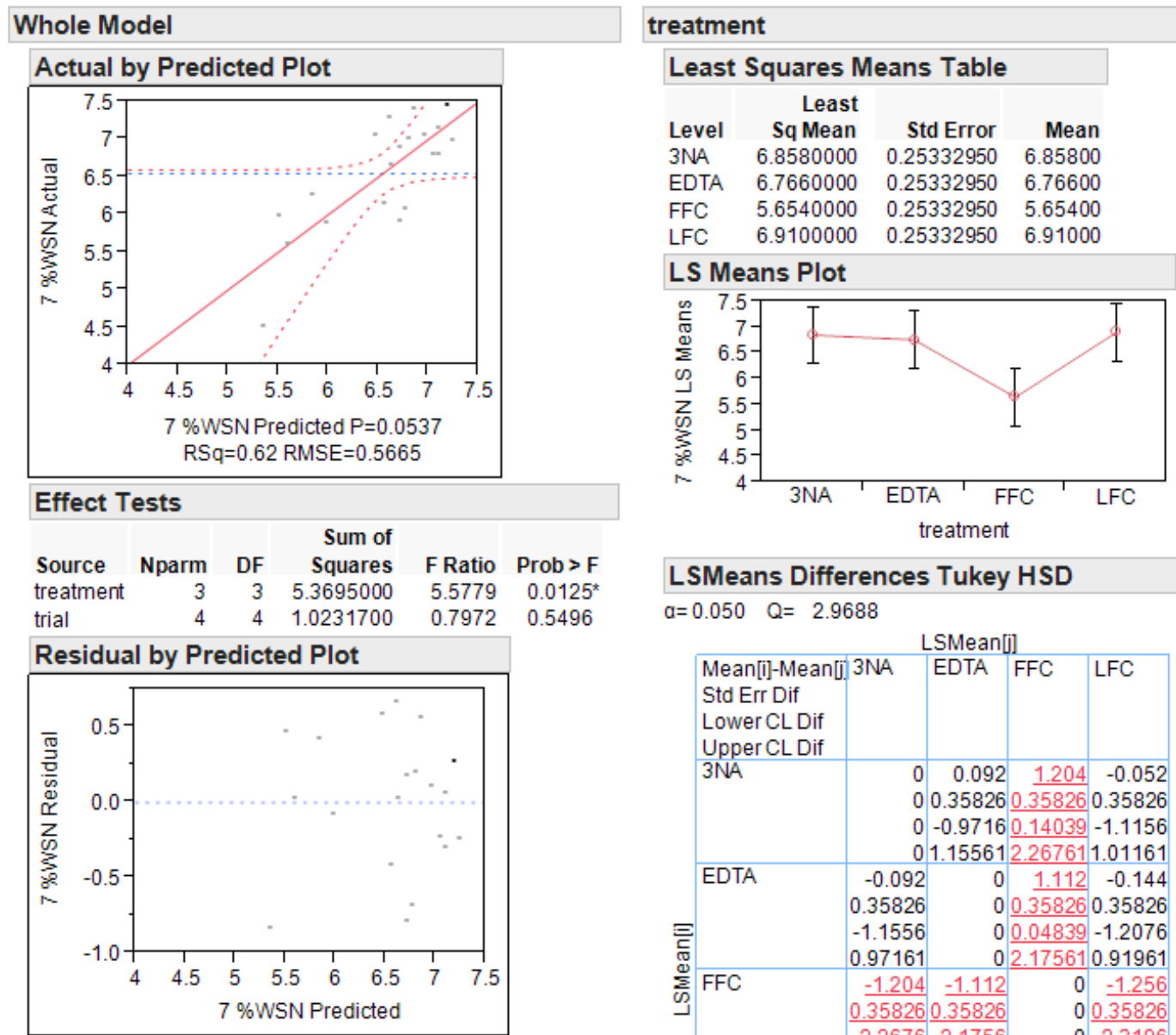

LSMeans Differences Tukey HSD $\mathrm{a}=0.050 \mathrm{Q}=2.9688$
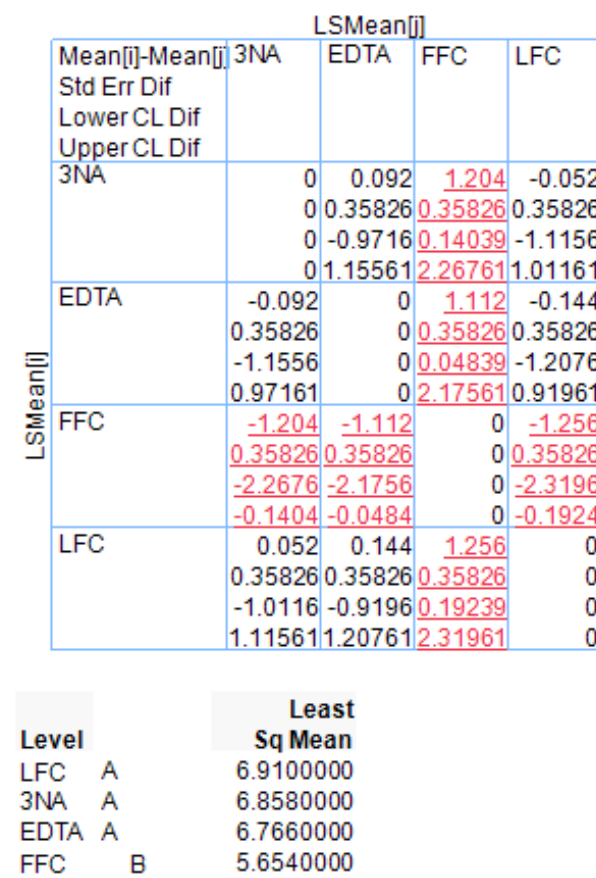

Levels not connected by same letter are significantly different. 
34. Statistical Data for Water Soluble Nitrogen (WSN) content in Cheese. Day 30
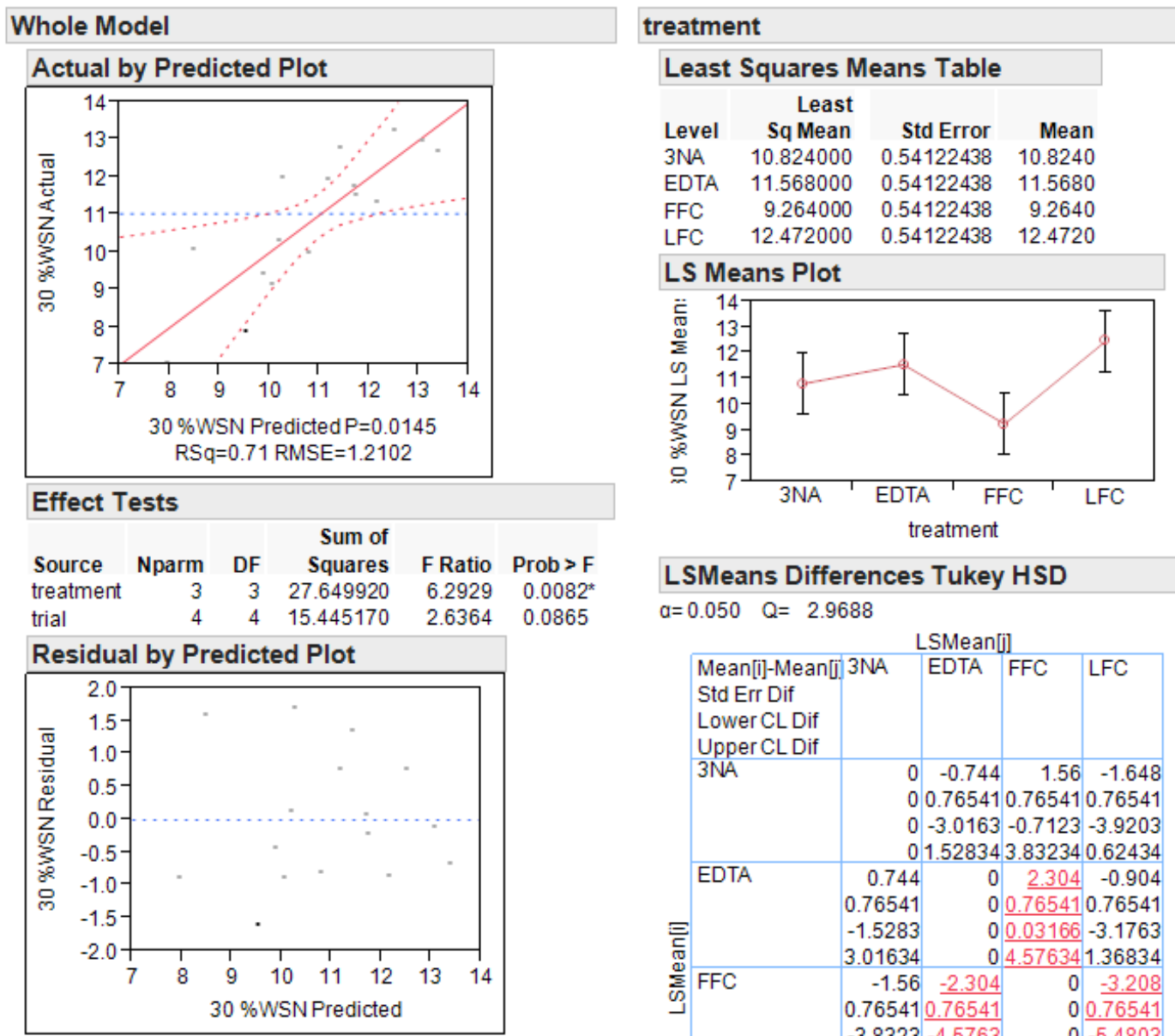

LSMeans Differences Tukey HSD

$\mathrm{Q}=0.050 \quad \mathrm{Q}=2.9688$

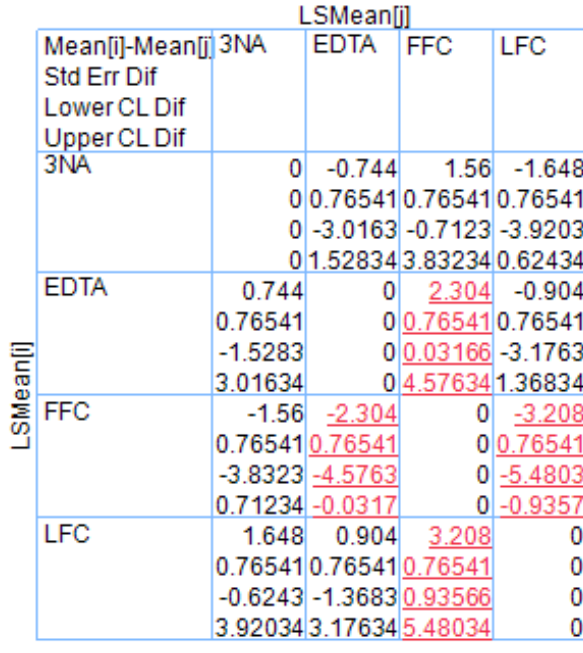

$\begin{array}{lrrr}\text { Level } & & \begin{array}{r}\text { Least } \\ \text { Sq Mean }\end{array} \\ \text { LFC } & \text { A } & 12.472000 \\ \text { EDTA } & \text { A } & 11.568000 \\ \text { 3NA } & \text { A B } & 10.824000 \\ \text { FFC } & \text { B } & 9.264000\end{array}$

Levels not connected by same letter are significantly different. 
35. Statistical Data for Water Soluble Nitrogen (WSN) content in Cheese. Day 60

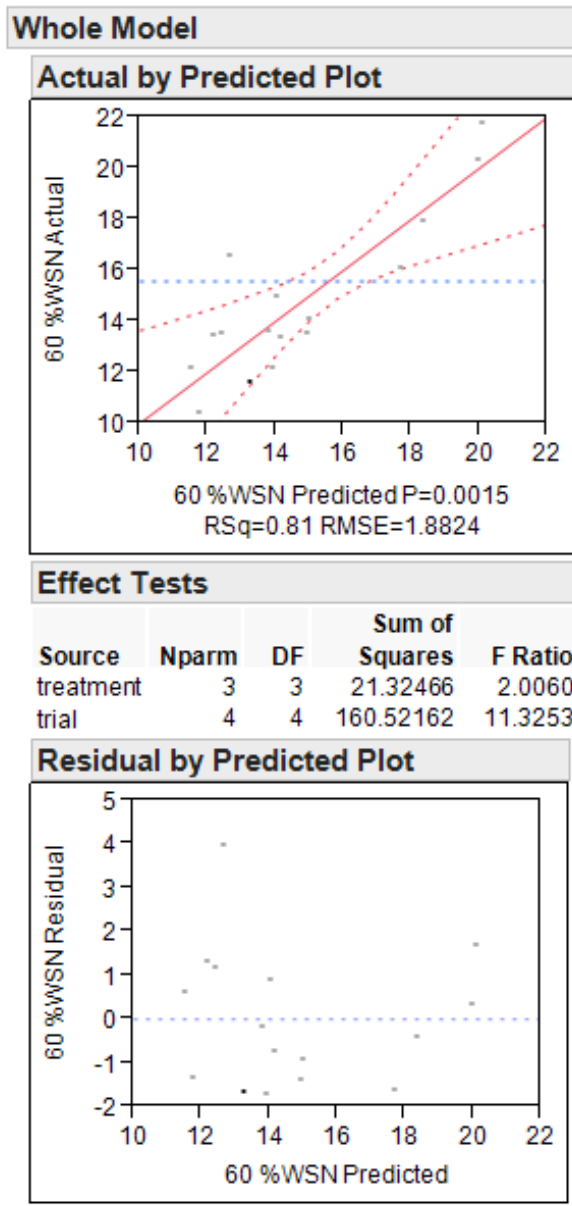

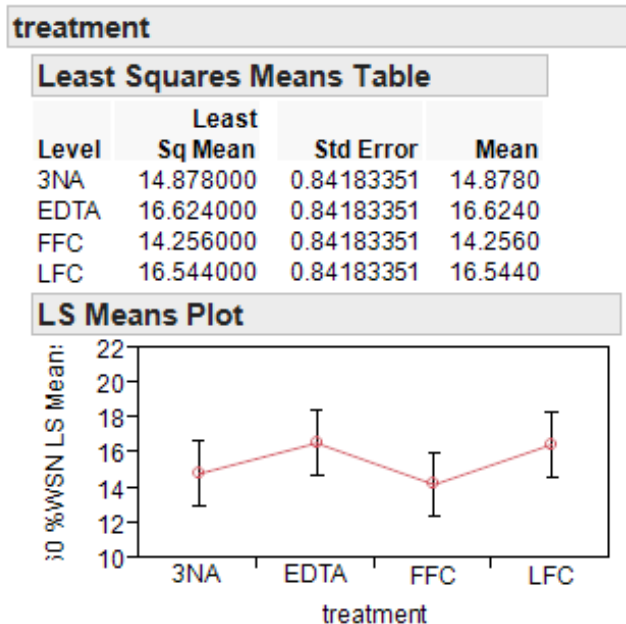

LSMeans Differences Tukey HSD $\mathrm{a}=0.050 \quad \mathrm{Q}=2.9688$

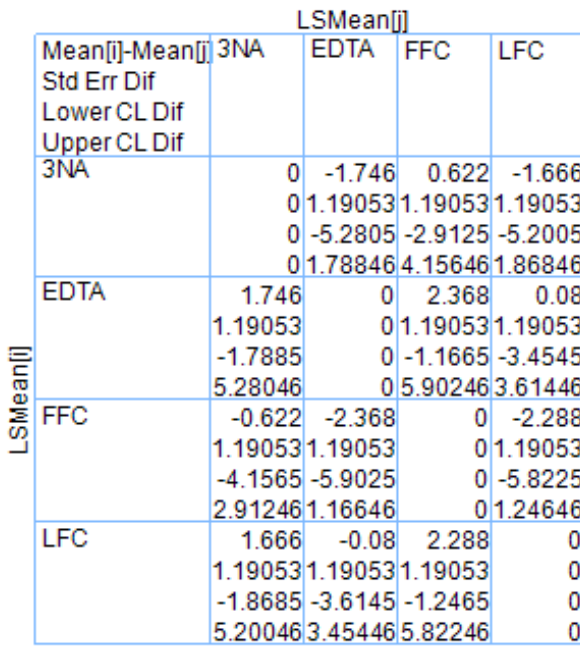

$\begin{array}{lrr}\text { Level } & \begin{array}{r}\text { Least } \\ \text { Sq Mean }\end{array} \\ \text { EDTA } & \text { A } & 16.624000 \\ \text { LFC } & \text { A } & 16.544000 \\ \text { 3NA } & \text { A } & 14.878000 \\ \text { FFC } & \text { A } & 14.256000\end{array}$

Levels not connected by same letter are significantly different. 
36. Statistical Data for Water Soluble Nitrogen (WSN) content in Cheese. Day 90
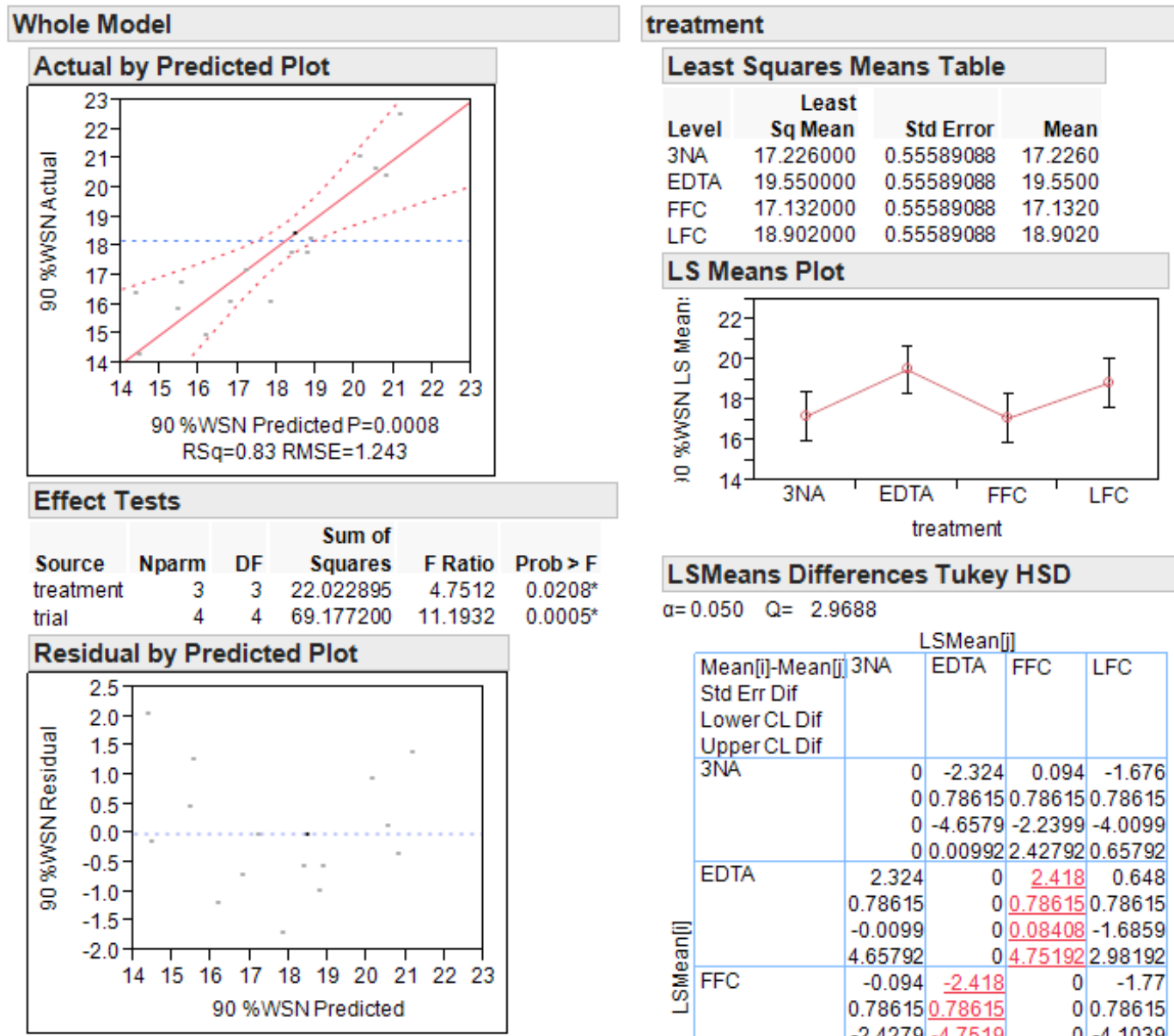

LSMeans Differences Tukey HSD $\mathrm{Q}=0.050 \mathrm{Q}=2.9688$

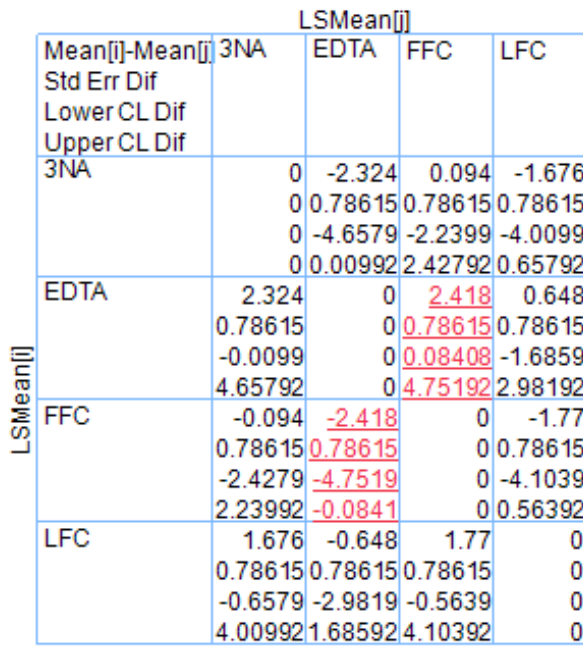

$\begin{array}{lrr}\text { Level } & & \begin{array}{r}\text { Least } \\ \text { Sq Mean }\end{array} \\ \text { EDTA } & \text { A } & 19.550000 \\ \text { LFC } & \text { A B } & 18.902000 \\ \text { 3NA } & \text { A B } & 17.226000 \\ \text { FFC } & \text { B } & 17.132000\end{array}$

Levels not connected by same letter are significantly different. 
37. Statistical Data for Water Soluble Nitrogen (WSN) content in Cheese. Day 120
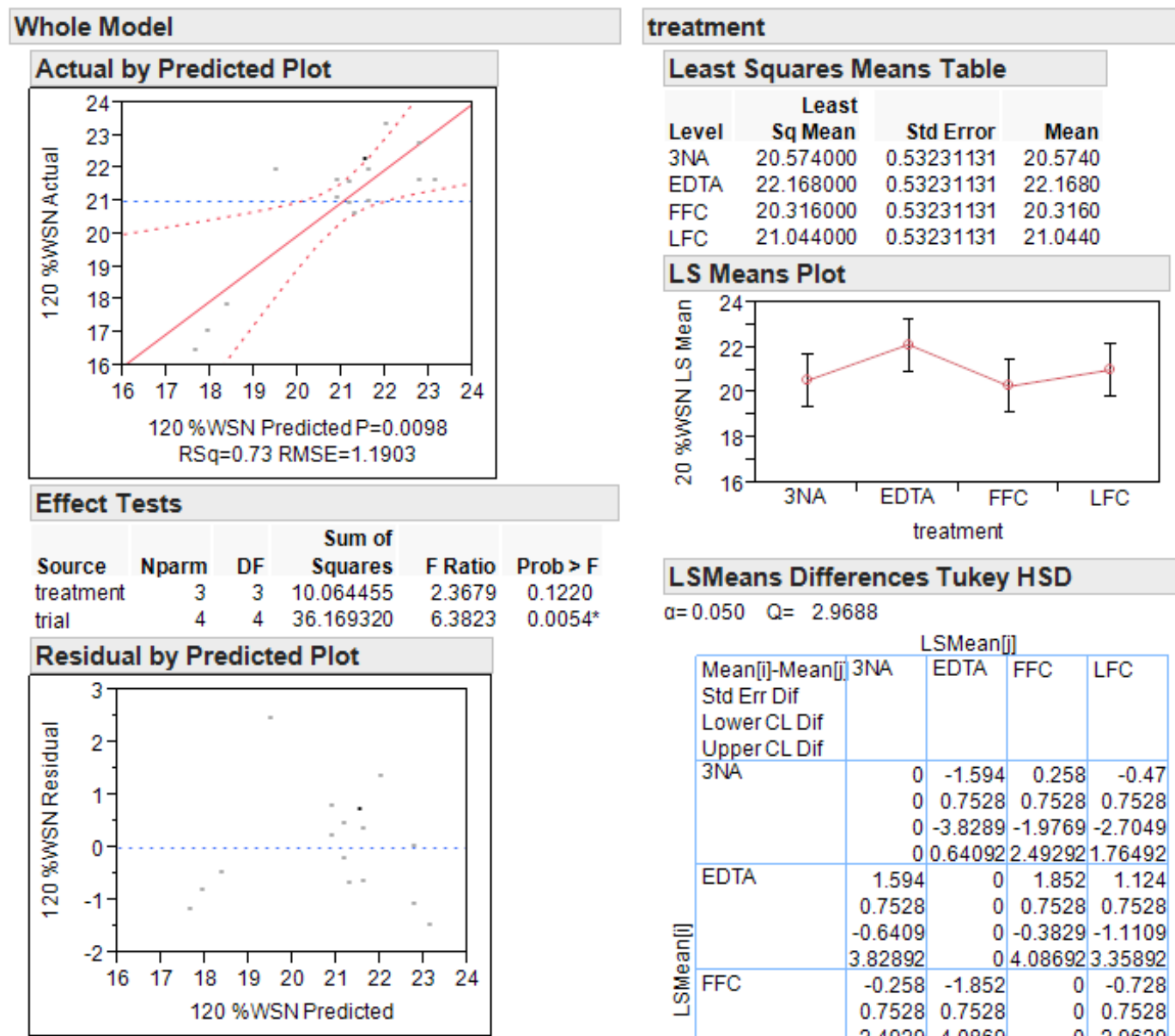

LSMeans Differences Tukey HSD

$\mathrm{a}=0.050 \quad \mathrm{Q}=2.9688$

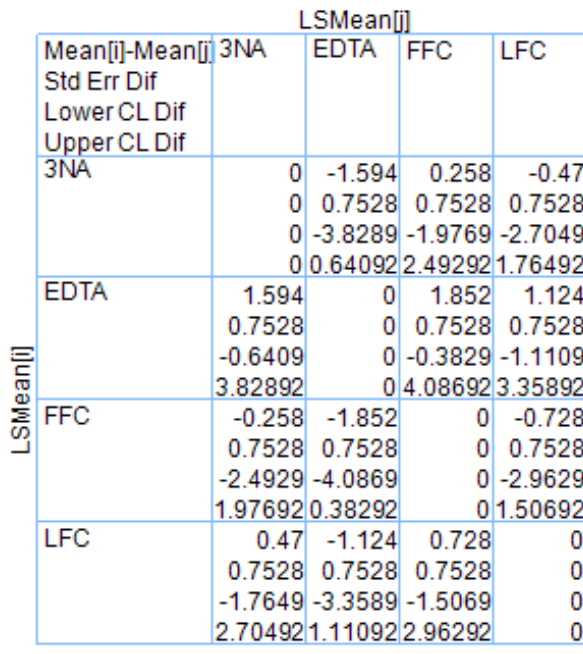

$\begin{array}{lrr}\text { Level } & \begin{array}{r}\text { Least } \\ \text { Sq Mean }\end{array} \\ \text { EDTA } & \text { A } & 22.168000 \\ \text { LFC } & \text { A } & 21.044000 \\ \text { 3NA } & \text { A } & 20.574000 \\ \text { FFC } & \text { A } & 20.316000\end{array}$

Levels not connected by same letter are significantly different. 